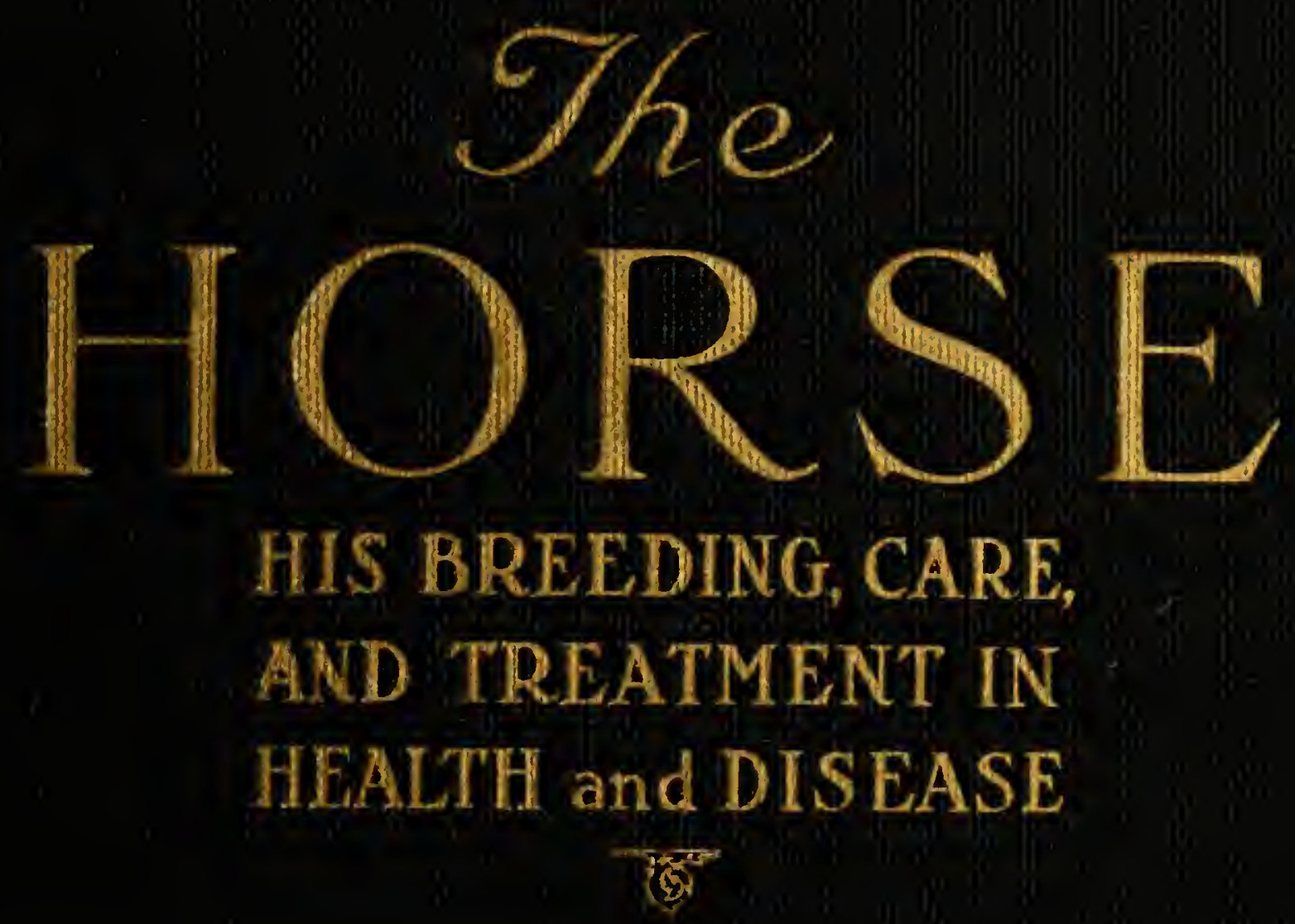

HENRY C. MERWIN 


\section{$62 \frac{30}{0}$}

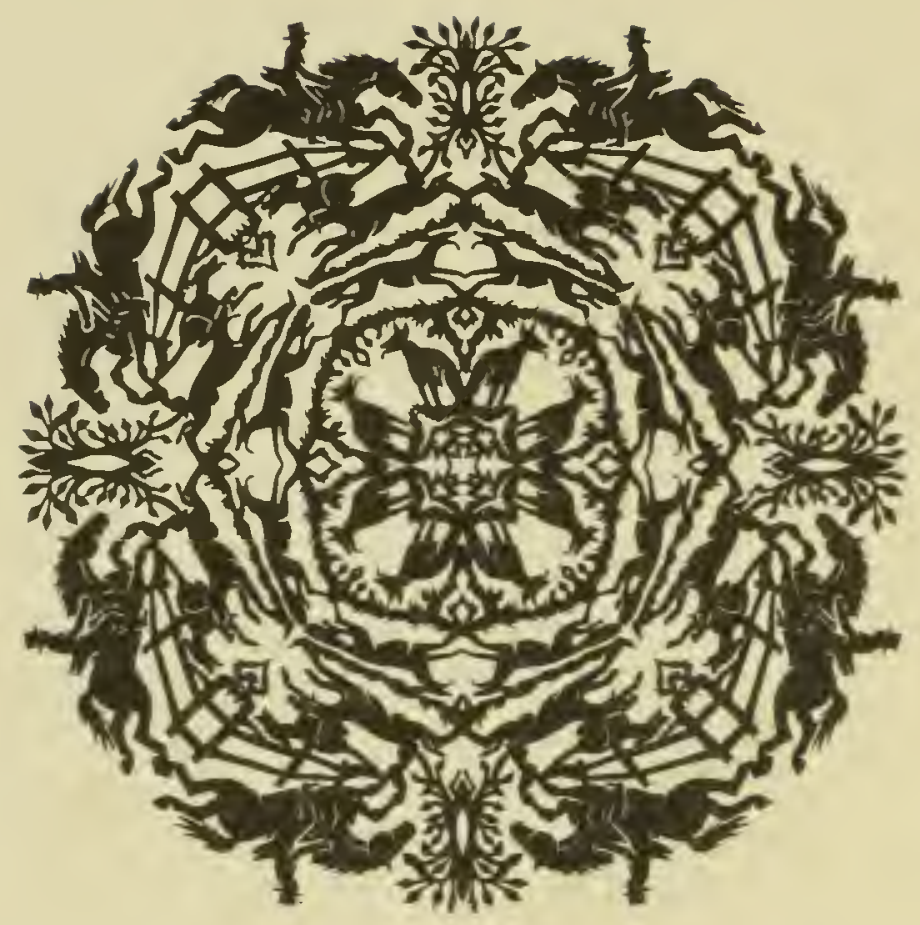

JOHN A.SEAVERNS 


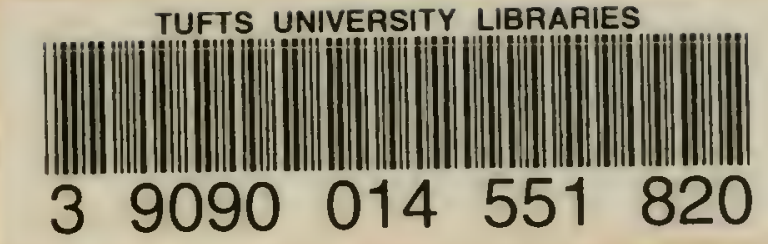

Fin

George W. Itarestion,

with the complineste

the anther

th.

thoth Gonion

a. 1919

Webster Family Library of Veterinary Medicine

Cummings School of Veterinary Medicine at

Tufts University

200 Westboro Road

North Grafton, MA 01536 



\section{THE HORSE}

His Breeding, Care, and Treatment in Health and Disease 




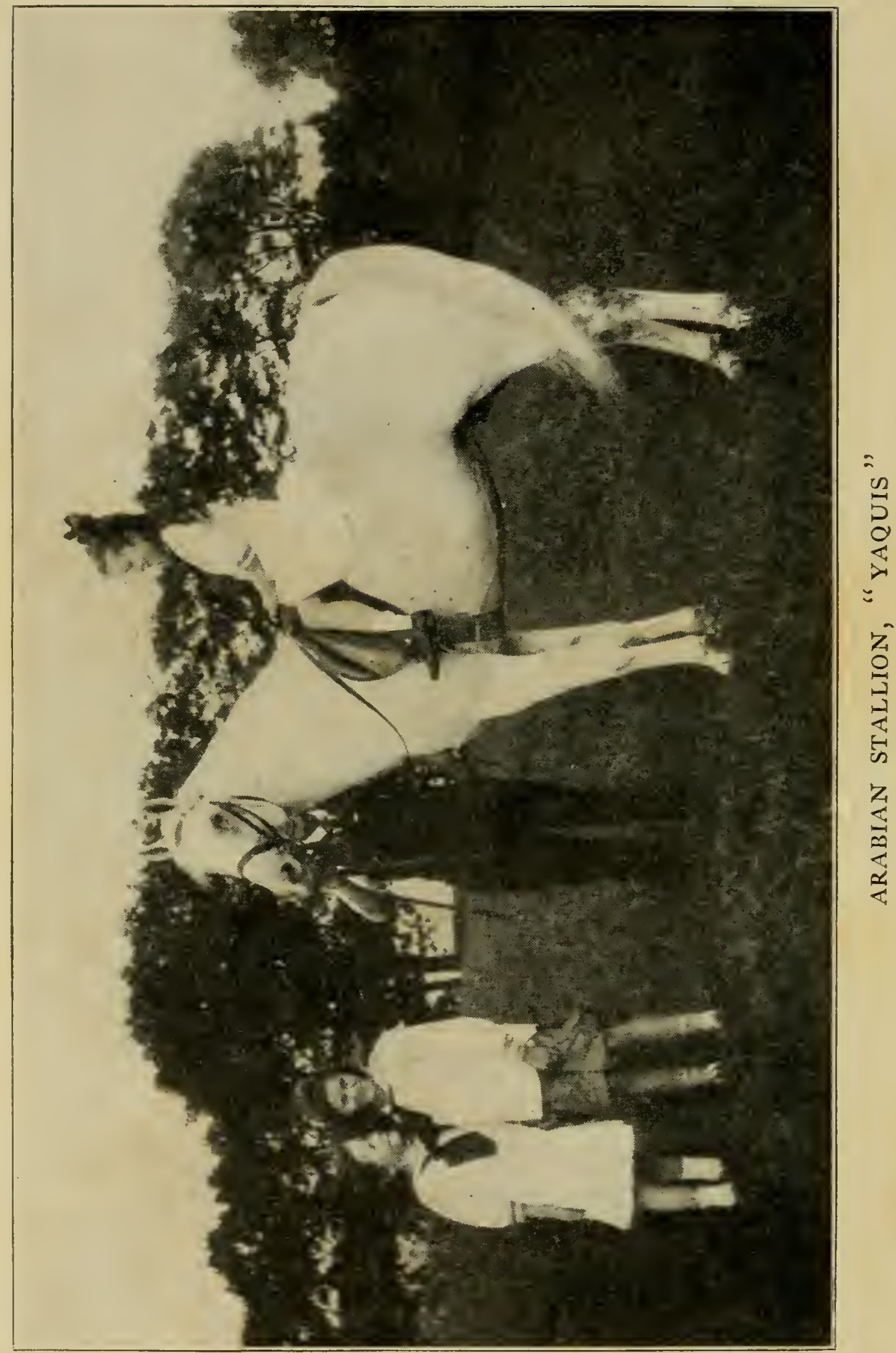




\section{T H E H O R S E}

His Breeding, Care, and Treatment in Health and Disease

BY

HENRY CHILDS MERWIN

Author of "Road, Track and Stable,"

"Dogs and Men"

ILLUSTRATED

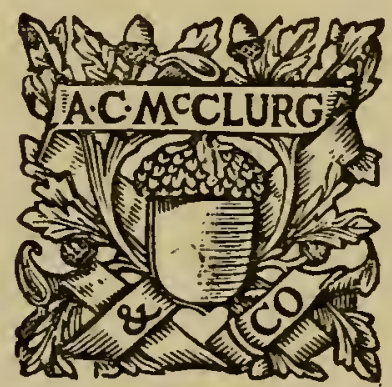

CHICAGO

A. C. McCLURG \& CO.

1917 


\author{
Copyright \\ A. C. McClurg \& Co. \\ 1917 \\ Published May, 1917 \\ Copyrighted in Great Britain
}




\section{This book \\ IS DEDICATED TO THE AUTHOR'S FRIEND, CLASSMATE, AND FELLOW-LOVER OF THE HORSE,

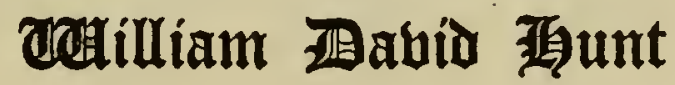





\section{PREFACE}

I F the author of this book were to say that he had 1 been engaged in writing it, or at least in preparing it, from his earliest childhood, there would be no exaggeration in the statement, for he cannot remember the time when he was not deeply interested in horses and everything that relates to them. There is a great deal of horse lore that does not find its way into print, but can be gathered from the lips of long-experienced grooms and hostlers, from stablekeepers, dealers, farmers, and farriers, from fox-hunters, veterinary surgeons and trainers, and the author has never, he trusts, neglected an opportunity to profit by their suggestions.

He is especially indebted to Dr. Frank J. Sullivan, to his brother-in-law, George W. Harrington, and to those experts in the science of horse-shoeing, Charles A. McLellan and Gilbert Tompkins.

But many, indeed most, of those horse-lovers with whom the author has exchanged ideas have passed away, and their faces rise before him as, not without reluctance, he commits to the printer and the public this work with which he has long been occupied. One typical figure, especially, stands out in his recollection. It is that of an old Irish groom, a small; but muscular, trim-built man, with white hair, and well-cut features, 
one who understood horses and dogs and loved them, a true "sport," not averse to a "scrap," and with a particular fondness for Boston terriers. "I like a little sand," he used to say, "be it in man or dog." He died, as he would have wished, from the kick of a horse - not a vicious kick, I hasten to say, but a kick playfully intended for a fellow-steed.

It is among such men that one most often finds the true lover of the horse. Your real horse-lover is not, as a rule, the owner of many horses, but the attendant of one; not the master-truckman with fifty or a hundred horses in his stable, but the humble teamster who drives and looks after a single horse or a pair; not the rich patron of the turf who maintains a costly stable of runners or trotters, but the impecunious "swipe" who shares a box-stall with the horse committed to his charge, and is at once his servant, his nurse, his valet, his confidant, and his faithful friend. Whatever their faults may be, and they are not without faults, these men have a spark of that divine affection which is the essence of Christianity, and which, if it should ever become an universal feeling among men, would unite all animals, the human and the nonhuman, in one brotherhood, and would transform this blood-stained earth into a near approach to Paradise. 


\section{GONTENTS}

\section{羽art Ore}

THE BREEDING, TRAINING, AND CARE OF HORSES CHAPTER

I The Nature of the Horse . . . I

II Principles of Breeding . . . . 3

III Brood Mares . . . . . . 8

IV Treatment of the Foal . . . . I I

$\mathrm{V}$ Colt Raising . . . . . . . . I6

VI How to Select a Horse . . . . 23

VII Watering and Feeding . . . 32

VIII Hay and Grass . . . . . . 35

IX Grain and Vegetables . . . . . 39

$\mathrm{X}$ Salt and Sugar . . . . . . . 45

XI Bedding . . . . . . . . . 48

XII Grooming, Rubbing, and Scraping . 53

XIII Hot Weather Treatment . . . 6I

XIV The Mane, Tail, and Forelock . . 65

XV Blanketing . . . . . . . . 70

XVI Clipping . . . . . . . . . 78

XVII Care of the Teeth . . . . . 82

XVIII Care of the Feet . . . . . . 85

XIX Shoeing . . . . . . . . . 90

XX Harness . . . . . . . . . IO3

XXI Stables . . . . . . . . . I I6

XXII Stablemen . . . . . . . . I 24

XXIII Vacations for Horses . . . . . I 27

XXIV The Disposal of Old Horses . . . I 29

XXV The Transportation of Horses . . I30

XXVI The Art of Driving . . . . I33

$$
\text { [ix ] }
$$


CHAPTER

XXVII Farm Horses . . . . . . I45

XXVIII Saddle Horses

XXIX The Cavalry Horse . . . . I6I

XXX The Arabian Horse . . . . . I70

XXXI Thoroughbreds . . . . . . I73

XXXII The Morgan Horse . . . . I76

XXXIII The Trotting-Bred Horse . . . I84

XXXIV The Kentucky Saddle Horse . . 197

XXXV The Hackney . . . . . . 200

XXXVI Coach Horses . . . . . . . 202

XXXVII Draft Horses . . . . . . 204

\section{稀art Timo}

\section{DISEASES AND INJURIES}

XXXVIII General Treatment . . . . 2I 5

XXXIX Cuts, Bruises, and Burns .. . . 2 I 9

XL Diseases of the Stomach and Bowels 222

XLI Diseases of the Kidneys and Liver 228

XLII Diseases of the Throat and Lungs . 23 I

XLIII Diseases of the Skin and Blood . . 237

XLIV Diseases of the Legs . . . . . 245

XLV Diseases of the Feet . . . . 253

XLVI Cribbing and Weaving , . . 264

Bibliography . . . . . . 271

Index . . . . . . . . . 275 


\section{ILLUSTRATIONS}

PAGE

Yaquis, Arabian stallion; stands 14.3 and weighs about I,O00 pounds; formerly owned by Spencer Borden. This is a horse of very great endurance and remarkable docility . ... . . . . . . Frontispiece

Bingara, at fourteen years of age. Trotting-bred stallion by Bingen; dam, Ligeria by Arion; owned by Silver Spring Stock Farm, at Goshen, New York . . . . 20 Turquoise, Percheron filly, at the age of seventeen months; owned by the Dunhams of Wayne, Illinois . . . . 20 Prize-winning team at the Boston Work-Horse Parade in I914; owned by the Boston Blacking Company . . 42 Welcome, Morgan stallion, owned by A. Fullerton Phillips of Windsor, Vermont . . . . . . . . 62

Little Justin and Hazella; Morgan stallion and mare owned by E. A. Darling of East Burke, Vermont. The driver is Major C. A. Benton, U. S. A., retired, who judged these horses at White River Junction 62

Bob B., Morgan stallion, standing fifteen hands, weight I,O50 pounds; owned by E. A. Darling . . . . . 80

Uhlan at Goshen, New York, driven by Charles Tanner. Uhlan is a black gelding by Bingen; dam, Blonde by Sir Walter, Jr. He holds the fastest trotting record for a mile in harness, namely one minute and fiftyeight seconds. (For this picture the author is indebted to the Trotter and Pacer of New York.) . . . . 80

Codero, roan stallion by Bingen; dam by Jay Bird. Type of a trotting-bred cavalry horse. Codero died recently [xi ] 
PAGE

in Austria. (For this picture the author is indebted

to the American Horse Breeder of Boston.) . . 98

Model harness for a work horse . . . . . . . II4

Shahwan, gray Arabian stallion, now dead. Imported from

Arabia to England by Lady. Anne Blunt, and brought to this country in 1895 by J. A. P. Ramsdell of Newburgh, New York . . . . . . . . . . . I30

Bennington, thoroughbred horse, standing I5.3, weighing I, I5O pounds; bred by H. V. Colt of Geneseo, New York. This horse is well known as a hunter both in this country and in England . . . . . . . 130 Uhlan, to wagon, driven by his owner, C. K. G. Billings . I 52 Dragon, Percheron stallion; owned by E. B. White of Leesburgh, Virginia

Percheron grade gelding, sixteen years old; owned by Armour \& Company . . . . . . . . . . 186

Paul de Weils, Belgian stallion; four years old, I7 1/4 hands, weight 2,400 pounds; owned by Denison Farms, Buffalo, New York . . . . . . . . . . 206 Royal Friar II, shire stallion; owned by Truman Stock Farm, Bushnell, Illinois . . . . . . . . . 230 Ashmoor Romeo, Suffolk stallion; owned by Hawthorn Farm, Lake County, Illinois . . . . . . . . 230 Lizzie, Clydesdale mare; owned by Alexander Galbraith and Son, De Kalb, Illinois . . . . . . . . 250 Shire grade gelding; owned by Truman Stock Farm, Bushnell, Illinois 


\section{狂art (1Bne}

THE BREEDING, TRAINING, AND CARE OF HORSES 



\section{THE HORSE}

CHAPTER I

\section{THE NATURE OF THE HORSE}

THE horse is subject to many distressing infirmities. 1 There are certain forms of spavin, for example, so painful that they produce a peculiar emaciation of the loins which is easily recognized. What, to take another example, is navicular disease? Simply the decay of a certain small bone in the foot, and this decay often progresses so far that the bone is largely eaten away. It may be imagined how much the animal suffers in stepping on a foot so diseased.

The horse, as everybody knows, is also an excessively nervous, sensitive creature, and suffers greatly from harsh treatment, even though it stops short of being brutal treatment. The reason why horses are more docile in the hands of women than of men is that a woman's voice and touch are more gentle than those of a man. ${ }^{1}$

This sensitiveness is not confined to race horses. The work-horse is often as sensitive as a trotter or runner,

${ }^{1}$ Dr. Reginald S. Timmis in Modern Horse Management, one of the very best books on the horse ever published, says: "I remember a thoroughbred mare that understood by my face whether I was angry or pleased, and by smiling I could make a distinct impression upon her." 
and needs the same kind of man to handle him and take care of him. "A horse is like a child," said an old circus trainer. "He appreciates kind treatment and rapidly learns to love the attendants who greet him with pleasant words and a caressing pat, and in nine cases out of ten he will prove to be a willing pupil."

No matter how well fed a horse may be or how easy may be his work, if he has a brutal driver or groom he will never be in an easy frame of mind, and consequently will never be in really good condition. "What is the reason," said one teamster to another, "that Phin's horses always look so bad? He feeds well." "Why!" said the other, "Phin is like a wasp around a horse;" and that explains exactly the attitude of some men to their horses.

This same sensitiveness is what makes the horse so interesting, so capable of training and development, so responsive to the slightest word, sign, or touch. Here is an animal highly organized, spirited, docile, and, if well treated, beautiful - a creature so wonderfully contrived that a man might spend a dozen lifetimes in learning how to ride, drive, shoe, handle, and train him - to say nothing of curing him when he is ill, or healing him when he is injured. To some persons, and I trust that the reader is included among them, this animal is the most interesting thing in the world. 


\section{CHAPTER II \\ PRINCIPLES OF BREEDING}

THE time has gone by when an inferior kind of horse 1 could be raised with some prospect of selling him at a profit. Buyers of horses, whether for pleasure or for business, now have a high standard and demand a certain amount of quality and good looks. It is a mistake, therefore, to breed from any two animals unless they are both of a useful and attractive type.

It is a mistake also to mate animals of different breeds. Do not breed a draft horse to a trotting mare, or vice versa, and do not breed a thoroughbred to a farm or trotting-bred mare, or vice versa. Such a violent cross sometimes indeed results in an animal that combines many of the good qualities of both sides, but far more often it produces a slab-sided, leggy, and otherwise highly objectionable animal.

On the other hand it is, of course, advisable to mate a stallion and mare that supplement each other; that is, if either one has any particular defect, be sure that its mate is not only free from that defect, but particularly strong in that point.

Cross breeding is sometimes necessary in order to get a particular type of horse, such as a hunter, or an express-wagon horse; but in such cases the two cross breeds should, if possible, have some part of their ancestry in common. For example, both the Percheron 
and the trotting-bred horse trace back, in part, to the Arabian, and a cross between a trotting stallion of good bone, and a Percheron mare, of the smaller sort, often results well - the offspring inheriting the action of the sire and the substance of the dam. The opposite cross, that of a Percheron stallion and a trotting-bred mare would not be so good; for it is a rule in breeding, subject, it is true, to many exceptions, that a foal derives his action mainly from his sire. It is the inward qualities, the nervous energy, etc., that are supposed to come mainly from the dam.

There is another principle in breeding similar to the one just stated, namely, that if the mare has a certain strain of particularly valuable blood, it is well to mate her with a stallion who has the same strain. In this way, you give the foal a double quantity of the desirable strain. In some families the horses and in other families the mares seem to be superior; and certain sires are known as "brood-mare sires," because their daughters have proved very successful in breeding more so than their sons. Among trotters, for example, Mambrino Patchen, Daniel Lambert, Nutwood, and Arion are recognized as brood-mare sires, and mares descended from them are valued accordingly. A broodmare sire, it may be added, is always a horse of great nervous energy.

\section{THE STALLION}

In choosing a stallion, two things are to be considered, first, his pedigree and, second, his individuality. Practically all breeders now agree that the first is of 
more importance than the second. A horse without good breeding may be a fine animal, but he is a freak and is not likely to reproduce himself. A stallion well bred on both sides, but defective himself, is more apt to produce good colts than a stallion who traces back to inferior ancestors but is himself a good specimen. However, the only safe way is to have both — breeding and individuality.

In estimating the value of a stallion it is more important to become familiar with his colts than with himself. His colts may be free from a defect which is very apparent in himself. On the other hand, he may transmit to his colts a fault which he does not have himself but which he inherits. There was a trottingbred stallion in Maine some years ago whose colts had a very marked type of head, and it was a bad type, being narrow between the eyes and between the ears. The head was so distinctive that you could tell one of this horse's colts at a glance, but the stallion himself had a very good head, not at all like the head which he transmitted with remarkable uniformity.

These facts and many others are summed up in the old saying that a horse produces his like or the likeness of some ancestor, and you cannot tell which it will be until you see his produce.

A stallion that has any important defect in shape, action, or disposition should be rejected. This does not apply to forms of unsoundness produced by hard workespecially by such excessive work as race horses, whether trotters or runners, are called on to perform, unless the animal also shows that he had a natural 
tendency to the same defect. For example, if a horse has naturally a good leg, do not reject him as a sire because he has become unsound. But if the bone of his leg is too small, or if his hind leg is crooked or has a curby formation, he should be rejected because constitutional defects like these are very likely to be transmitted. Bad feet, for example, are usually inherited, and so, in fact, are all forms of unsoundness. On this subject, a vet of great experience said recently:

In my business I often see colts with ring-bones, spavins, or curbs before they are two years old which, I personally know, they have inherited from the sire or dam. We have a stallion standing for service in this county that gets 70 per cent of bad hocks on his foals.

It is almost more important to have a stallion of intelligence and good disposition than to have a sound one. Stupidity and viciousness are transmitted very commonly. Not many horses, it is true, are naturally vicious. The vicious ones are usually made so by bad treatment, but occasionally there is a vicious strain. I remember a stallion of fine breeding and remarkably good conformation who had a bad disposition, and the great majority of his colts were difficult to break, being inclined both to kick and to be sulky. They made unsatisfactory horses.

The size of the stallion is important in this way: it is a rule, with few exceptions, that a stallion unusually large for his breed will not get good and tough colts. A stallion of compact build and clean, stout bone, but undersized rather than oversized, is the one to choose 


\section{PRINCIPLES OF BREEDING}

for a sire - I5.2, is the ideal height for a trotting stallion, and I 6 or I6. I for a draft horse.

\section{TREATMENT OF THE STALLION}

Stallions are often treated like criminals; that is, condemned to solitary confinement. Nothing could be worse or more irrational than this, or more likely to produce a vicious horse or to encourage self-abuse. A stallion should always be kept in a stable with other horses, and his stall should be so constructed that he can see other horses about him and put his nose against the nose of his nearest neighbor.

Stallions also suffer from want of work or exercise. No stallion can be healthy, and he certainly is not likely to produce strong colts, unless he receives a suitable amount of exercise. A stallion kept on a farm should do his share of the work, for there is nothing better adapted than farm work to make a horse not only strong but docile and intelligent.

Do not neglect your stallion's feet. Many a stallion looks the picture of health but his feet have been neglected and permitted to become hard, and following that come contraction and unsoundness. 


\section{CHAPTER III \\ BROOD MARES}

A LMOST everything that has been said above in A respect to stallions applies also to the selection of brood mares. The best brood mares, as a rule, are animals that are rather small than large for their breed. Perhaps the only difference in conformation between the ideal stallion and the ideal brood mare is that the stallion can hardly have too short a back or be too closely ribbed, whereas a brood mare should be a little longer in the back and body. The disposition of a brood mare should be somewhat different from that of the stallion. A brood mare should be high-strung and full of nervous energy. The mothers of many noted race horses, both runners and trotters, have been mares so high-strung that it was almost impossible to break them, and in some cases absolutely impossible. The stallion should be of a more quiet disposition; but if the brood mare is inclined to be quiet and free from nervousness, and still more, if she is at all sluggish, she should be mated with a stallion that has the opposite disposition.

\section{TREATMENT OF THE BROOD MARE}

Most of what has been said about the treatment of stallions applies also to the treatment of brood mares.

The mare should be worked or exercised until within 
a short time of foaling, but, at least a week before foaling, she should be placed in a roomy box stall, with plenty of good, dry bedding, so that she may be accustomed to the new surroundings before the foal arrives. During this period she should receive less oats and more bran than she received while at work. Oats and bran are the proper grains for a brood mare. If the season is suitable, and flies are not too troublesome, the mare should, if possible, be turned out to pasture two or three weeks before foaling, instead of being kept in a box stall.

It is very important not to make sudden changes in the treatment of a mare in foal. If you are working her, do not for any reason stop working her abruptly; but diminish the work slowly, day by day. If, on the other hand, she has been idle, and you want to use her, begin working her in the same careful and gradual way.

Avoid giving the brood mare excessively cold water to drink, or too much water at one time. Very cold water often causes abortion. So does a slip or strain; and if there is any smooth ice in the yard where the mare is turned out for exercise, pains should be taken to cover it with ashes or some other like material. Many a mare, and many a colt also, has been ruined by slipping or falling in the barnyard. Backing a load is another dangerous thing for a mare in foal.

If the mare loses her foal, great care should be taken of her. She should be milked at frequent intervals, fed on dry food with little or no grain, and her udder should be rubbed with camphorated oil. A similar 
change from juicy to dry food should be made at the time when the foal is weaned.

After the foal is born, if the after-birth does not come away of itself, it should be carefully removed by hand. But the hand that is to perform this operation should be well washed with soap and water, and then dipped in a solution of one per cent creolin or carbolic acid or some similar antiseptic; and in all cases the womb should be flushed with a like solution as soon as the mare has foaled.

The best time to breed the mare again is the ninth day after foaling.

If possible, give the mare a month's rest after foaling; and if this is impossible, she should be fed liberally with oats, bran, and clover hay, substituting grass for the hay and bran when that is practicable. If the mare scours, the quantity of grass should of course be reduced. 


\section{CHAPTER IV \\ TREATMENT OF THE FOAL}

A S soon as the foal is born, the navel should be $A$ washed with a solution like that used on the mare, and if it is necessary to sever the cord this should be done with the same attention to cleanliness observed with respect to the mare.

These precautions are necessary to prevent "navel ill," a dangerous infection of the navel cord, caused by those filth germs found everywhere, and especially in dark, damp corners of the barn. Tying the navel cord with a dirty string, or with dirty hands, often causes it. For the same reason it is important that, if the mare foals in a stall, the stall and the bedding in it should be perfectly clean.

The next thing is to see that the foal's bowels are open, and if this is not the case the foal should be given an injection of warm water and soap, or a dose, by the mouth, of olive oil, about one or two tablespoonfuls. Castor oil should never be given to a foal as it is too severe in its effect.

Sometimes retention of the meconeum is mistaken for constipation. The meconeum is the contents of the intestines at the time of birth, and, if all goes well, it will be passed by the foal, a few hours after birth, in the form of dark-colored balls. If this does not happen, and the foal is straining without avail, it means 
that the meconeum is retained, and it must be extracted by the oiled finger, supplemented by an injection of a few ounces of warm water and linseed oil or glycerine. This operation should be repeated until the feces become yellow.

If possible, let the foal follow the mare, if the mare is at work. If this cannot be done, the mare should be returned to the stable in the middle of the forenoon, and again in the middle of the afternoon, so that the foal can be nursed by its mother. This is important for both of them. But the foal should not be allowed to suckle the mare when she is heated, for in that condition she is likely to give the foal indigestion and diarrhea.

If the foal loses its mother, it can be brought up on cow's milk, to which a little water and some sugar have been added. A mare's milk is not quite so rich as that of a good cow, but it is a little sweeter. Some great horses, including the famous Black Hawk, were brought up on a bottle.

When the foal is a month old, if not before, it should be halter-broken, and taught to lead. (I knew one enthusiastic horseman who haltered a foal from a favorite mare before it was quite born.) Care should be taken not to let the foal break its halter, or get away. But it is well to tie the foal securely to a post and then let him try to get away. When he finds that he cannot break the halter, he will soon stop trying, and will never attempt the same thing again. Another method which may be used, if the foal is so high-strung that he might injure himself by pulling on the halter, 
is to fasten a long trace to the headstall so that it drags on the ground, and then, when the colt steps on the trace, he will be held and so become accustomed to being fastened. But, of course, this is not so thorough a discipline as can be got by tying him to a post.

The feet of the colt, especially during the first few months of his life, should be looked after carefully. Says H. L. Allen, a high authority:

The form of the colt's legs depends largely upon the shape his hoofs assume during colthood. Seldom do the hoofs grow evenly. Sometimes they wear off on the inside, while the outside remains long, and that makes the bones of the leg assume a position that causes him to toe out, and in the light harness horse that means a knee-knocker when he comes to be used on the road or track. On the other hand, if the inner side of the hoof is allowed to become high and the outer side is worn off, the colt beromes "pigeon-toed" which is almost as bad. Watch the little fellow's feet closely, and with a rasp keep the hoofs even and of proper shape. These details require but little time, and will add greatly to the value of the colt in after years.

When the colt is in pasture his feet may not need any attention, but when he is kept in the stable, and the same thing would probably happen in a pasture free from stones or gravel, his toes will grow out too long and should be pared down at regular intervals. When the foal is kept in the stable, as in winter, his feet should be lifted and picked out every day to clean them, and this process will accustom him to being handled and will make it easy to shoe him when the time comes. He should also be taught to back - in fact, will learn to do so almost without your knowing it. 


\section{THE HORSE}

It is a mistake to leave foals out with their mothers in cold rain storms such as we have in the autumn or early spring. A warm, summer rain will not hurt the foal, but a cold northeasterly storm is likely to give him colic or a cough, or to encourage the development of worms in him, and to retard his growth. "There is no more pitiable sight," says the Horse World, "than a mare and foal standing in the open, with their coats turned the wrong way, and shivering with cold."

A hot, midsummer sun may do a foal as much or even more harm, if there is no tree or shed to protect him. For a foal born in early spring the sun is of course very beneficial; but the summer sun is a different matter. "A real baking-out in the hot, unbroken sunlight will give the foal a set-back from which he may never recover." 1

The foal may be weaned at six months of age, but long before that he should be accustomed to eating oats and bran, so that he will not fall off in health and condition when weaned. As a rule, he will begin to munch the oats in his dam's grain box at the tender age of two or three weeks, and he can be encouraged in this by mixing a little sugar with the grain.

A good practice, when mare and foal are at grass, is to erect in one corner of the pasture a bar high enough to exclude the mare, but low enough to permit the foal to pass beneath it, and to put a separate grain box for the foal within the space protected by the bar.

A good grain ration for the foal, after weaning, is a mixture of oats, bran, and oatmeal in the proportion of

1 The National Stockman. 


\section{TREATMENT OF THE FOAL}

6. 3. I. A bulletin on this subject issued by Purdue University says :

Bran is an excellent feed and contains material for bone and muscle. A mixture of oats sixty per cent, corn thirty per cent, and bran ten per cent, makes a ration that will enable any colt to grow rapidly. A handful of oil meal may be added with prafit.

Milk is not so good a food for colts as grain, but a diet of hay and milk is far better than a diet of hay alone. Bran should be fed liberally when milk is given. Hay for the foal should be fine hay or rowan. His teeth are not big enough to chew coarse hay properly. 


\section{CHAPTER V \\ COLT RAISING}

THE raising of good colts depends almost wholly on 1 two things: first, upon keeping them growing, secondly, upon keeping their feet in good condition and in normal shape. What is said above about the care of the foal's feet applies with almost equal force to the feet of colts. See that your colts, when housed for the winter, do not get thrush, on the one hand, or hard, contracted feet on the other. See to it also that the feet are kept properly pared, so that the colt will stand level at all times.

As to the growth of colts it should be remembered that if a colt is allowed to become thin his growth will be checked, and he will never recover the lost ground, no matter how well he is fed afterward. ${ }^{1}$

It is necessary not only that the colt should winter well, but also that he should do well through the pasturing season. On this subject the National Stockman gives us some valuable advice:

The colt that goes into the winter thin is going to stay skinny all winter, and of course he isn't going to grow much unless special attention and feed are given him - and that means

${ }^{1}$ One of the largest dealers in the Chicago market remarked lately: "A half-starved colt seldom develops into a shapely horse, no matter how good the care he gets in later years. Starvation means weakness, and weakness means misshapen, undeveloped parts." 
time and money.... Fall is the dangerous time. At that time pasture is liable to become short, and the colt gets a start down hill which the change to dry, winter feed does not tend to check.

The dryness of the winter feed should be offset by feeding bran or potatoes. Otherwise, constipation is inevitable. Bran has another advantage as a colt food, for it is an excellent bone-producer.

A fair ration for a colt is one quart of oats and one quart of bran three times a day - with a bran mash once or twice a week, and all the good hay that he will eat up clean. The hay should be fed at least three times a day. This is a small grain ration, but usually sufficient to keep the ordinary, medium-sized colt in good condition through the winter, provided that he comes to the barn in good condition. For big colts of draft breeds it should be increased. ${ }^{1}$

No colt properly kept and fed will be troubled with lice, but if you should have an animal so infested, apply a mixture of Scotch snuff and train or black oil - onefourth of a pound of snuff to one-half pint of oil. This should be well rubbed in, with a rag or brush, especially at the root of the mane, on both sides of the neck, along the spinal column, and on the breast and flanks.

The proper handling of colts is treated below in the paragraphs headed "Colt Training"; but one remark on that subject may be made here. If the colt is to become a safe and gentle horse he must be cared for and handled by a man who is fond of colts. Never

${ }^{1}$ At the Allen Farm, in Pittsfield, Massachusetts, a famous nursery of trotters, the colts receive seven quarts of oats a day, mixed with bran. 
trust a colt to the man who opens the stall door with a whip in his hand, and at whose approach the colt retreats to the further side of his box. A colt accustomed to kind treatment will come up without fear and put his nose in your hand. Some men have a foolish practice of scaring their colts, when they are in pasture or paddock, so as to make them show their speed. I knew one man who used to set a dog on his colts for this purpose with the result that the best colt he ever had was driven over a stone wall and broke a leg. Another man used to bring out the family umbrella, and scare the colts into a fast trot by rapidly opening and shutting it. Needless to say, his horses were always afraid of umbrellas, and at least one bad accident was the natural result.

\section{COLT TRAINING}

It is to the honor of American horse-trainers that they have substituted the word "gentling" for "breaking." English writers about horses commonly agree that our harness horses are better broken and safer than theirs, and they ascribe the difference to this fact that we educate or "gentle" them instead of breaking them.

Colts should not be played or fooled with; nothing could be worse than that, but they should be handled, their feet should be picked up, and they should be taught to lead and to back - and all this before they are six months old. Yearlings should be bitted, harnessed, and driven a little to some light vehicle.

Colts should always be broken in an open bridle, and 
should gradually become accustomed to having umbrellas opened behind them, etc. Many lives have been sacrificed to the absurd practice of breaking horses in blinders. If, in after years, the horse accustomed only to a bridle with blinders happens to be harnessed with a bridle which is broken or ill fitting so that he can see backward over the top of the blinders he is apt to become panic-stricken and to run away. The same thing may occur if an open bridle is incautiously substituted for a close bridle, or if the bridle is taken off to feed the horse while he is in harness, or if he rubs it off while in harness.

The use of the Dumb Jockey to make a horse yield to the bit and arch his neck is highly valued by some trainers and strongly condemned by others. Certainly if used at all it should be used with great care. The danger is that, if the straps are buckled too tight, or if the contrivance is left on the horse too long at a time, he will bear down on the bit, with the result of spoiling both his mouth and the carriage of his head. A wellbalanced horse, if driven by a man with a light hand, will, as a rule, learn to carry his head right, though nothing more than a snaffle bit is employed; and if this does not suffice, let the horse be ridden by a man or boy, not too heavy, using a double bridle - that is a curb bit and a snaffle bit, each with its own pair of reins.

Opinions differ as to whether it is better to drive colts for the first time single or double. But it is the safer plan to hitch them first with a mature horse. In that way they get accustomed to the sight of the vehicle following them, to the rattle of harness and vehicle, 
and to the pressure of the traces against their sides and hind legs - a thing which greatly frightens some nervous colts. If driven double, they should be harnessed sometimes on one, sometimes on the other side of the pole.

When the colt is hitched single for the first time, it is well to have a stout kicking strap, and if he comes of kicking blood this is indispensable. Then if he starts to kick, let him do so; and if, after one thorough trial, he finds that he can accomplish nothing by kicking, it is probable that he will never try it again. Still it is safer to keep the kicking strap on for some time longer.

An overdraw check should not be used on a colt, unless it is needed to control him. It is bad for two reasons: first, it makes the colt a slow walker, and, secondly, it tends to give him a straight neck, instead of an arched neck, and the beauty of a horse depends more upon his arched neck than upon any thing else.

The following is an excellent rigging to use in training a colt, especially one that is likely to misbehave: take two long, stout poles or saplings, rounded off at one end, and attach one pole on each side of the colt, so that the rounded end projects a little beyond his shoulder, the other end dragging on the ground, very much like the poles on which the Indian ponies used to haul their loads. If the colt tries to turn around, the end of the pole will press against him and keep him straight, and if he starts to run you can pull his head to one side. As he becomes accustomed to the contrivance you can gradually push the poles against his 


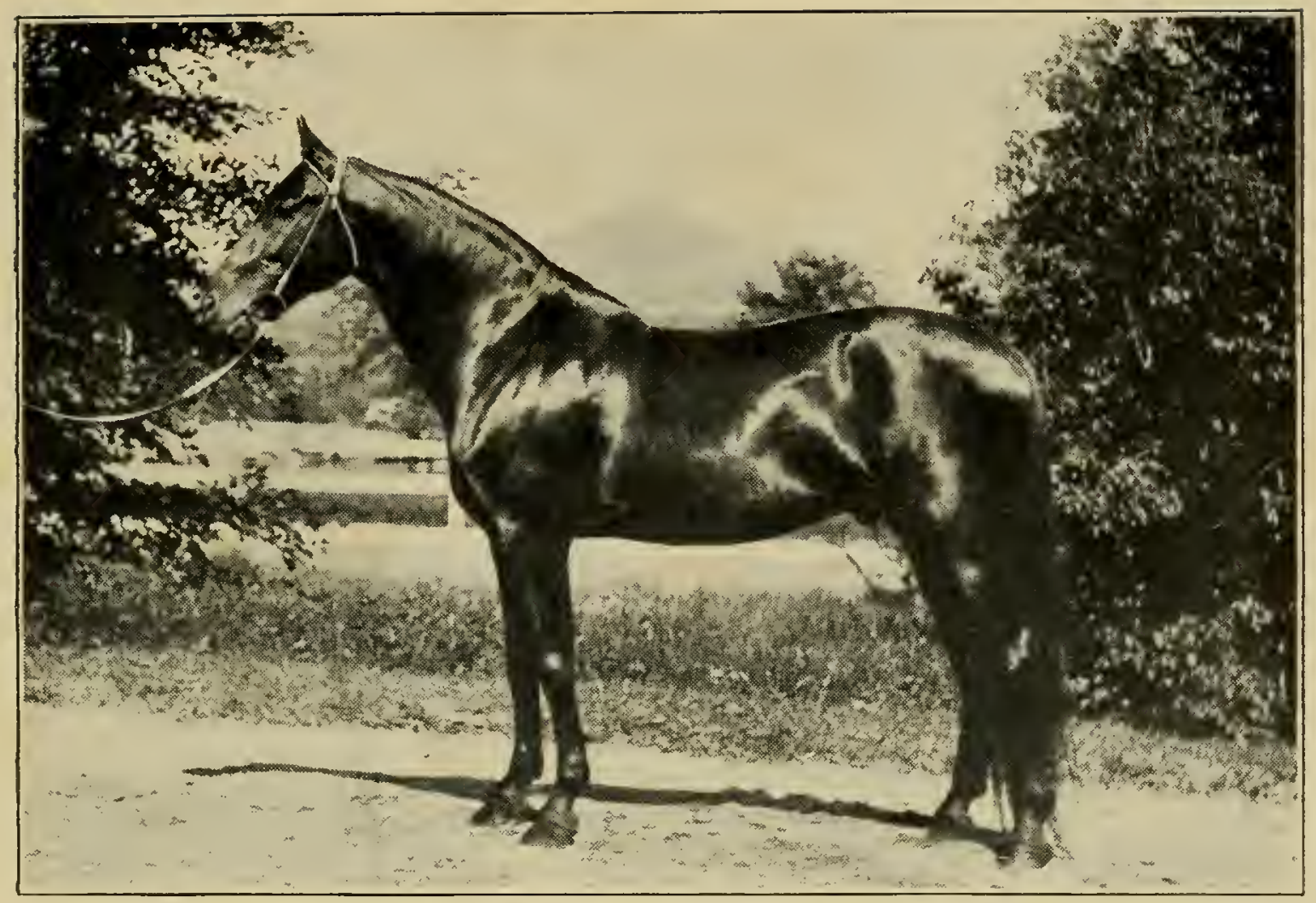

TROTTING-BRED STALLION, “BINGARA "

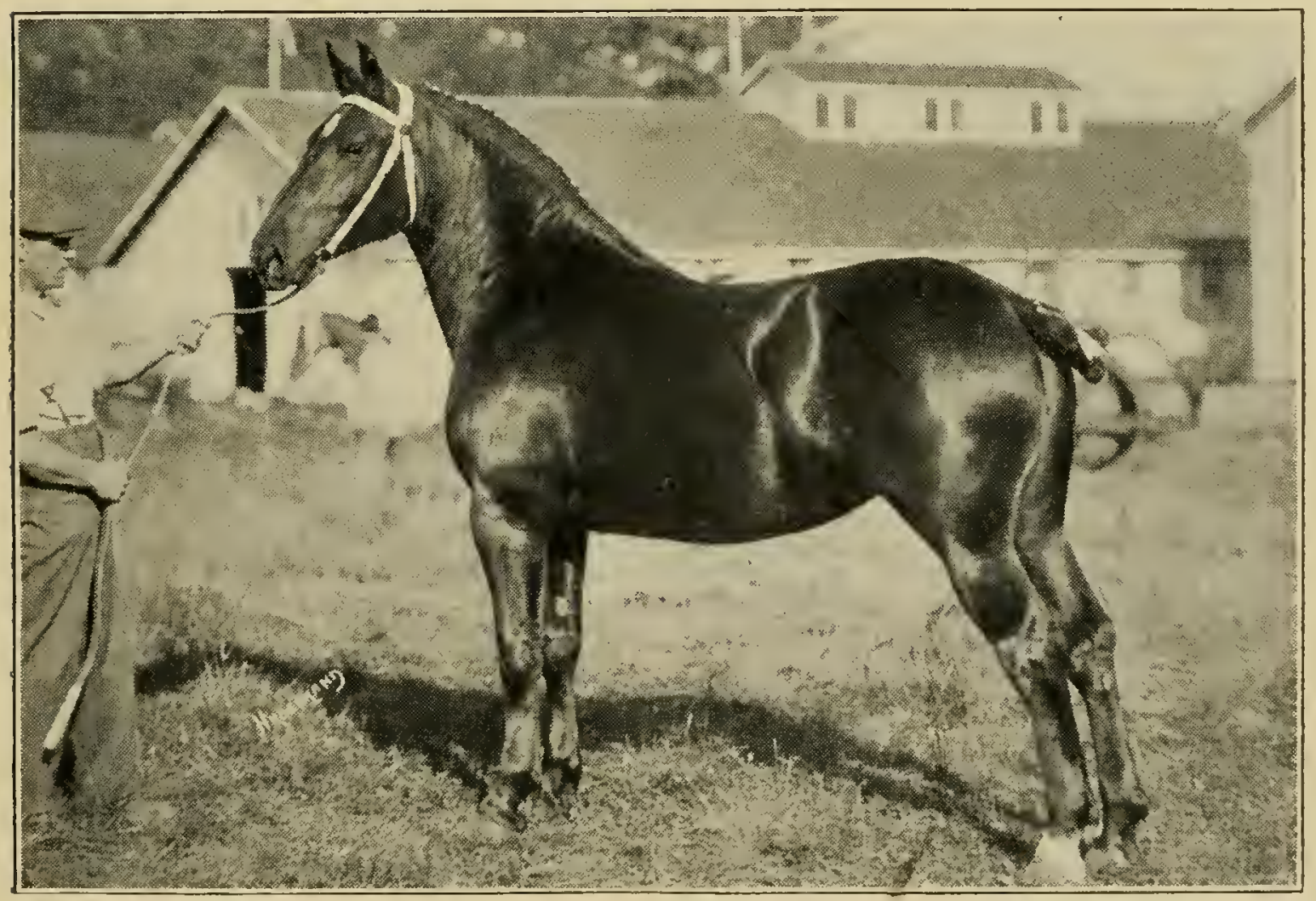

PERCHERON FILLY, "TURQUOISE" 

hind legs, and after this education he will find nothing to frighten him in the shafts of a wagon.

A timid colt will, of course, be more dangerous the first time he is hitched than afterward; whereas a colt inclined to be vicious is a little dazed the first time or two that he is driven, and may surprise you by his good conduct. He will assert himself somewhat later in the game. A colt should never be whipped for refusing to move or for balking. Sit still, for hours if necessary, until the colt is willing to start, and after a few experiences of that kind he will go along freely of his own accord. Remember that he dislikes monotony even more than you do. Never strike a colt twice with the whip - if one blow does not accomplish the object, you must change your tactics or you may ruin the colt. A single blow of the whip, indeed, is often enough to spoil a high-bred, high-strung horse. Such an animal will not submit to the bullying and punishment that a coarse-bred horse will endure. In general, a severe bit, that is, a bit that becomes severe if horse or driver pulls on it, such as a four-ring bit, is far better than the whip as a means of punishment.

Tying up one foreleg is an excellent way of subduing a refractory colt without injuring his temper.

The difference between "breaking" and "gentling" is largely this: suppose that the colt refuses to do what you want him to do, so that there is a contest of wills between you. If you are "breaking" him, you will go at him with whip or bit or a "war-bridle," or some such device, and force him to do your will. You will probably succeed, but you will, in some degree at least, 
either cow your horse or injure his temper. If you are "gentling" him, and he refuses to do what you want, you will wait for him, or keep at him quietly but firmly until he is sick of the contest and yields. This is what is meant by "letting the colt train himself." A colt trained in this manner will insensibly acquire the habit of willing obedience, which is far better than obedience rendered through fear.

John Young, a very successful trainer says:

The colt himself must do much of his own training, and the man who can discover the many different ways differently tempered youngsters have of aiding their own education is the man who is bound to succeed.

Perhaps the art of training or gentling colts may be summed up by saying that it consists in putting the mind of the man against the mind of the horse. I would rather have my colts handled by a man of the right sort - courageous, firm, good-tempered, kind, who had no experience with horses whatsoever, than by the most experienced man who was ill-tempered or cowardly. 


\section{CHAPTER VI \\ HOW TO SELECT A HORSE}

IN selecting a horse - or a wife, for that matter 1 do not be satisfied until you can please both your judgment and your fancy. Trust largely to first impressions. If your first impression is unfavorable, reject the horse without further scrutiny, for you will never be satisfied with him. But if you take a fancy to him at first sight, look him over carefully to make sure that he has no serious defect or fault.

The most important part of a horse is his head, for that shows what his inward qualities are, and in a horse, as in a man, the inward qualities are more important than the outward. A horse with a good head always turns out better, and a horse with a bad head always turns out worse than you expected. This is true no matter how much or how little you expected. All great horses have had fine heads. "Flora Temple," said her old groom, William Cunningham, "had a remarkably good head, clean at the throttle, and the expression of her hazel eyes was something one will never forget." Maud S., Lou Dillon, Bingen, and other famous horses have had the same expression of intelligence and will power.

The character of a horse always shows itself in his eyes. Choose the horse with a large, serene eye, well set out on the side of his head. Stupid horses have 
a peculiar, flurried, unsettled expression of the eye. Avoid most of all the horse with a small, sunken eye, for he is apt to be vicious and stupid. He is even more to be shunned than the horse that shows the white of his eye. A coarse, heavy eyelid is also an indication of a bad, or at least unpleasant, disposition. Intelligence is even more important than a good disposition. A vicious, intelligent horse may easily be improved, and usually can be reformed by kind treatment. Sugar, apples, and firm but gentle handling will work wonders with such horses; but very little improvement can be made in a horse naturally stupid.

The brain of a horse is contained in the space between his ears and his eyes. Therefore look for a horse who is wide between his ears, and especially between the eyes, and who is also long from the root of the ear to the eye. A horse wide between the eyes, but noticeably short from ear to eye, will show some lack of sense. The ears can hardly be too far apart except that a horse unusually wide between the ears is apt to be lazy. A horse with a narrow head is the least intelligent, and therefore the most dangerous of horses.

The ears are important. Look for a well-shaped ear, and if it be finely cut no matter if it is somewhat long. Many trotting-bred horses have long ears, but they are well-shaped. A short, stubby ear, a "mouse ear," as horsemen call it, is the mark of a stupid or flighty animal. When the ears are pricked forward at an unusual angle, so as to have a drooping look, you may be sure that the horse is a timid one. The nearer 


\section{HOW TO SELECT A HORSE}

the ears come together when they are pricked forward the more nervous and excitable the horse. Years ago there flourished in a certain village in northern New England a mare nicknamed "Piccadeer" (Peaked Ear). Her ears actually touched at the tips when they were pricked. She was noted for her speed, and still more for her incurable habits of shying and running away. A flopping ear is held to indicate a want of strength or energy; but some very high-lifed horses will flop their ears when they are standing. In such cases the flopping is probably due to some defect in the muscles of the ears - not to the inward spirit of the horse. The quick-moving, alert ear - and especially the ear that is turned forward and then backward, and then forward again - is the sure sign of a lively, pleasant disposition.

Roman-nosed horses are apt to be obstinate, but once broken they are broken forever, and they are very seldom flighty or timid. The Roman nose does not often occur in a high-bred horse, except in the English draft breeds. The opposite, the dish-faced formation, is, on the other hand, associated with good breeding, and is usually the sign of high spirit.

\section{QUALITY}

Good breeding shows itself in what is called "Quality," which is thus defined by Professor Rufus C. Obrecht:

Quality in a horse is of prime importance. The term when applied to horses has reference to their bones, skin, hair and muscles. Its presence is shown by clean-cut features of the head; firm, 
clean bone; tendons well defined; close fitting, glove-like skin; hair fine and silky, an abundance of finish and absence of coarseness, but not necessarily small bone. When slightly exerted the skin will show clearly an intricate network of veins. Coarse hair is usually associated with coarse skin and a soft, spongy bone which is weak and subject to disease. With quality the muscles stand out prominently and are clearly defined, which aids in giving a horse finish.

Reject a horse with meaty legs, or very coarse hair, especially on the legs, or with a foot which is brittle and lacking in closeness of texture.

Quality and beauty are usually found together, and yet one may exist without the other. A horse may not be in the least beautiful, and yet he may possess quality. For example, he may have an ewe neck, a large head, long ears, a Roman nose, a sway back, flat sides, slack loins, calf knees, cow hocks and a rat tail; and yet if his coat is short and silky, if his head, though large, is bony and well-cut, if his ears, though long, are well-shaped, if his legs are flat and clean, and if his hoofs are of fine, close texture, then the horse has quality. Horses of the Shire and Clyde breeds often look coarse at first sight on account of their Roman noses and hairy legs, but in the best specimens of these breeds the long hair about the fetlock is fine and silky, and their heads, though not handsome, are clean-cut.

In many large stables, where horses have been bought without much judgment, almost all the horses may be divided into two distinct types: first, the well-bred, smooth-hipped, fine-coated type; and, second, 


\section{HOW TO SELECT A HORSE}

the low-bred, ragged-hipped, coarse-haired type. The horses of the first class will look fat and sleek, whereas the horses of the second type will look thin and jaded, although all the horses do the same amount of work. The Old-Horse Class in a Work-Horse Parade is another illustration. The veteran steeds shown in that class are almost invariably horses of quality. They represent the survival of the fittest; and the fittest are the well-bred ones.

\section{CONFORMATION}

There is a close similarity between the good points of all horses, whether they are race horses, draft horses, or what not; the main difference being this, that a rather long leg is essential to speed either at the running or trotting gait, whereas a draft horse can hardly be too short-legged, except that an extremely short-legged horse is apt to be a slow walker.

The legs, especially the cannon bone, should be broad, flat, and "clean," as horsemen say, by which they mean free from flesh - all bone, muscle, and skin. "There isn't meat enough on the whole four legs of that horse," I once heard an enthusiastic dealer declare, "to make a lunch for a dyspeptic sparrow."

A leg that has a small, tied-in look immediately below the knee is always a weak leg. Round legs are subject to windgalls and other infirmities. Cow hocks and sickle hocks are weak formations, subject to spavin. A rather crooked hind leg is indeed associated with speed, but for strength and endurance the hind leg should be fairly straight; not absolutely straight, for, 
with that kind of leg, you get too much concussion, and, as a frequent consequence, unsound hocks.

For the same reason short, straight pasterns, whether before or behind, are apt to cause unsoundness in the feet, and especially side-bones. In fact draft horses in recent years have been so subject to side-bones, attributed to short, straight pasterns, that breeders are now going to the opposite extreme, and breeding for a long, oblique, and somewhat weak pastern.

No horse can be beautiful without a fairly long neck. A short neck almost always means poor wind, and usually, also, a poor mouth. Even a draft horse should not be noticeably short in the neck. With a neck of good length, he will not only have better wind, but will be better balanced.

As to the shoulder, it can hardly be too sloping for a saddle horse, roadster, or carriage horse; and a sloping shoulder is valuable in a draft horse, because it is better adapted for pulling, and, moreover, it affords a better resting place for the collar than a straight shoulder. It may, indeed, be too sloping for the collar, but this is a rare defect in draft horses. A shoulder too straight is far more common among them.

A short back is, of course, stronger than a long back. This is true of all animals. A good formation, not unusual among trotters, is the combination of a short back with a long barrel. This is possible only with a sloping shoulder. Horses so made are described as being "short on top and long underneath."

A "slack-ribbed" horse, by which is meant one with too much space between the last rib and the hip, is 
almost always a horse rather hard to keep. A horse's ribs should be well sprung out, that is rounded out in barrel shape. These horses are almost always stronger than flat or slab-sided horses. This formation is characteristic both of the Arabian and of the Morgan horse.

Thin-waisted horses are usually delicate. A good "bread basket" is what the experienced horseman looks for. And yet some thin-waisted horses have so much nerve force and courage that their endurance is great. "Blood is better than substance."

\section{THE FOOT}

The most important part of the foot is its texture. The foot should be of fine, close-knit texture, wide at the heels, with a strong, tough wall, and neither too high nor too low at the heels. A thin or weak wall is apt to accompany low heels. A horse that is high at the heels, especially one that has what are called "mule feet," or a "cup-foot," has really stronger feet than other horses, and could go without shoes on soft roads better than other horses; but this kind of foot, inasmuch as it receives less frog-pressure than a foot of less depth, does not usually last as well in the city as a foot with lower heels and less depth to it. All horses in the city must suffer more or less from want of frog-pressure, and the high-heeled foot suffers more than the low-heeled. Even in the country, a horse with a deep foot and high heel needs more attention than a horse with low heels, for, owing to the want of frog-pressure, it is more apt to harden and contract. 
Ridges in a foot are indications of existing or former disease, and the horse with a ridged foot should be viewed with some suspicion. The same remark applies to a foot the surface of which presents a dished appearance.

It need hardly be said that the size of a normal and healthy foot varies not only absolutely but relatively, according to the breed of the horse. Well-bred horses, especially Arabs, thoroughbreds, and Morgan horses, have small feet - small even in proportion to the size of the horse. Draft horses have larger feet. A small foot, if well-shaped and of good texture and not contracted at the heels, is to be preferred to a larger foot, especially in the case of a saddle horse. A saddle horse with large feet can hardly escape being somewhat clumsy and hard to ride.

Sometimes a horse will have one foot, especially one forefoot, smaller than the other. This is always suspicious, and will probably indicate that the horse is or was lame in that foot, or else that some lameness in the leg has occurred and the foot has become smaller from want of natural use.

\section{COLOR}

There is a common belief, and, no doubt, a correct one, that certain colors indicate strength of constitution. These colors are roan, especially black roan, dark steel gray, and flea-bitten gray. A flea-bitten gray horse is almost always, I think, intelligent and goodtempered, as well as tough. I once asked a general of cavalry, who had bought thousands of horses for the 


\section{HOW TO SELECT A HORSE}

army, what color he preferred, and he replied, "A flea-bitten gray."

On the other hand, certain pale, washed-out colors, such as a bay with a yellowish tint, or a very light sorrel, seem to indicate some want of constitution. White hair, or even very light bay hair, on the legs of a bay horse is objectionable. A bay horse should have black legs. An exception, however, to this rule must be made in respect to Shire horses and Clydesdales, as they usually have light-colored legs. White is also, I think, a weak color; but this of course does not apply to gray horses that become white through advancing age. Gray horses, as they become old, are subject to small, melanoid tumors, especially about the anus, but these are not often big enough to do any harm.

It is sometimes said that chestnut horses are apt to be fiery, and this, I believe, is true. A bright chestnut horse with a white strip in his face and white stockings, is a very showy animal, and usually a high-spirited one. It was such a horse that Lord Cardigan rode when he led the charge of the Light Brigade at Balaklava. 


\section{CHAPTER VII \\ WATERING AND FEEDING}

THE best way is to water your horse first, then give 1 him his hay, then water again, and finally give him his grain. Water immediately after grain has some tendency to interfere with his digestion. This is especially the case when the horse is put to work immediately after feeding. Truckmen in the city often speak of "afternoon colic." This is usually caused by first graining the horse, then watering him, and at once starting on the afternoon's work. These horses should be watered before receiving their grain, and again two hours later.

One often sees the statement that a horse will worry if not watered immediately after feeding. He certainly will worry if any change whatever is made in the time of watering or feeding him, but once accustomed to any system he will eat or drink freely at the appointed time. What the horse objects to is irregularity or unpunctuality. He carries no watch, but he knows almost to a minute when the usual time for feeding or watering him arrives. "Livery horses," says Dr. Schoenleber, "are never sick except when over-driven. Why is this? Because a livery horse gets a certain amount of feed regularly, is watered regularly, and cleaned regularly."

To eat grain does not make a horse thirsty, but the 
eating of hay does make him thirsty, and therefore a horse should always be watered after eating his hay; not necessarily immediately after, in fact, it would probably be better to let an hour elapse between the time when he finishes his hay and the time when water is given. This, however, is not so important. The great matter is to water him after he has had his hay, especially at night. To leave a horse without water all night is not only cruel but bad economy.

The whole system of a horse craves water after he has eaten his hay, hay being both a dry and a bulky food, and the digestion of the hay cannot take place properly, especially in the intestines, unless the horse receives water after eating it. Nothing could be worse than the practice of giving a horse a lot of hay late in the afternoon or in the evening, and letting him go without water until the next morning. If, however, he is watered after eating his hay and then receives his grain, he will not, as a rule, need any more water until the next morning, and even then he will probably not be thirsty, unless the weather is hot, until he has had his morning supply of hay. Gilbert Tompkins, a high authority, says on this point:

The time when water counts for the most is after the evening meal has been eaten and digested. A good drink at that time washes away undigested debris, restores the natural fluids of the body, and brings on a restful sleep, not disturbed by thirst.

Horses, as is well known, require pure water, and are very fastidious about it. Water that contains much sediment of any kind is bad for them, because 
the sediment irritates the membrane of the stomach and intestines and often produces what is called "sand colic."

Soft water is much better for horses than hard water, and for this reason a brook, spring, or pond is always to be preferred to a well as a water supply.

The matter of watering on the road is treated in the chapter entitled "The Art of Driving."

Every horse doing regular work should receive his grain in at least three separate feeds, and if he is hardworked and highly grained he should be fed four times a day. This latter is the custom in many work-horse stables in the city, especially among milk dealers. F. M. Ware, a man of great experience, says that all horses should be fed four times a day - the stomach of the horse being, as everybody knows, extremely small in proportion to his size.

Never give grain to a tired horse. The most experienced veterinary surgeon in New England stated recently in a public lecture that giving grain to tired horses produces more colic than all other causes combined. Let the tired horse rest and nibble hay for an hour or two before he receives his grain. Nothing looks worse to a man experienced with horses than to see grain ready in the manger before the horse comes in. If the horse is very hot, it is better that he should eat nothing, not even hay, until he is cool, and to give grain to a very hot horse is, as almost everybody knows, extremely likely to founder and ruin him. 


\section{CHAPTER VIII \\ HAY AND GRASS}

THE best way to feed hay is on the floor of the 1 stall, whether it is a box stall or a straight stall. This is the natural way for the horse to eat, and consequently the easiest and most comfortable way. Moreover, with his head down, a horse will secrete more saliva in eating, and will therefore digest better than if he is forced to hold his head up. The next best way is to have it in a deep manger, and the worst way is to have it in an old-fashioned hay rack so placed that the horse has to stretch up his neck in an unnatural position, and is also likely to have hay seed fall into his eyes. Horses should receive the greater part of their hay at night, and if the horse is worked all day, it would be better to give him very little hay at noon. If, however, the horse is used but little so that he is in the stall a good part of the time, and receiving very little grain, then it is best to give him an ordinary feed of hay in the middle of the day; for if the horse receives only a small amount of grain and no hay in the middle of the day, he is apt to get hungry and restless an hour or two later, and may take up some bad habit, such as cribbing or weaving.

It is a mistake to give a horse more hay than he will eat up clean, and worse yet to have hay always before him. Roughly speaking, horses should have at night 
as much hay as they will eat in about an hour and a half.

The worst possible policy is to feed poor or damaged hay. Many a fine horse has contracted heaves and been ruined from eating hay that was smoky or dusty, especially the former. But if you are forced to use such hay, sprinkle it freely with water, and, if possible, lime water. Half-cured hay, which is undergoing a kind of fermentation process, is very injurious. Many a horse has incurred a bad attack of colic by eating half-cured hay or wilted grass in the hayfield. Horses at work in a hayfield should wear an easy side check to prevent them from eating the hay.

New hay often produces colic and is very bad for horses that are hard at work, for it induces much sweating and has a weakening effect. New hay should not be fed until November; but if you are obliged to feed new hay, or are going on a journey where you may find nothing else, it is very advisable to accustom the horse to it beforehand by feeding him for a time, half new and half old hay.

The staple hay is, of course, herd's grass, but if it has a little clover mixed with it so much the better. A slight mixture of clover, of red clover especially, makes the hay more palatable, more digestible, and less constipating, and is particularly good for horses that have a tendency to colic. Another reason for feeding clover is that it contains a large percentage of lime, and lime makes bone. The blue-grass region of Kentucky, famous for the beauty of its horses and women, is a limestone country. 


\section{HAY AND GRASS}

Most stable keepers prefer very coarse hay, but I think that the horse himself prefers hay that is not excessively coarse. Do not feed your horse the same kind of hay all the time. A horse likes a change of diet. He will even eat with appetite a little good meadow hay or salt hay for a change.

The hay grown on neglected farms in New England and called "June Grass" is thought little of, but it is very clean and is tender if cut early, and horses like it and thrive on it, although possibly it has not the same amount of nutriment as herd's grass or timothy. If cut late, it is hard and wiry, and of little value.

Hay should be cut early, when it is flowering, and then, if well cured, it will have a green look and a pleasant flavor. Hay made from grass cut too late, or too much dried in a hot sun, lacks the green color and the pleasant odor, and is hard and wiry. Hay that is discolored from being wet while in process of curing is fit only for bedding.

Generally speaking, the health of a horse depends upon the kind of hay that he gets; his strength and endurance depend upon the kind and amount of grain that he gets.

\section{GRASS}

It used to be thought that grass was about the worst thing possible for a horse doing hard work; but it is now known that a small feed of grass every day is good for all horses; and the modern trainers of trotting horses "grass them out," if they can, every day while they are in training. Nothing is better or more 
refreshing for work-horses in the city than grass; and it can easily be sent to the city in bags, at small expense.

Farmers often put their work-horses in pasture every night, but some care should be exercised about this. A hard-worked horse should be turned out only on warm nights, and his chief food should be hay, not grass.

Some care should also be exercised in transferring a horse from stable to pasture. Let him be fed grass, a little every day, until his stomach is accustomed to the change; and take off his stable blanket. There is great danger in making a sudden change from a warm stable to a pasture. But if you are bound to do so, turn the horse out at night rather than in the morning. If he begins his pasture life in the morning, his stomach will be full by night, and he will then lie down and perhaps get cold or colic; whereas if he is turned out at night-fall, he will graze all night, and will not lie down until the morning sun has warmed the air and the ground.

\section{SODS}

A horse that has no access to pasture should be given now and then a sod or piece of turf. He craves the earth which is thus obtained, and it is good for his digestion. Everyone has noticed that when a horse is turned out in a field, his first act is to paw up the earth or sod and eat that, even before he takes a mouthful of grass. 


\section{CHAPTER IX \\ GRAIN AND VEGETABLES}

THE staple grains are, of course, oats, corn, and 1 bran. There are many kinds of prepared feed on the market, some of them very bad, some fairly good and some perhaps that are very good, but the safest way is to avoid them all unless you have special "inside" knowledge about them. Oats are the proper food of a driving horse, and, we think in New England, should be the principal grain fed to any kind of a horse. In the South and West corn is fed more than oats, but in the eastern and middle states corn is feared as a cause of colic, and many horse-owners, truckmen especially, look upon it as almost a poison. However, the most sagacious and the most experienced horse-owners feed more or less corn to work-horses in cold weather, and no doubt this is beneficial. In the first place, corn supplies heat which is much needed in a New England winter, especially by horses exposed in all weathers; secondly, it is nutritious; and thirdly, it offers some variety from the regular feed of oats. The best way to feed corn is on the cob, the next best is probably in the form of cracked corn, the third best in the form of whole corn.

Cornmeal fed by itself is dangerous for it tends to form a compact mass in the stomach and thus produce colic. Cornmeal should be fed either with bran or 
with hay cut by a hay cutter. This method of feeding, that is, giving cut hay and cornmeal, or a mixture of corn and oats ground together, called "provender," was formerly a common practice in New England and a very good one. Mixing hay with the grain tends to make the horse chew the whole thoroughly, and it is probably better than the feeding of hay and grain separately. Cut feed is always given to work-horses in England. So far as I know there is only one large stable of truck horses in Boston that now receives "cut feed," but these horses are among the very best in the city in point of condition and roundness and sleekness of appearance.

Oats should be plump, hard and dry, with thin husks. Some oats are very deceptive, being apparently large, but their size is due to the thickness of the husks. New oats have an earthy odor; they should look bright and rattle like peas. Old oats should be almost without odor or taste. Oats are often adulterated with barley, and with rape seed. "Nothing is more extravagant," says T. F. Dale - and a hundred other authorities might be cited to the same point - "than inferior oats or hay."

Oats should never be fed until they are two or three months old. New oats are extremely likely to cause indigestion and colic. Kiln-dried oats are safe, but sometimes, in order to remove the deep yellow tinge of kiln-dried oats, they are treated with sulphur, which is injurious to the horse - except when he needs sulphur as a medicine. The sulphur can be tasted by chewing the oats. 
In recent years crushed oats have been fed by many truckmen and others, and they believe that this is not only economical, but also that it tends to prevent colic. It is certainly well to feed crushed oats to horses who bolt their grain so hastily that many oats pass through them whole. Machines for crushing can be procured - small, hand machines, and also large machines to be run by electric or other power. The oats can be crushed more or less - but preferably only just enough to break open the husks.

Ground oats soon become sour, and anyone who feeds them should make sure that they are freshly ground.

\section{BRAN}

Next to oats there is nothing so useful in a stable as bran. A few horses that have a tendency to looseness of the bowels cannot be given bran even in the dry form, but most horses, especially work-horses, need a bran mash once a week, and when work is light they would be better for a bran mash twice a week. Six quarts of bran is about the ordinary quantity for a bran mash, and it is made by pouring boiling water upon the bran, then thoroughly mixing it and covering it up and leaving it to steam for ten or fifteen minutes, or perhaps longer, and then feeding it to the horses, lukewarm in hot weather and hot in cold weather. It has a slightly loosening effect upon the bowels, tends to purify the blood, and contains some nutriment.

In the case of a hard-worked horse that receives a good deal of grain, it is well, in summer, to add a 
heaping teaspoonful of saltpetre to his Saturday night mash.

In some good work-horse stables a small quantity of dry bran is mixed with every feed of oats. This tends to make the horses eat more slowly and chew their oats better. It also helps digestion.

If you want to keep a horse looking round and well filled up across the loins, and if at the same time, the horse is doing little work, bran is very useful and is best given dry or mixed with a little water. If a horse is fed only a small quantity of oats and plenty of hay, he tends to sag down in the belly and lose flesh over the back ribs so that his appearance will be injured, but by feeding him plenty of bran with a small quantity of oats and the usual quantity of hay he will still retain the rounded, well-filled-up shape which is produced by liberal feeding of grain.

After a long day's work in hot weather, nothing is so refreshing to a horse as a bran mash, given luke-warm, although, of course, if a horse is to be used hard on the following day the bran mash should not be given on account of its laxative effect. So in cold weather, or after a long day in a cold rain storm, a hot bran mash made, say, half of oats and half of bran with the addition of a tablespoonful of ginger or of brown sugar, or both, will be relished immensely by the horse and will be good for him. If he has been chilled, or greatly fatigued, an ounce of gin may be added to the bran mash.

Bran can also be fed to advantage dry and mixed with oats or corn. In fact, the proper winter feed for 


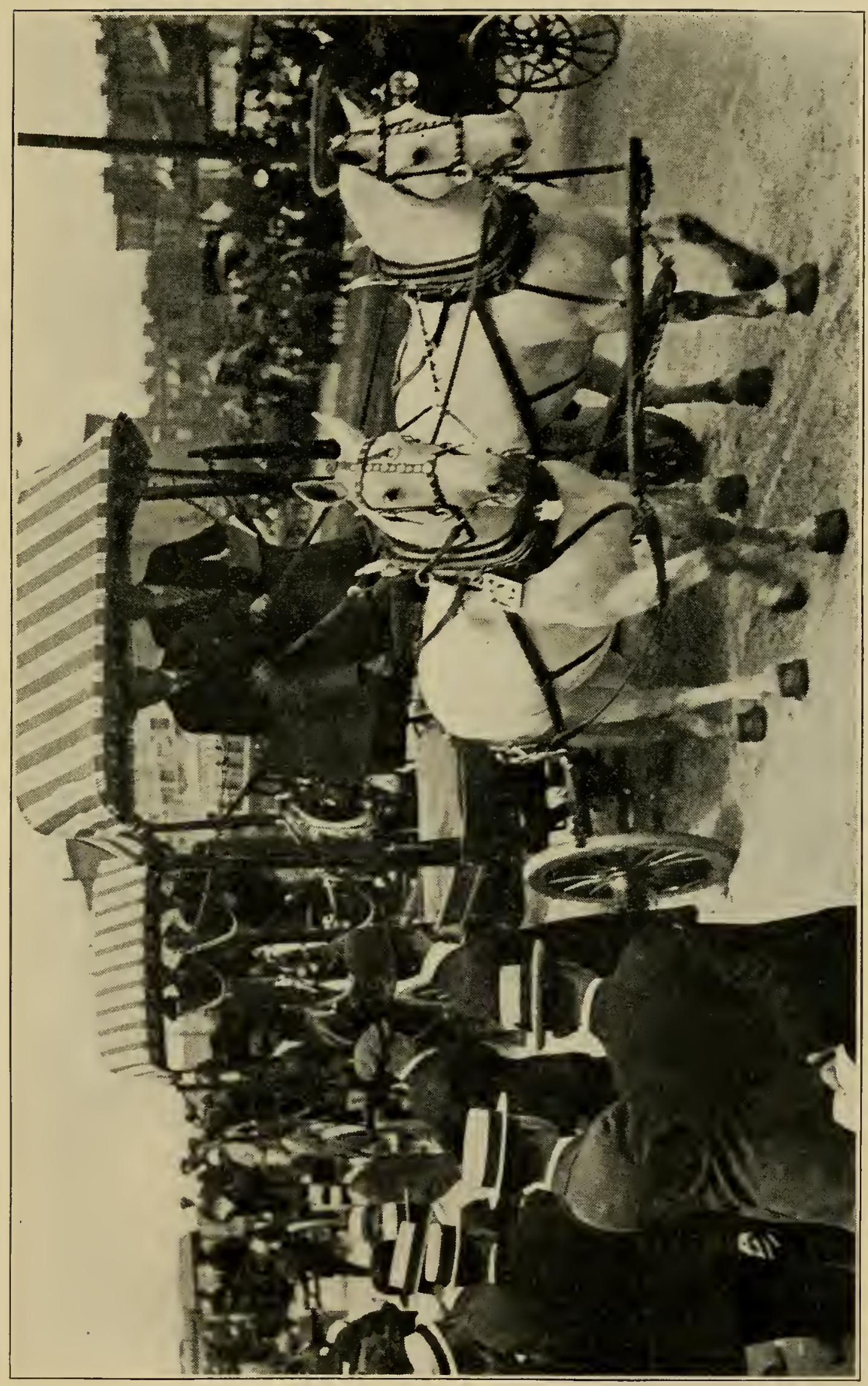

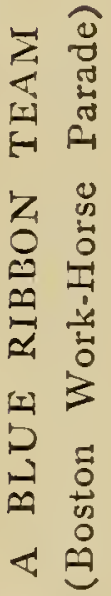



horses doing little work, and for brood mares and colts, is a mixture of dry bran and oats or dry bran and corn, preferably the oats and bran once or twice a day - if the horse is fed three times - and the corn and bran once a day at night. A mixture of oats, corn and bran ground up together will do as well. Horses thus fed will also, as a rule, require a bran mash once a week in place of the night feed of oats and bran, or corn and bran.

Bran, or some other laxative food, is absolutely necessary to prevent constipation in horses changed abruptly from pasture to stable, and from grass to hay.

Bran is especially good for pregnant mares and also for colts, because it is a good bone producer. Bran is much better than what is known as middlings - bran, which is the outer coat of a kernel of wheat, having a more laxative effect. It should have a sweet smell, should be in large flakes, of a pale flesh tint, and should make the palm of the hand floury, when it is rubbed with the bran.

There are, of course, things that will take the place of bran as a laxative, such as potatoes, and the farmer who has a good store of small potatoes can perhaps economize by feeding the potatoes to his horses instead of bran.

It might be mentioned here that whereas uncooked potatoes have a slightly laxative effect on the bowels, boiled potatoes, thoroughly cooked, have the opposite effect, and a chronic case of looseness of the bowels can usually be cured by feeding boiled potatoes. 
The potato is probably the most wholesome vegetable for the horse. Carrots, as everybody knows, tend to purify the blood and to give a good polish to the coat, but carrots should not be fed lavishly for they sometimes produce indigestion and colic. Beets and turnips in small quantities are also good for horses. Horses love apples, and the apple is a more efficient instrument in training a horse than whip or spur. There is no danger in feeding sweet apples, but sour apples, if given freely, sometimes cause colic, and sometimes make the teeth and gums sore.

Alfalfa, mixed with oats or corn, or with both, is now fed in many stables in the eastern states, and with good results. It does away with the necessity of bran, and, by keeping the bowels regulated, diminishes the danger of colic. It has long been a staple food for horses in the West and South. 


\section{CHAPTER X \\ SALT AND SUGAR}

B Y far the best method of giving salt to horses is to $B$ have it always before them. A horse knows better than anybody else just how much salt he needs, and one horse may need very much more or very much less than another. For this reason, the common practice of giving a stable-full of horses their salt by putting an equal amount into the mash for each horse once a week is not a good practice. A small quantity of salt, however, often makes the mash more appetizing, and therefore, for a horse off his feed or tired or chilled, a mash with the addition of some salt or sugar is good.

The best way of giving salt is to have it either in the form of a block or in a small, separate manger in which a lump of rock salt can be put, or the lump can be put in the hay manger. If a piece of salt is put in the grain manger it is apt, before the horse has finished it, to become broken up into small fragments, and to make a kind of dirty mixture in the bottom of the manger.

For sick horses a little fine table salt should be provided, for the sick horse will often use salt in that form, and it is good for him - whereas he would not take the trouble to stretch up his head and apply his tongue to a block or lump of salt. These are fine points, but they count for a good deal in the case of an animal so highly organized and so sensitive as the horse. 
Horses at pasture should be salted at least once a week.

\section{SUGAR}

A perfectly healthy horse in good condition probably does not need sugar, except as an occasional treat, and perhaps sugar regularly fed to him in any considerable quantity might cause indigestion; but for thin horses and especially for old horses whose teeth are beginning to give out, sugar in some form is extremely wholesome; and as a means of recovery from fatigue it is good for any horse. ${ }^{1}$ It is difficult to feed a horse molasses without getting the animal and his manger sticky, and for this reason sugar is best given in the form of brown sugar or molassine, although molasses can be fed by sprinkling it on the hay. Molassine, an English product, is widely sold in this country. It does not contain anything of value except molasses, according to the analysis of the Massachusetts Agricultural College, and it therefore may be regarded as simply a clean and convenient form of feeding molasses. It is, of course, a rather expensive form, for the molassine costs more than pure molasses.

For a horse weighing, say, a thousand or twelve hundred pounds, the proper ration of sugar, molasses, or molassine would be about an ordinary cupful fed twice a day. In the case of an old or run-down horse this quantity might gradually be increased - even until

${ }^{1}$ In many excellent work-horse stables it is now the custom to feed a certain amount of sugar in some form every day, and the effect appears to be good. This is a new practice, however, and it is too early yet to pronounce upon it with certainty. 


\section{SALT AND SUGAR}

the animal was receiving a quart, or the equivalent, every day. Worms in horses can often be gotten rid of by feeding molasses, with the advantage that your vermifuge is not only that, but a tonic and a food as well. 


\section{CHAPTER XI}

\section{BEDDING}

NEXT to feeding and grooming, bedding is the most important thing for a horse, and to deprive the horse of a comfortable bed is very bad economy, to say nothing of humanity. The horse should have a good, deep, dry bed under him at all times when he is in the stable, day and night, and on Sundays as well as week days. Experience shows conclusively that when a horse is well-bedded, he will lie down much more than if he is poorly bedded. Horses, especially workhorses, that are bedded during the daytime almost invariably lie down a part of the day as well as during the night, and this practice has a very marked effect in saving the wear and tear of their legs and feet.

The writer once entered a stable of work-horses in the daytime in which there were twenty-five horses. Only one had bedding under him and that one was lying down; all the others were standing up. In another stable was a horse that worked in a grocery wagon three successive days, resting every fourth day. This horse, somehow, was able to keep his own calendar, and every fourth morning, as soon as he had finished eating his breakfast, he would lie down comfortably on the plentiful supply of bedding kept under him at all times, and frequently he would stay down the better part of the day. 
There is an old saying that a good city horse could use up four sets of legs and feet. This means that a large part of his bodily strength and endurance is wasted because lameness and suffering wear out his legs and feet long before his time. "His shoulders is all gone savin' his legs," is the way in which one stableman described the condition of a horse that had worked all his muscles excessively in trying to ease the strain on his battered legs and feet.

Nothing will tend more to preserve legs and feet than the habit of lying down. For many years the Boston Work Horse Relief Association has conducted a system of stable inspection with prizes for the best kept stables, and among the stables entered for inspection a few years ago was one containing a fine lot of horses well fed and well groomed. The only fault the inspector could find with the stable was that the horses were not bedded in the daytime on Sunday. This fault was corrected, and four weeks later the owner wrote to the Association:

I am now convinced that horses should be bedded both day and night when they are in the stable. My horses now lie down a good deal through the day on Sundays, and my teamsters all say that, as a result, they are better horses on Monday than they used to be.

The importance of a good bed is always insisted upon by English experts in horseflesh, and one of the most noted of them attributes the excellence of English horses partly to the practice of liberal and skilful bedding. "A French groom," he says, "could never bed a horse to the satisfaction of an English trainer." 
In many stables it is the practice to roll up the bedding, often wet, and leave it at the head of the stall, under the manger, where it cannot dry and is offensive to the horse.

Another important thing is to tie the horse with a sufficiently long halter rope to enable him to rest his head on the bedding. "Give a horse a wide stall," says H. W. Sayre, "a good soft bed, and halter rope enough to let his head go down comfortably on his bed, and you can keep him on three-quarters of the feed which would otherwise be required."

If a horse is properly cleaned there is little danger of his getting cast, unless he belongs to that small class of horses that make a practice of becoming cast. Such horses should really be kept in a box stall, and if that is not done, they should be so tied with a rope coming from overhead, fastened to a weight, and attached to the headstall, that they can touch their noses to the floor, but cannot lay their heads flat on the floor.

When there is a man in the stable all night even this precaution is not necessary, for he can easily take care of a horse that becomes cast. Sometimes, to save themselves trouble, stablemen will tie up a horse that is apt to become cast in such a way that the poor brute can never lie down at all. Nothing could be more cruel, or better calculated to wear out the horse.

Some horses never lie down, and in almost every stable that contains fifty horses or more, you will find one or two of these unfortunates. As a rule, the cause is fear: the horse has been hurt through being cast, or has injured his hips in a stall too narrow for him, or 
has gone through the floor of his stall, or has had some other accident. Such experiences last for years. Often, however, a horse that never lies down in a straight stall, will do so in a box stall; and often, too, a horse that will not lie down in any kind of stall, will lie down if you give him a good bed on the barn or stable floor, or in a shed, or in any other place where he is not inclosed, as it were, by walls or partitions.

A horse that never lies down should occasionally be slung for the night, as that will enable him to rest his over-worked joints and feet.

To use a good supply of bedding is really more economical than to use a small amount for each horse, because when only a small quantity is used, pretty much all of it will become wet and spoiled and will be thrown away, whereas if a liberal amount is used the moisture will be diffused through it, and it can all be dried and used again. Oat straw or meadow hay can be dried once or twice, and rye straw four or five times. In stables where it is possible to have a platform outside for the purpose of drying the bedding, a great saving can easily be effected. In rainy weather the wet bedding can be allowed to accumulate on the platform, and when the weather clears it can all be dried without much trouble, no matter how wet it has become. Sunshine and a west wind will do the work with surprising rapidity.

\section{KINDS OF BEDDING}

It does not make very much difference to the horse what kind of bedding is used, whether rye straw, oat 
straw, wheat straw, meadow hay, sawdust, shavings, or peat moss, except that the three latter are cold bedding for winter use. Rye straw is bad if the horse eats his bedding, for it often gives colic. Oat straw does not have this effect, and, if clean and sweet, is a good equine food. In England it is fed regularly to almost all horses.

Peat moss is best adapted for box stalls, and it has a decided tendency to soften a horse's feet and is good on that account. But unless often renewed in the stall, it may soften the horse's feet too much. Peat moss must be used with discretion. If the horse is not a good feeder, that is, if he scatters his hay about and does not eat it up cleanly, it is likely to become more or less mixed with the peat moss, and when that is the case, the peat moss soon becomes unfit for use.

Dry autumn leaves make a fairly good bedding, and they are much used in some lumber camps in New England, the leaves being raked into heaps by horse hay rakes and then carted into the stable.

Farmers' horses certainly should never suffer from want of bedding because the farmer can always procure either straw or meadow hay at the cost of a little labor, and yet there is perhaps no class of horse owners so remiss in bedding their horses as farmers. 


\section{CHAPTER XII \\ GROOMING, RUBBING, AND SCRAPING}

$T$ is a frequent saying of horsemen that a good 1 grooming is as beneficial to a horse as a quart or two of oats, and this undoubtedly is true. In winter when horses' coats are long and they are very little if at all sweated, the grooming is not important, provided that the coat is kept free from outside dirt. In fact, the accumulation of dandruff in the hair will tend to keep the horse warm, and by making the hair somewhat oily, will tend to shed the rain.

But in summer the case is different. Then, if the coat is full of dandruff, it becomes extremely irritating to the horse when he is sweated. A horse with a summer coat should be so thoroughly groomed that the dandruff will be wholly removed from his skin and hair. If, when the horse has been sweated and dries off, white marks appear on his hair, it is a proof that he is not properly cleaned. I confess that I cannot help despising a man whose horse exhibits these telltale white marks.

It does not matter much what tools are used in cleaning a horse. In India the work is done almost wholly with the bare hands of the groom. A currycomb affords a quick and fairly easy way of cleaning a horse, but it should always be used with a light hand, and on thin-skinned horses it should not be used 
at all. The best kind of currycomb is the currycomb with corrugated edges instead of teeth. This is far less irritating to the skin than the ordinary currycomb with teeth. A mane brush, especially one with a rather small handle so that it can be firmly clasped, is a good tool; but even this is irritating to a thin-skinned horse. It is, however, always useful for the legs, as well as for the mane and tail.

Still more useful even than the mane brush are those small, cheap bristle-brushes which are made for miscellaneous purposes. They are light and easily grasped, and I like to use a stiff one instead of a currycomb, and afterward one with soft bristles. The motion of the brush should be a circular one. This screws the dandruff out of the hair. The final polish should be given by a cloth, or it can be done with a crumpled newspaper, and sometimes it is useful to moisten the cloth or newspaper with a little kerosene. It used to be the custom in "York State" to plant oats and peas together, and the resulting tangled straw made an ideal horse-cleaner.

When a horse is full of dandruff, especially if his coat is long, it is very difficult, in fact impossible, to remove it with a currycomb or brush. The best way is, first, to loosen the dandruff with a currycomb or brush, and then to take a wet wisp of hay or straw, preferably rather fine hay, and rub the hair up and down and around. In this manner the dandruff will adhere to the wet wisp.

If the legs are wet and muddy, they can be dried, if the hair is not too long, by vigorous rubbing, first with 


\section{GROOMING, RUBBING, SCRAPING 55}

a wisp of hay or straw, and then with a cloth. (See page 59.)

The one essential thing about grooming horses is that the man who does it should be willing to exert himself, for a horse cannot be well cleaned without a considerable amount of muscular effort.

\section{GROOMING BY MACHINERY}

There are two kinds of machines for cleaning horses by power. One is a rotating brush applied by electric or mechanical power, but the objection to this is that it creates much dust in the air which is injurious to the man who operates the device. The second form is a vacuum cleaner, substantially like that used in cleaning carpets, and this is effective and useful in large stables.

\section{WHEN THE HORSE COMES IN HOT}

If a horse comes in at all warm, the harness marks should always be sponged off with water; and also his nose and mouth, the dock and the inside of his hind legs should be well-sponged. In warm weather a horse should be wiped all over with a damp sponge, and in excessively hot weather it is safe and refreshing to wash the horse when he comes in, thus removing all dirt and sweat and cooling the horse; but this must be done with care, and, unless the heat is very great, the horse should be walked about until dry, or covered with a light blanket. Nothing could be more dangerous than to give a groom general instructions to wash a horse when he comes in. This should be done only under the eye 


\section{THE HORSE}

of the owner or by a thoroughly experienced and trustworthy man.

It is a great cruelty to put a horse up at night all sticky with sweat. A horse in that condition cannot rest well and will not come out fresh in the morning. Especially should this not be done in the case of a horse that does not receive a thorough grooming every day, for if the dandruff has been allowed to accumulate in his coat then the sweating will cause great itching and irritation. Many a horse has become cast from trying to scratch himself by rolling in his stall under these circumstances.

If you want to test the character of the groom who takes care of a horse, you can come pretty near doing so by looking at certain parts. For example, a careless or ignorant groom will be almost sure to skip the hollow between the jaws of the horse, where dirt and sweat sometimes accumulate, the inside of the ears, the root of the mane and forelock, the inside of the hind quarters and the dock.

\section{WHEN THE HORSE COMES IN WET WITH RAIN}

A horse that comes in wet through, after being out in a cold rain, requires some care. In the first place, with a scraper remove what water can be scraped from his coat, and if there is no regular scraper at hand, a smooth shingle will serve the purpose very well. It is astonishing how much water can be removed in this way, which otherwise would have to be evaporated by the warmth of the horse's body - a very chilling process. After scraping, throw a blanket over the horse, 


\section{GROOMING, RUBBING, SCRAPING 57}

and if you have a hood put it on. If you have not a hood, rub his ears, head, and neck until they are fairly dry, and then rub his legs, and bandage them if you do not rub them dry. If the horse is very wet and the weather is cold, an additional blanket should be put on in about twenty minutes, and in a very cold stable a third blanket. The moisture will go to the top blanket, and the top blanket can be removed when the horse becomes dry. In a stable where help is scarce, the hood, blankets, and bandages will take the place of rubbing fairly well, and when the horse is dry the bandages can be removed and the mud easily and quickly brushed from the legs and belly. As is mentioned above, after a long, cold, wet day a hot bran mash, half oats and half bran, with the addition of a little salt or sugar, or better yet, ginger, will be extremely good for the horse.

\section{WHEN THE HORSE COMES IN TIRED}

In addition to what has been said about the treatment of the wet horse and the sweated horse, the following suggestions will apply to the treatment of a tired horse, or to one that has done severe work, even if not tired. In the first place, give him a chance to roll, if possible, in a paddock or yard, or box stall. In all large stables a stall well-bedded with sand, peat moss, or straw should be reserved for this purpose. Next, brush him off lightly and quickly, body and legs, with a mane brush, and then bathe his fore legs from the knee to the foot, and his hind legs from the hock to the foot, with water as hot as your hand will bear. 


\section{THE HORSE}

This will relieve the pain and soreness in the tired muscles. Then gently rub the legs downward, and put on a thick bandage, or two thin ones, loosely. Do one leg at a time, so that each leg will be dried and bandaged before it has a chance to become cold, after the application of the water. Then, with a diluted liniment, rub the forearms and knees, the shoulders, the thighs, and especially the hocks. Leave the bandages on for at least three hours, and rub the legs gently when you take them off. If the ears are wet, rub or pull them, if the horse does not object, but do it very gently. Work about the horse quietly, so as not to fret or disturb him, and get through as quickly as possible if he is annoyed. Most horses, however, like to be fussed over, if it is done in the right way. (This kind of work should really be done by a woman.)

Keep watch of the horse for some hours, and feel of his ears now and then, and if he breaks out in a cold sweat, see that he does not get chilled. Dry him with a cloth, or blanket him more warmly.

After hard work or a long drive in hot weather, there always comes a time when, the horse having cooled and rested, a slight reaction occurs, and something approaching a chill sets in. Every man accustomed to the care of horses must have noticed this fact, although, so far as I know, it is not mentioned in any book. Look out for this reaction. Feel of the horse's ears, and give him a light blanket, if necessary, and when you water him under such circumstances, take the chill from the water by adding hot water. Almost any horse will drink water thus tempered, or even luke- 
warm, as readily and freely as he will drink cold water.

In summer the careful groom will always have a bucket of water standing in the sun, for use in watering and sponging.

\section{THE LEGS}

The legs should be kept clean mainly by brushing with a stiff brush, and they should be washed only under exceptional circumstances. In warm weather it will do no harm to wash the legs before the horse goes out; but they should not be washed when he comes in except on an exceedingly hot day - when the thermometer is at, say, $85^{\circ}$ or over. In ordinary weather, the legs should never be washed when the horse comes in after work. No matter how muddy the legs may be, do not wash them - unless you are prepared to rub them perfectly dry or to rub them partly dry, and then bandage with thick bandages.

A horse coming in on a rainy, muddy day, needs to have his legs made warm and dry as soon as possible. Therefore, rub the legs dry, or if the hair is too long or time is too short for that, rub them off quickly with a wisp of hay or straw, so as to remove some of the mud, and then bandage rather loosely with a thick bandage or two thin bandages. This will keep the horse's legs warm until they become dry, when the mud can be rubbed off. You often hear it said that to rub the legs when they are wet and muddy is bad, because you rub the mud into the skin. This theory is not borne out by the facts, and was probably invented by some 
groom who was more ingenious than industrious. A strong, active groom can rub a horse's legs perfectly dry, but not many men will take the trouble to do this.

If a horse is put into a straight stall with his legs wet, it is especially bad for the hind legs, because they are more exposed to draughts of air than the forelegs, and so the hind legs at least should be rubbed dry or otherwise protected. This is a great preventive of scratches and stiffness.

In cold, wet weather, or when there is snow or slush on the ground, it is a good thing to put vaseline, or better, glycerine on the fetlocks and around the heels before a horse goes out, as this will tend to keep out the moisture and to ward off scratches or mud fever. The hair on the legs should never be clipped, and it is especially dangerous to clip the long hair around the fetlock. This often results in scratches, even in warm weather. 


\section{CHAPTER XIII \\ HOT WEATHER TREATMENT}

$\mathrm{N}$ addition to what has been said in the preceding 1 chapter as to the care of a horse that comes to the stable heated or sweating, the following suggestions as to the general treatment of horses in very hot weather may be useful.

A driver will, of course, load more lightly than usual, and drive more slowly; at least he will do so if he has any regard for the horse either as a living being or as a valuable piece of property. To stop in the shade is also a great relief to the horse, and it is well worth while to take a little trouble for this purpose rather than to let the horse stand in the sun, even though the stop is to be for a few minutes only. Even in three or four minutes the temperature of a horse may change materially for better or worse. (This, however, does not mean that when your horse is reeking hot you are to let him cool off in the shade with a wind blowing on him. Many a horse has been foundered in that way.)

Horse hats do more harm than good unless they are of the canopy-top kind, so that the air can circulate between the top of the head and the hat. The ordinary, bell-shaped horse hat is a bad contrivance, for it confines the heat of the head. A sponge on top of the head, or even a cloth, is very cooling and beneficial, 
if kept wet; but if it becomes dry, it is far worse than nothing.

Water to drink in small quantities will not hurt the horse, so long as he keeps moving, unless the water is very cold. But if the horse is to be stabled or to stand still, he should have only a few swallows, if he is heated. If, however, the horse is very thirsty, and really craves water, you can safely give him a quarter of a pail of luke-warm water, and fifteen or twenty minutes later, half a pail more of the same, and still another half pail in another fifteen minutes. Most horses will drink water that is really warm, nearly as well as they will drink cold water.

Above all things, give your horse all the water he wants at night after he has eaten his hay. This is important at all seasons, and especially so in hot weather.

If the horse gets off his feed, as delicate horses often do in hot weather, try him with a small feed of oats, say two quarts, mixed with a little bran, with water enough to moisten it, and a little salt or sugar. Sugar is a great appetizer, and very nourishing. A delicate feeder will also, as a rule, drink oatmeal gruel or barley water, especially if the beverage is slightly salted or sweetened. When horses are too hot to receive their ordinary noon feed of grain, the oatmeal gruel or barley water will take its place. It was customary to feed fire engine horses in this way on the Fourth of July when alarms were so frequent that the unfortunate animals had no chance to cool off.

It is not unusual nowadays to see electric fans in city 


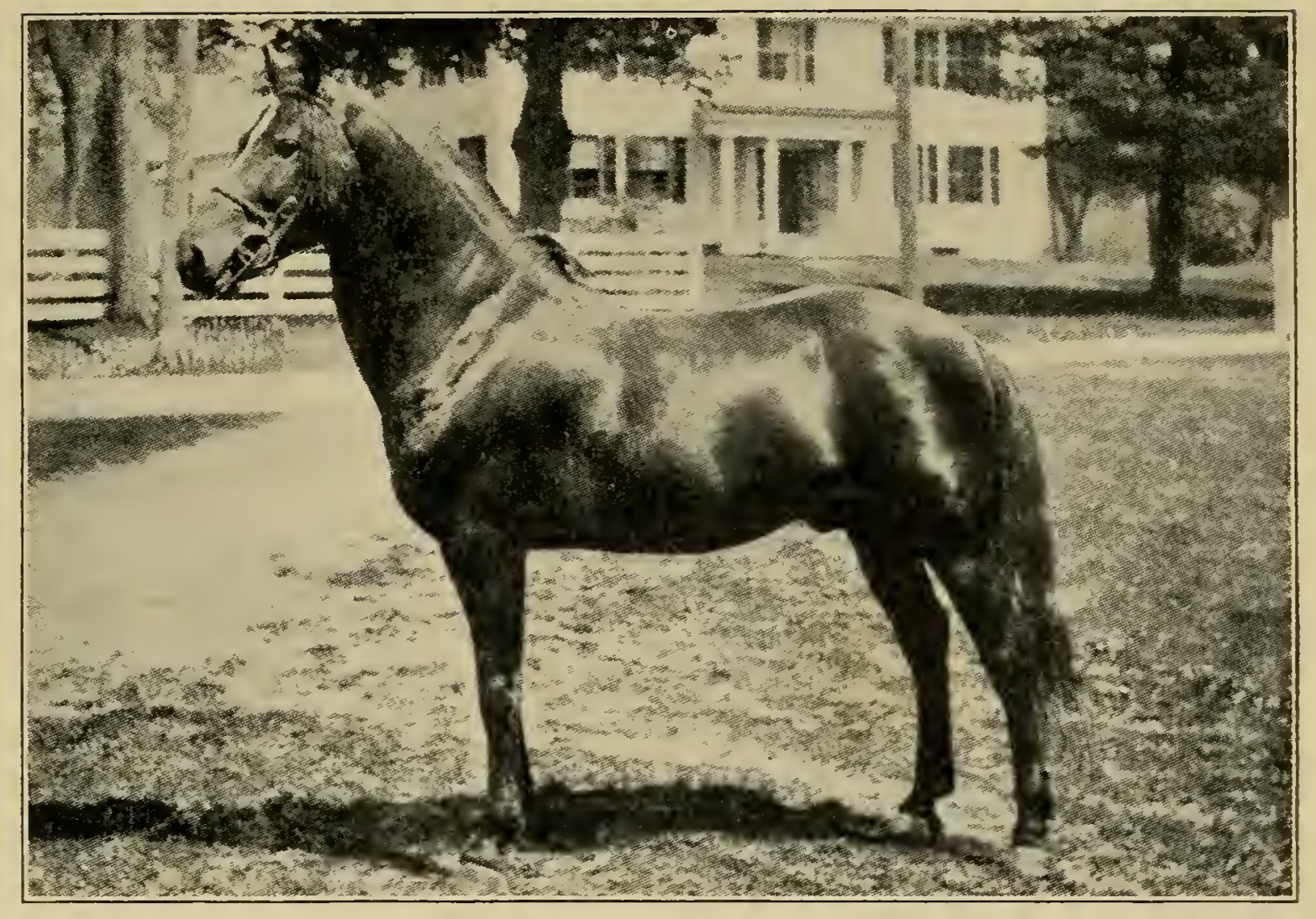

MORGAN STALLION, "WELCOME"

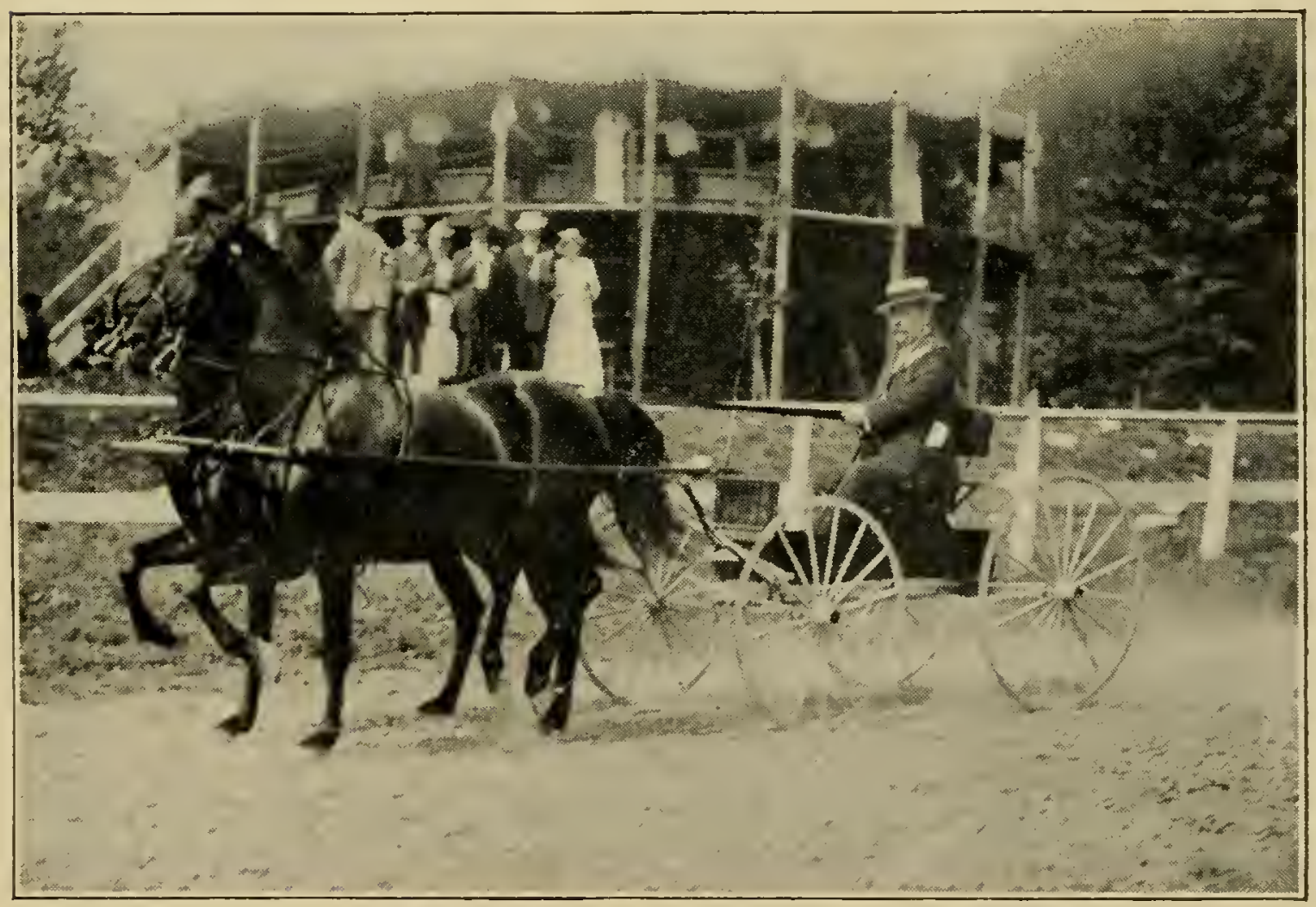

MORGAN STALLION, " LITTLE JUSTIN," AND MARE "HAZELLA" 

stables, and they are very useful in hot weather both for stirring up a breeze and for driving away flies. It is an economical way of maintaining the efficiency of the work-horse.

A driver should watch his horse carefully on an excessively hot day. If the horse stops sweating suddenly, or breathes short and quick, or if his ears droop, or if he stands with his legs braced sideways, as if he feared a fall, he is in danger of a sun or heat stroke and needs attention at once. The cessation of sweating and the short and quick breathing, like the panting of a dog, usually come together. So long as a horse breathes naturally he is safe. Some horses sweat very little under any circumstances, and these are the horses most apt to have a sunstroke.

When a horse has a sunstroke or is overcome by the heat, the first thing is to get him into the shade, if possible, then strip off bridle and harness, wash out his mouth, sponge him all over with water, shower his legs and give him two ounces of aromatic spirits of ammonia in a pint of water, or two ounces of sweet spirits of nitre in a pint of water, or the same quantity of water with about two ounces of gin or whiskeypreferably gin; or a pint of coffee warm. Most important of all, his head should be cooled as quickly as possible by bathing it with cold water, or, in extreme cases, by applying chopped ice wrapped in a cloth.

A horse that has once been overcome by the heat, will always be less able to resist it, and should be left in the stable on excessively hot days. A second sunstroke is almost always fatal. 


\section{THE HORSE}

Finally it is all important that during a hot spell the horse should cool off through the night, for otherwise he cannot well stand another day's extreme heat. Therefore, if your stable is so hot that the horses sweat in it at night, by all means tie them outside, making them as comfortable as circumstances permit. 


\section{CHAPTER XIV}

\section{THE MANE, TAIL, AND FORELOCK}

$\mathrm{N}$ keeping the mane and tail free from tangles it is 1 better to use a comb and the fingers of the hand, instead of a brush, for less hair will be torn out. If the mane is so heavy and long as to give the horse a coarse look which you wish to remove, carefully thin and shorten it by pulling out a few hairs at a time. If scissors are used for this purpose, the fact will be apparent, and the appearance of the mane will be spoiled. The root of the mane and of the forelock is a particularly good place for dandruff and hayseed to accumulate, and pains should be taken to keep these parts clean.

For the sake of cleanliness and coolness the hogging of the mane is practiced by many owners of workhorses, and on the whole this is probably productive of more good than harm, although there are two opinions on the subject. The objections to the practice are, first, that it deprives the horse of some defense, on one side of his neck at least, from excessive cold in winter and the hot sun in summer, and, secondly, it is in some degree a protection from flies on that side of the neck. The mane of the wild horse divides, and falls both ways, so as to protect both sides of his neck not only from the weather, but also from the attacks of other animals. 
The forelock should be left on as it undoubtedly serves to protect the head and brain of the horse from the excessive heat of the sun in hot weather; and to some extent, also, it protects the eyes from the sun. This is particularly the case with a horse in pasture, the forelock partly covering the eyes, when the head is held down in feeding. The forelock grows rapidly on a horse at pasture. Most horses, moreover, look much better with the forelock than without it. If, as will sometimes be the case, the forelock is a source of irritation and itching when the horse becomes heated, as in the case of a trotter, it can easily be braided and tied.

\section{THE TAIL}

A long tail is so useful to the horse in protecting him from flies that it is cruel to deprive him of it. Anyone who has watched a docked-tail horse standing in the street on a muggy day in August can partly imagine how much he suffers from this cause. Every hair on his back is "staring" on account of the irritation of his skin, and his legs, head, neck, and the ineffective stump of his tail are in constant motion.

I have watched a carriage horse stamp one of his feet every 20 seconds for an hour. That multiplied by 16 hours a day (daylight in midsummer) means that the unfortunate animal has stamped his feet the enormous number of 2,800 times a day. That in itself is enough to tire and wear out any horse. George Foster Howell.

But there are other reasons why the long tail is beneficial. For one thing, it serves to protect the 
belly, to a certain extent, from draughts of cold air coming between the hind legs. The most experienced shipper of horses in the East always insists that when his horses are loaded on the cars at Chicago their tails shall be let down.

Another benefit of a long tail is that in the case of a cold rain it conducts away from the horse's back to the ground a good deal of water which, in the case of a short-tailed horse, runs down the inside of his hind legs and has a chilling effect. For this reason the tail of a horse should not be tied up in a cold rain storm. It looks neater that way, but the horse is much better off under such circumstances with his long tail, and by putting the tail in a bucket of water when he comes in and then swishing the tail sideways back and forth, the mud and water can easily be removed.

In warm rains, however, and in fair weather when the roads are muddy, and generally with respect to saddle horses, the tail can be neatly braided and tied up, and when thus disposed it is very becoming to the horse - far more so than is the docked tail. In fact, between a horse with his tail artistically braided and tied and a dock-tailed horse, there is the same difference that exists between a woman with her hair neatly coiled close to her head, and a woman with short hair.

Docking is a custom so cruel and so absurd that it does not seem as if it could long continue; and there are signs even now that it is ceasing to be fashionable. The feeling against cruelty to animals slowly but surely increases. It was not so many years ago, perhaps a 
hundred, that horses' ears were cropped, but we cannot imagine that cropping will ever be revived; and of the two practices docking is the more cruel because, although the pain of the operation may possibly be less, the after effects are far worse.

Docking has actually been defended on the ground, absurd as it may seem to the reader, that the docktailed horse cannot get his tail over the reins, and is therefore safer in harness than the long-tailed horse. Now, in the first place, this particular trick or vice is extremely rare: in the second place, it is easier instead of harder for the dock-tailed horse to catch the rein under his tail, and, thirdly, a horse that has been subjected to the painful process of docking is apt to be nervous about his hind parts, and therefore more likely to put his tail over the rein, or to kick, than is the unmutilated horse. Walter Winans, a horse-owner and expert of international reputation, says:

I consider docking as not only cruel but ugly, and also dangerous, as a docked horse is always nervous about his hindquarters being touched, or the reins touching his tail, or his tail touching the dashboard. . . . . In the United States it is worse than in England. In England riding horses and hunters at least are spared being made ridiculous by docking, but in the United States even ladies ride about on mutilated horses with tails like hat pegs.

He might have said also that the practice of docking is much more cruel in America than in England because the flies here are far more numerous and more ferocious than the British fly.

Docking is a matter of fashion, and fashion always 
mars the beautiful by adding some element of the grotesque.

\section{WHEN THE TAIL IS TOO HEAVY}

In some cases the tail is bushy and heavy, so that it is hot against the horse in summer, and it is not easy for him to switch it about as a defence against flies. In such cases the tail should be thinned, in the manner described for thinning the mane. This will make it more comfortable for the horse, and also cause him to carry it better, that is, further away from his body.

\section{RUBBING THE TAIL}

It is a great annoyance to have a horse rub the hair from the upper part of his tail, as the occupant of a box stall is apt to do, especially when he is shedding his coat. But this bad habit can usually be stopped without much trouble. Wash the bone of his tail thoroughly with warm water and soap, and then apply a little kerosene oil at the exact spot where the rubbing was done. It may be necessary to apply the kerosene two or three times more, without the preliminary washing; but usually one application is sufficient.

As a substitute, or alternative, for kerosene, the following ointment might be used after washing the tail:

Sub-nitrate of bismuth........... I ounce

Lard ................... ounces

If the horse should persist in rubbing his tail, the bad effects of the rubbing may be prevented by attaching a flap of cloth or leather to his blanket in such a manner that it will cover and protect the upper part of the tail. 


\section{CHAPTER XV}

\section{BLANKETING}

TO blanket a horse properly you must sympathize 1 with him. Feel of his ears occasionally to learn if they are cold, and notice the appearance of his coat. There is an immense difference in the amount of blanketing that two horses in the same stable will need. A thin-coated horse will, of course, need much more than a heavy-coated one as a rule; but the greatest difference is between young and old horses. An old horse, like an old man, feels the cold. I have known a young clipped horse to be perfectly comfortable under circumstances where an old horse with a heavy coat would feel uncomfortably cold.

The only safe way to treat a horse is to treat him as you do yourself. As the famous trainer John Splan remarks, "If it is a cold night and you need an extra blanket on your bed, give the horse an extra one too." On cold nights in late summer and early autumn most persons do not blanket their horses, but at those times the horse has a thin coat and suffers from the cold just as much as would a man who had no more covering on his bed than he had on a hot night in June or July. If, on a frosty morning, you go into a stable where the horses are not blanketed, you will notice that their hair is standing up and that their ears are cold. Moreover, the blanketing of horses early in the autumn and 
on cold summer days or nights will tend to keep down an excessive growth of winter coat.

The proper way of blanketing a horse that comes in wet, has already been touched upon.

Care should be taken not to put on a thick blanket too soon when the horse comes in after work. This applies especially to a driving or saddle horse. It is better not to blanket him when he first comes into the stable, for a blanket put on then will surely cause him to sweat. Let him stand for a few minutes or longer according to the weather and the temperature of the stable before putting on his heavy blanket. A "cooler," that is, a big, light woolen blanket, such as is used for trotting horses, is very useful for clothing a horse when he comes into the stable after a drive. The cooler is as big as a street blanket, and covers the horse from ears to tail.

I have seen a horse driven fast on a very cold day in winter enter the stable without a wet hair on him, but being blanketed immediately he soon burst out into: a profuse sweat, and afterward became chilled. Sometimes a horse should be allowed to stand two or three minutes, sometimes five minutes, sometimes ten, occasionally even fifteen or twenty before his blanket is put on. It depends upon how hot he is, upon how warm or cold the stable is, and upon how much hair he has. It is much better, of course, to make the mistake of putting on the blanket too soon than to leave it off too long. Do not go into the house and forget all about the horse.

A clipped horse should, of course, be blanketed im- 
mediately or almost immediately on coming into the stable. A "cooler" is especially useful for a clipped horse, to be left on until he cools off, when his regular blankets can be put on. If the weather is cold, a heavy blanket should be added to the cooler after five, ten, or, at most, fifteen minutes.

Horses with heavy coats that are wintered without being used, and receive their exercise only by being turned into a barnyard, will do better without blankets than with blankets. The long hair and dandruff which nature provides for them will keep them warmer than a blanket would, and, moreover, there is much danger in taking a blanket off a horse and then turning him into a barnyard or paddock.

A horse accustomed to a warm climate will, of course, need careful blanketing when he comes into a colder climate. Thus, a Kentucky horse brought to New England should be blanketed in the stable the first winter under any circumstances.

In a northern winter, horses that have to stand about the streets, such as truck horses and hack horses, suffer very much from the cold. The truck horse is often protected by a heavy street blanket which is left on even while he is at work in excessively cold weather, and even a hack horse should wear a light, woolen blanket under the harness in such extreme weather when, as is usually the case, he makes only short trips. A clipped horse should always have a blanket under the harness in very cold weather, unless he is going a long distance.

Loin blankets or "quarter" blankets, as they are 
called, that is, a short blanket just covering the loins, are useful under such circumstances. These blankets are sometimes made of rubber or leather, and in that case are extremely dangerous, for when they are taken off, the horse is very likely to catch cold, there being no ventilation whatever in the rubber or leather blanket.

All street blankets should be provided with a strap and buckle to fasten them under the belly in windy weather.

The size of the blanket is very important, and it is almost impossible nowadays to get a good-sized blanket ready-made. In order to cut down the price, manufacturers have scrimped blankets, both stable blankets and street blankets, unmercifully. This applies especially to the depth of the blanket. A blanket should be deep enough to cover the horse's belly, and the street blanket should be much deeper than that. The minimum depth of any blanket intended for an ordinary horse should be forty-two inches.

It is economical to buy a fairly expensive blanket of good material, for, if properly cared for, such a blanket will outlast three or four cheap blankets. After the winter use of a stable blanket, it can be put in a tub of water, even cold water will do, and by poking it with a stick now and then and changing the water two or three times, the ammonia contained in the manure will take the dirt all out of the blanket without any scrubbing or soaping. It can then be dried, and, with a little patching and mending, will be practically as good as new. Street blankets should be treated in the same 
way, and there should always be two on hand for each horse, the old patched blanket for rainy weather, and the new blanket for good weather.

Another means of saving the wear and tear of a blanket is to fasten it somewhat loosely across the breast of the horse, for if it is buckled in the last hole, according to the practice of most grooms, it will be strained across the breast of the horse and will be more likely to tear than if it is buckled somewhat loosely.

It might be mentioned here that, as the reader doubtless knows, there is no special reason for protecting the breast of a horse. That part is defended by large muscles, and his lungs are not there but immediately back of his forelegs.

For a clipped horse there should be provided for stable use three blankets, a thin woolen sheet and a heavy woolen blanket for ordinary use, and another heavy blanket to be added in extremely cold weather. For an unclipped horse, a linen sheet and a thick blanket for ordinary use, and an additional heavy blanket for use in excessively cold weather.

In summer, a linen or cotton blanket, as a protection from flies and to keep his coat clean is necessary; and a light woolen blanket is a luxury which the horse should have, if possible, for use when his winter blanket would be too heavy.

There is one time in the year when a horse, even a colt, may require a blanket in the stable, although he is unblanketed all the rest of the year, that is in the late spring when cold and rainy weather follows close 
upon a period of mild weather. In the mild weather, occurring in early spring, as it sometimes does, the horse loses his winter coat. Then, perhaps, comes a spell of cold, wet weather, and if the horse is not blanketed, he feels the change in temperature severely. Under these circumstances, I have known an epidemic of colds and pneumonia to run through a whole township of horses, the only animals that escaped being those whose owners took pains to blanket them.

\section{RAIN-COVERS}

Rain-covers of rubber or other material are very useful in some cases but should be used with discretion. They should not be used in warm rains unless the horse is doing his work at a walk with frequent stops; otherwise the rain-cover will tend to sweat the horse, and he is likely to catch cold when he stands still. Raincovers should never be used on horses going long distances except, of course, on a clipped horse, and in cold weather they should be supplemented by an old, woolen blanket. If, in a cold storm, a horse wears a rain-cover and then is left standing for a while, he is sure to become chilled because he has no more over him while stationary than he had when in motion, and the wind is always likely to blow up the rain-cover and cool the horse off suddenly.

In eastern cities the practice among the best truckmen, whose horses do all their work at a walk, is to use in place of rain-covers heavy blankets put on outside the harness. A good, stout blanket will keep the horse dry even in a hard rain, partly because the heat of his 
body tends to dry up any moisture that penetrates to the inside of the blanket. In this way the horse is kept warm and dry throughout a cold, rainy day, and inasmuch as he moves only at a walk with short stops, he does not become sweaty. If, in a work-horse stable, there are no rain-covers, and there is only one street blanket for each horse, a drying room should be provided fitted with steam pipes or some other contrivance for drying the blankets at night after a rainy day. A very small room will suffice for many blankets. Our rain and snow storms usually clear off cold, and if there are neither extra blankets nor drying room, the driver will have no protection for his horse on the succeeding day except a wet blanket, or, what is worse, a blanket frozen as stiff as a board.

A wet blanket is much better than none provided that it is folded, and thrown over the loins of the horse. If it is so used, the outside air cannot get through the double thickness; whereas if a wet blanket is unfolded and put on in the ordinary manner, the horse will be chilled. If only one part of his body can be kept warm, the loins should be the part selected. That part is even more delicate than the lungs.

Rain-covers should never be used on horses, such as hack horses, who have to travel at a good pace and are often obliged to go long distances. On the whole it seems likely that a horse who is provided with two good street blankets, one newer one for fine weather, and one old one for wet weather, would be better off in the long run not to have a rain-cover. Of course, in this matter as in all others, much depends upon the 


\section{BLANKETING}

driver. A careful, intelligent man might make good use of a rain-cover, whereas a careless, indifferent or stupid driver would be very apt to misuse it, and by failing to add a heavy blanket while the horse was standing in a cold rain would make him liable to a chill. If any rain-cover is used it is best to have one that covers the neck as well as the body. 


\section{CHAPTER XVI}

\section{CLIPPING}

CLIPPING is often an advantage to the horse, and on the other hand it is often the cause of great suffering. Some horses retain a fairly short coat even through the winter, and such horses should never be clipped. Coachmen in private families usually have all their horses clipped, partly because it is the fashion, and partly because it saves them trouble in grooming; but a well-bred carriage horse kept in a warm stable, with heavy blankets, should never be clipped, or almost never, for, except in some very few cases, his coat will remain short throughout the winter.

The hair on the inside of the ears, especially the long hairs, should never be clipped, for these hairs protect the ears not only from cold, but also from the intrusion of dust, insects, and other foreign substances. If this hair becomes very long, the ear can be closed and then the hair that projects beyond the ear can be cut off without detriment.

If a saddle horse is clipped, the clipping should be done with the saddle on him, so as to leave unclipped the part covered by the saddle, for if the hair under the saddle is removed a sore back is likely to result.

It is much better not to clip the legs. Your horse may not look quite so well with unclipped legs, but it is impossible to blanket the legs, and any horse whose 
legs are clipped must suffer more or less from cold, and, moreover, clipping the legs tends to make the hair grow out coarser the next summer. This last remark applies also to the whole coat. The clipping of a horse, especially when it is done year after year, necessarily results in making his coat longer and coarser than it was originally.

A horse that does not stand about in the streets but is taken out and driven or ridden at a good pace and is then brought back to the stable, can be clipped without suffering, and it will often prevent a great deal of sweating, and therefore is a safeguard against chills. On the other hand, if a horse goes only a short distance every day it is a distinct advantage to his health to get sweated, provided, of course, that he is carefully protected after returning to the stable.

Unquestionably many hard-working horses such as stage horses will do better clipped than unclipped; but in all such cases the legs should be left as they are, and the clipping should be done early in the season, about the first of November. By that date flies have ceased to trouble the horse, and clipping at that season will enable him to grow out a short coat before the severely cold weather arrives.

There is another time when clipping is often beneficial to a horse, and that is in late winter or early spring when the weather gets warmer, and the horse sweats profusely. In that season horses with a heavy coat will sometimes sweat even in the stable, and if they are worked hard they become reduced in flesh. But if clipping is to be done in the spring it should be done 
when the horse begins to shed his coat or very soon afterward.

In short, whether a horse should be clipped depends on several circumstances, on the kind of work that he does, on the kind of coat that he has, on the kind of stable in which he is kept, and on his age.

It is hardly necessary to say that clipped horses should be carefully protected from the cold. As already stated, a clipped horse should have three blankets, one thin, woolen one, and two thick, woolen blankets, so that in ordinary weather he can wear the thin, woolen blanket and one thick one, and in extremely cold weather he can have all three blankets. The winter climate in this country is so variable that horses cannot with comfort wear the same clothing all the time. If a clipped horse is compelled to stand out in cold weather, he should be covered by two heavy street blankets.

If a clipped horse is kept properly warm, he will never require a second clipping in early spring. The long, coarse, straggling hairs that you often see growing out on a clipped horse are sure proof that he has suffered much from the cold either in the stable or out of it, and usually in the stable.

There are various ways of clipping horses. Some owners of draft horses in this country clip them in those parts where they can be covered by a street blanket, that is, they clip the upper part of the body leaving the hair on the belly, legs, head, and neck. This is a good method for horses that require clipping, and yet have to stand outdoors much of the time. 


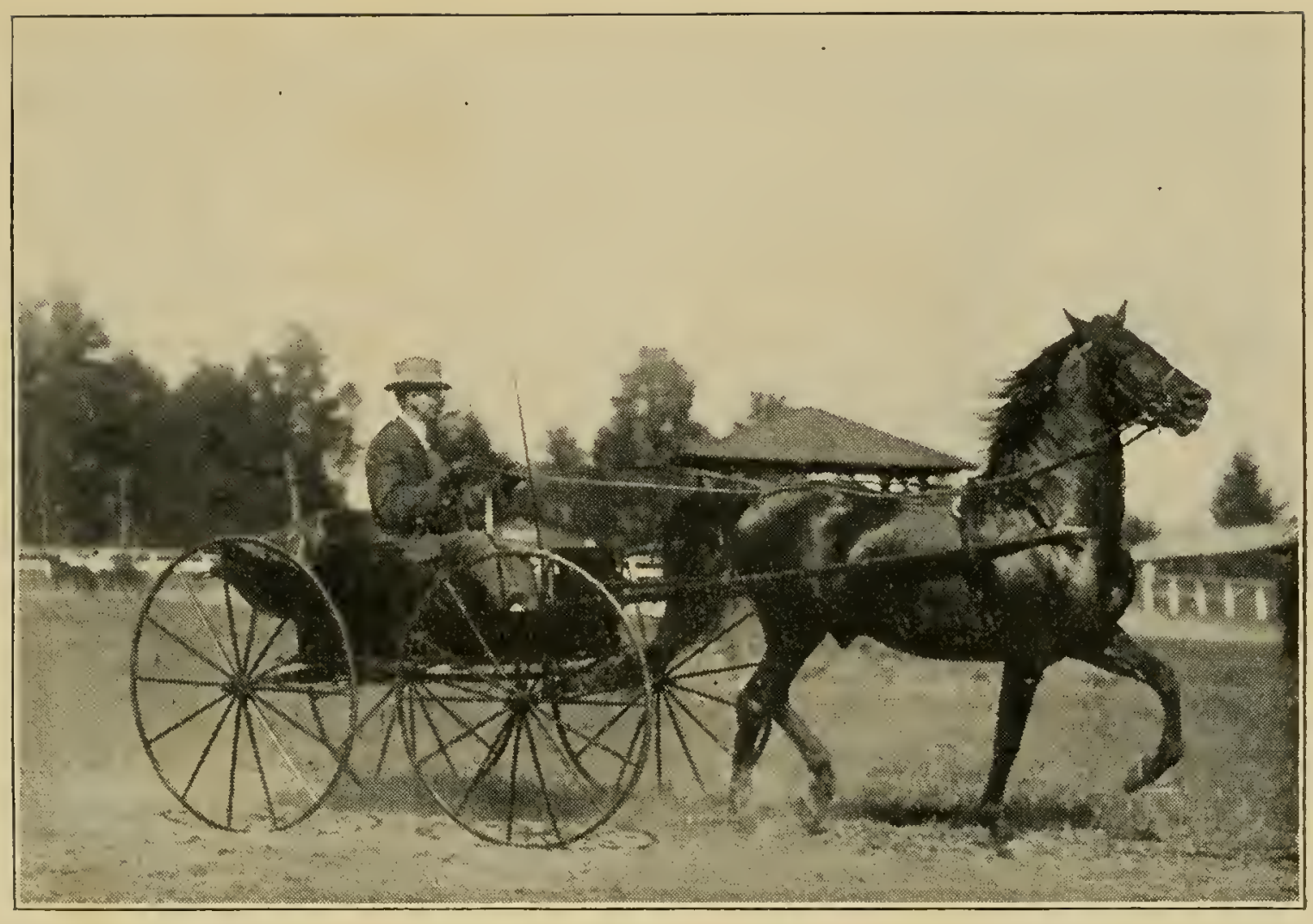

MORGAN STALLION, "BOB B."

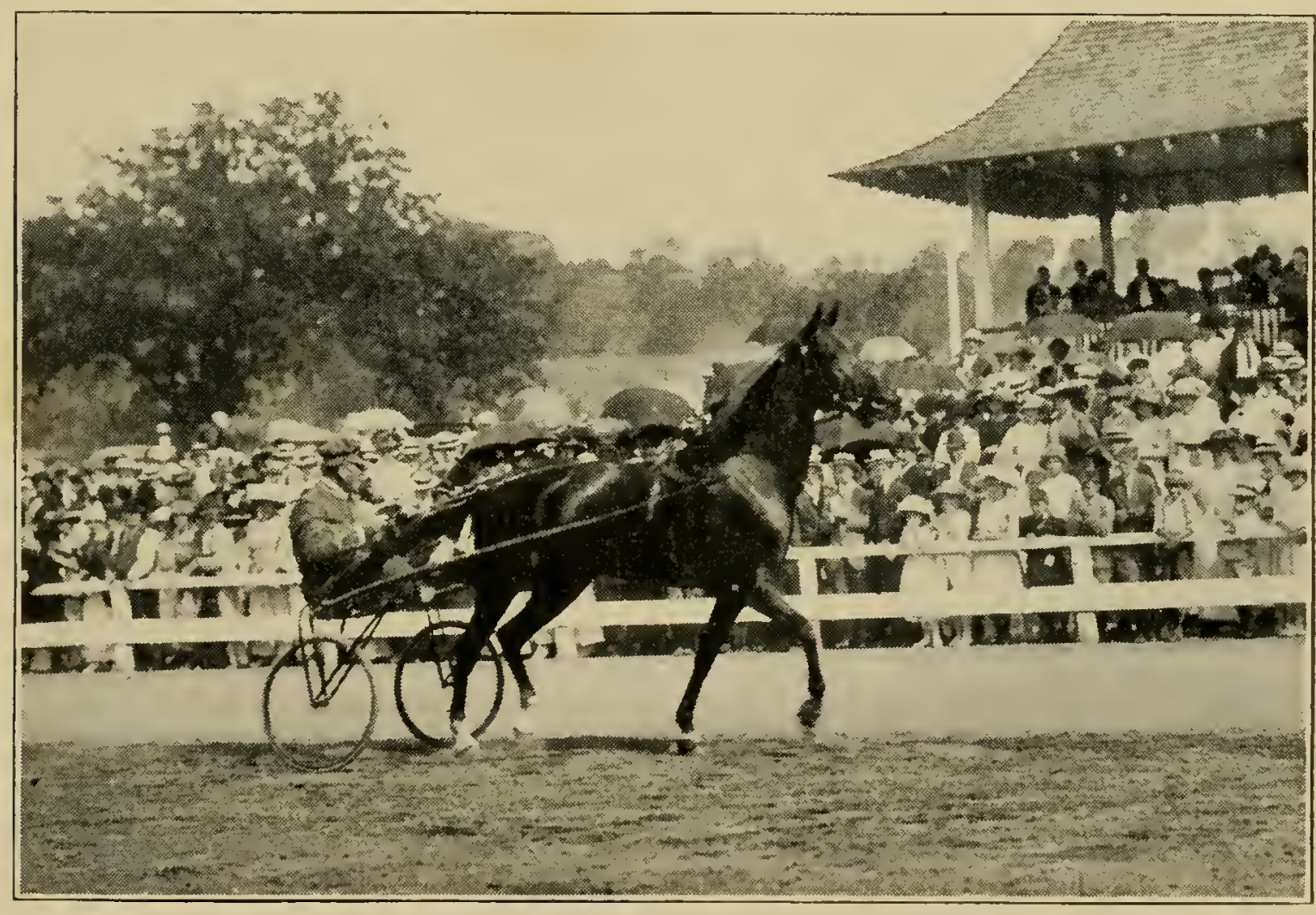

TROTTING-BRED GELDING, "UHLAN" 

In England, where the climate is different, a different method of clipping is often practiced, or used to be practiced, especially in the case of omnibus horses. In an English winter the thing to be guarded against is not cold but rain, and therefore it was customary to clip the lower part of the bodies of the 'bus horses, and to leave the head, the top of the neck and the top of the body covered with hair, those being the parts upon which the rain falls. This was called clipping "trace high."

If anything is done in the way of trimming the hair from the horse's fetlocks it should be only by way of cutting off the long hairs. To clip off all the hair produces discomfort and often scratches or mud fever.

If possible, clip your horse on a cool, dry day. On a warm day he is more likely to catch cold, as the pores of his skin will be open; and on a damp day a chill is more easily taken than on a day when the air is dry. As soon as the horse returns to the stable after being clipped, give him a feed of hay. This is good for two reasons: in the first place, if he is in a straight stall, having something to eat in his manger will keep him in the forward part of the stall so that his hind parts will be protected from the draught; and secondly, the mere process of eating tends to quicken the circulation. As horsemen often remark, "No horse ever catches cold while he is eating."

If the legs are clipped it is well to bandage them the first day, taking off the bandages on the next day when the horse goes out, and not resuming them unless the weather is wet or very cold. 


\section{CHAPTER XVII \\ CARE OF THE TEETH}

THE teeth of the horse should be examined at least 1 once a year. If he slobbers, froths at the mouth, drives on one rein, ${ }^{1}$ or drops small cuds of partly chewed hay, it is highly probable that his teeth are at fault. Interfering among trotters, and especially kneeknocking, is often caused by a sore tooth or cheek which makes the horse carry his head on one side, and thus throws him out of balance.

The most common trouble is for the teeth in the upper jaw to become rough and jagged on the outer or inner edges, and you will often find the sides of the cheeks or the tongue scratched or cut. The teeth should be sharp, but the cutting surface should be even. The edges can easily be smoothed with a file made for this purpose. But be sure that this slight operation is performed by a competent person. Amateurs are very apt to file the teeth too much, and more than one horse has starved to death, because his teeth were filed down so that he could not eat. A few minutes' work will be sufficient to do all that is necessary in this respect.

Another frequent trouble is for the upper teeth to become so long that they do not meet the lower teeth properly, or vice versa; and in this case also just so

1 Sometimes driving on one rein is caused by a sore shoulder.

[82] 
much filing should be done as may be necessary to shorten the teeth in the upper or lower jaw, as the case may be, so that they will properly meet the teeth in the other jaw.

Horses frequently suffer, moreover, from decayed teeth or from a diseased jaw, and from abscesses in the jaw, mouth, or head. Many a case of bolting, shying, or balking is really due to bad teeth, and even horsemen of great experience are often deceived in such cases. Dr. J. Gordon McPherson relates an interesting experience of his own:

I shall never forget the first time I harnessed this horse. I really did not know which would be killed, the horse or myself. Had it not been that during the fracas she showed me a wonderful burst of action and speed, I think I should have let her go. I made up my mind that there must be a cause, and after carefully studying the mare's actions for some days, I concluded that the whole trouble was in her mouth.

On examination of her teeth and the interdental space on both sides of the lower maxillary, I found a diseased portion of the bone extending from the first molar for about one and a half inches. I also found several decayed teeth. I removed the diseased part of the bone, and then cleaned all the cavities in the decayed teeth, and filled them with the amalgam ordinarily used for this purpose. I then left the mare standing in the stable for about ten days, and during this time I noted a wonderful change in her disposition, and also that she put on flesh rapidly. I then hitched her up and drove her through the crowded streets of Toronto with perfect safety, and she is now the kindest and most trustworthy beast that ever was harnessed. 
Small pieces of wood or corncob, and even nails, often become wedged between the teeth, or penetrate the gums, and cause the horse extreme pain which is shown by continual movement of the jaws, by an excessive flow of saliva, and by difficulty in eating.

\section{LAMPAS}

This is not a disease, though formerly it was so considered. It is simply a swollen condition of the roof of the mouth, seen most often in young horses, especially while they are teething. Sometimes, also, it is caused by colic or indigestion. The simplest and, as a rule, the best remedy is a corncob, with the corn on it, and the horse by chewing that will reduce the swelling.

There used to be a barbarous practice of cutting the roof of the mouth with a knife, or searing it with a hot iron. This was not only unnecessary but injurious.

If the corncob does not suffice, wash out the mouth with tincture of myrrh - one ounce in half a pint of water, or with undiluted vinegar. Be sure that the bowels are open, and give the horse plenty of bran mashes, and also a tonic (see page 226) if you think he needs a tonic. 


\section{CHAPTER XVIII \\ CARE OF THE FEET}

THE first rule for keeping a horse's foot sound is 1 to have him shod often - once in four or five weeks; and this is necessary whether the horse is worked or not. If this is not done, corns or contraction or other evils will surely result. If the horse is to be laid by for several weeks or longer, his fore shoes, especially if they have calks, should be removed, and the horse should be shod with tips so that his feet can rest and his heels expand. A still better plan is to take off his shoes altogether and let him stand, on peat moss if possible, in a box stall. It is not well to let the horse stand wholly unshod on hard floors for more than a few days, for he would probably become footsore. But a horse with good, strong feet needs no shoes in a stall well equipped with bedding. In some districts it is not unusual for a horse to be shod in the fall, and then left all winter with his feet untouched. This is one reason why really sound horses, above the age of six or seven, are seldom seen. in those places.

Frog-pressure is what every horse needs (and what he receives in a state of nature) to keep his feet sound. Frog-pressure may be obtained by dispensing with shoes at times, by dispensing with calks, by using low calks instead of high calks, and, in the city, by shoeing 
the horse with a rubber pad. The rubber or leather pad is extremely useful for two other reasons, first, it saves some jar and concussion, and secondly, and most important, the tar and oakum (or other like substance) which is always interposed between the pad and the foot prevents the foot from becoming hard and dry.

Moisture is essential to sound feet. There is a natural oil in the foot itself, and, moreover, when the horse is in a natural state, the frog receives moisture by contact with the earth. But when the horse is shod and kept in the stable on dry floors, the foot cannot receive moisture from the earth, and, besides, the loss of frog-pressure, due to shoeing, diminishes the natural oil in the foot. Consequently this want of moisture and of oil must be supplied artificially. How can it be done? The application of water is the simplest way. Horses that are always watered by being ridden into a stream, for example, will never suffer from hard feet; nor will a horse turned out to graze, even for a short time, in the early morning when the grass is drenched with dew.

The same result can be reached by applying water by means of soaking boots, coarse towels, or rags fastened around the coronet; or by means of wet moss or a wet sponge held in contact with the bottom of the foot by a strap or other device. If the foot is a deep or "cup" foot, the moss can be packed in by hand, and will keep in place of itself.

Cow manure is sometimes used as a hoof packing; but it is too strong, and is likely to produce thrush, unless well mixed with earth. 


\section{CARE OF THE FEET}

Washing the foot three or four times a day will usually suffice in ordinary weather, but not in a dry time. Climate has a great deal to do with the condition of horses' feet. Many a horse goes lame as the result of a long-continued drought in summer when the roads and the atmosphere are both deprived of their ordinary moisture. There is much less trouble with horses' feet in England than here, and this difference is, no doubt, accounted for by the peculiarly moist climate of England.

Another means of supplying water to the foot is furnished by the soaking tub. In the case of inflamed, injured, or diseased feet the soaking tub is invaluable; but, except in cases of extreme dryness, I think it should never be used for a sound foot. The first effect of the soaking tub is to soften the foot, but the second effect is to harden it, and to make it brittle, because all the natural oil is soaked out of the foot. For this reason, if the soaking tub is used, its use should be followed by the application of oil or ointment of some kind.

Too much water is as bad as too little. For example, drive your horse a moderate distance on muddy roads, and the next day his feet will be in good, soft condition; but drive him a considerable distance in a hard rain, when the roads are full of water, and the next day his feet will be hard and dry and in need of oil or ointment.

A convenient way of supplying moisture to the foot is to use one of the many hoof ointments that are on the market for this purpose. These, however, are expensive, and I have found that a good and cheap sub. 
stitute is "Snowflake Axle Grease," a petroleum product. An old-fashioned hoof ointment is the following:

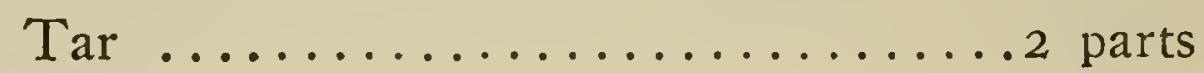

Beeswax ............... I $1 / 2$ parts

Honey ................... part

Beef or mutton suet............. parts

Whale oil................... parts

Mix, and melt together in a hot water bath. Wash the feet clean, and apply this dressing every third day.

Another is as follows:

White $\operatorname{rosin} \ldots \ldots \ldots \ldots \ldots \ldots \ldots$ ounces

Spirits of turpentine..........6 ounces

Linseed oil ............... ounces

Beeswax .................. ounce

Tincture of camphor........... ounce

Mix together in a hot water bath.

That very successful trainer, John Dickerson, strongly recommends the following hoof ointment:

Five pounds each of sweet, unsalted butter, vaseline, and Burgundy pitch. Set to simmer, but not to boil.

Linseed oil is not a bad hoof dressing; and a sponge, tow, absorbent cotton, or any other absorbent substance can be soaked with "Snowflake Axle Grease" or linseed oil and tied over the frog of the foot in such a way that it will also come up against the cleft between the heels.

In most cases, I doubt if it makes much difference whether the moisture is supplied by water or oil or both; but in the case of a brittle foot it is certain that oil should be used, as the foot would not be brittle if 


\section{CARE OF THE FEET}

there were not a deficiency of natural oil in it. Such a foot, moreover, is almost always more or less feverish; and therefore I believe that the best treatment is the application of cool water in some form (dew for example) followed by the application of oil or ointment.

It is often said, but probably the remark originated with some person who had hoof ointment to sell: "Do not use a greasy oil or preparation on your horse's hoof, for it will clog up the pores, and prevent the entrance of natural moisture." But there is no possible danger of this kind. In the first place all oils, ointments, and hoof-dressings are more or less "greasy"; and in the second place the hoof of the horse is practically without pores. Little or no oil or moisture of any kind can enter either through the outside of the hoof, or through the wall of the foot. This is a fact not generally understood. It can do no harm to apply oil or moisture to the outside of the hoof, but it will not do much good. Moisture, whether it be oil or water, to be effective must be applied either around the coronet, or over and around the frog, and in the cleft of the heels just above the frog. The manner of applying it has already been described.

But how can a man tell when his horse's foot is too hard? A simple test is the following: Pinch the frog of the foot with your thumb and finger, and if the frog does not yield a little to the pressure, the foot is too hard. If you are in doubt, ask the blacksmith, when your horse is shod, if the animal's feet are too hard, and take measures to soften them if he thinks it necessary or advisable. 


\section{CHAPTER XIX \\ SHOEING}

T should always be kept in mind that the reason for 1 shoeing is simply to protect the foot of the horse from the wear and tear to which it is subjected on hard ground or pavements. The great object, therefore, should be to have the shoe interfere as little as possible with the natural shape and position of the foot, and to raise the foot from the ground as little as possible.

\section{THE USE OF CALKS}

Calks are an evil though often a necessary one. They should be so low as to raise the foot from the ground as little as possible. Very high calks are especially injurious to the horse, for they make him travel as if on stilts, and are extremely likely to produce side-bones, spavins, and other malformations. What little is gained by the saving of shoes from the use of high calks is more than offset by injury to the foot or leg.

On the other hand, calks on the hind feet, if not too high, are usually beneficial. They assist the draft horse to pull, for pulling is done mainly by the backward thrust of the hind legs, and they are a help to the road or saddle horse in going up and down hill.

A roadster, saddle, or carriage horse should never have calks on his fore shoes unless the roads are icy. 
On asphalt or brick, calks are, of course, useless. On stone pavements where there are interstices or cracks, in which the calks might take hold, horses go better, it is usually thought, with calks, all around, whether they are draft horses or driving horses; but some high authorities believe that even on such pavements horses of all kinds will do better without calks on their fore shoes. No doubt it depends a good deal on the individual horse.

On all city streets the use of rubber pads, all around, is far better than any kind of calk. With such pads a driving horse will do pretty well even on rough ice, and, with the addition of a sharpened steel tip, he will be secure on smooth ice. But a work-horse cannot pull his load on icy streets without both toe and heel calks.

In the hayfield, calks are necessary all around for the turf is slippery; but they should be low calks.

In many cases long side calks, in place of heel and toe calks, are beneficial, for they furnish a larger bearing surface than the ordinary calk. But one caution should be observed here: the effect of a calk depends largely on its isolation, which allows it to take advantage of any depression or edge that it can settle into or against. Now, if the bearing surface of the calk is increased beyond a certain limit, the calk soon wears down so that it does not change much the flat bearing surface of the shoe.

\section{TOES AND HEELS}

It is a kind of fashion among many horse-owners to allow the toes of their horses to become long, and the 
heels to become high. This pernicious practice originated among the owners of trotters who thought, perhaps rightly, that the long toe tended to lengthen the stride of the horse. However this may be, it is certain that the long toe and the high heel are unnatural, for in a state of nature the hoof wears off continually; and it is equally certain that they alter the natural relation or angle between the leg and the foot. "Long toes," said Gilbert Tompkins, "are tendon-smashers." And the high heel is equally bad.

Many horse-owners and horse-shoers treat the foot as if it were wholly separate from the leg. In fact, however, as the reader doubtless knows, the bony structure of the leg extends down through the ankle and pastern into the hoof itself, ending in what is called the foot-bone - the flooring, as it were, of the horse. This foot-bone has in general the outline of the hoof, is from one-half to two-thirds of its width, and is connected with the outer horn-box or jacket by layers of sensitive tissue. Now, if the toe is too long or the heels are too high, or too low, the whole bony structure of the leg and foot is out of plumb, so to say, and pain and unsoundness must result. All horses that wear shoes need to have their toes shortened and their heels raised or lowered from time to time so that their feet will be in such balance that they will stand level and true.

Long toes or high heels are particularly bad for colts. Says Dr. John Seiter:

If colts won't trot without them they are of no use as racing tools. They may show speed for a time, but, sooner or later, 
contraction will set in, and this, coupled with the excessive strain on the tendons, ligaments, and bony structure, soon puts them out of commission.

This has been proved beyond all question.

\section{WEIGHT OF SHOES}

The weight of the shoe is a matter of great importance. Most horses, especially light horses, are shod too heavily, and the unnecessary fatigue caused by lifting a superfluous weight thousands and thousands of times is very great.

A road horse weighing about one thousand pounds should wear fore shoes weighing not over ten or twelve ounces. A work-horse weighing about $\mathrm{I}, 400$ pounds should wear front shoes that weigh from twenty to twenty-four ounces, and hind shoes weighing not more than sixteen to twenty ounces. But these weights are only approximate, for they depend largely on the peculiar action of the horse, on the nature of his work, and especially upon the character of the roads over which he travels.

It is hardly necessary to say that a shoe should always be heavy enough (strong enough would be a better expression) to prevent any twisting or bending under the weight of the horse. Moreover on very hard roads or pavements a fairly heavy shoe gives the foot less jar and concussion than a very light shoe. This is a fact hard to understand, but it is admitted by all experts in horse-shoeing, and it seems to be proved by this further fact that horses which are somewhat sore forward go better on hard roads in fairly heavy 
shoes than in very light shoes. The explanation is simply this: action and reaction are equal. When the foot comes in contact with the ground, the ground really strikes the foot a blow, just as much as the foot strikes the ground a blow, and the force of this blow is diminished if a fairly thick shoe is interposed between the ground and the foot.

It is the general belief that heavy shoes on the fore feet lengthen the stride of the horse and cause him to trot faster. But the effect is often otherwise. The heavy fore shoe causes the horse to lift his feet higher, and for this reason shoes cruelly heavy are much used by horseshow exhibitors; but they often tend to shorten, not to lengthen the stride, and therefore to decrease speed.

On this subject Mr. C. A. McLellan of Brockton, a noted expert, says:

The reason why many people have been fooled into the belief that the heavy shoe increases the length of stride is this: a horse is liable to shorten his stride as he becomes sore, and a sore horse with a light shoe feels the concussion more than he does with the heavier shoe. Consequently, when shod heavier the sore horse steps longer, because he steps with more confidence, in the belief that his foot is not going to hurt him when it strikes the ground.

Of course the heavy fore shoe will often make a horse trot instead of pace; but in such cases the weight should gradually be decreased, as the horse becomes habituated to the trot, until finally all the extra weight is removed.

As to extra weight in the hind shoes, it is an unneces- 
sary burden. The only case, so far as I know, in which it is ever beneficial, is that of the horse who overreaches because he steps too long behind. Sometimes a very light shoe forward, and a somewhat heavier shoe behind will stop the overreaching. In most cases, however, the exactly opposite course would be more likely to prevent overreaching, namely, making the fore shoes considerably heavier than the hind shoes.

\section{THE WEB OF THE SHOE}

Another point about which there has been some difference of opinion is this: Should the web of the shoe bear in any degree upon the sole of the foot? The answer is, No; except perhaps in the case of mules and of horses who have what is called a mule foot. This is a strong, upright foot, which can usually stand some sole pressure. But, generally speaking, the weight of the horse should come altogether upon the wall and frog.

Is there, then, any reason for using a broad-webbed shoe in any case? Yes; because in the case of a weak, flat foot, and most of all in the case of a horse that has been foundered, the sole, near the wall, needs protection, and that can be afforded by using a broadwebbed shoe so concaved that it protects the sole near the wall, but does not rest upon it. This kind of shoe will often save a horse from bruises. The farriers describe a shoe of this shape as "seated out."

TREATMENT OF THE SOLE, FROG, AND BARS

Undoubtedly many farriers pare the sole and frog too much; and in most books on this subject the gen- 
eral rule is laid down that the sole, bars, and frog should never be pared at all. But this is going too far. In the case of the unshod hoof the sole and frog will certainly wear off and flake off quite enough, and often too much. Horses at pasture frequently become footsore because their feet wear down too much.

But when the foot is shod, even in the case of a healthy fort, it often happens that the sole does not flake off naturally, and the superfluous, dead part should be pared away when the shoes are removed. Sometimes the sole grows in such a way as to present a lumpy, uneven surface, which should of course be leveled. In the case of a foot that is contracted or otherwise diseased, there is often an abnormal growth of sole which is very hard, and clings tenaciously to the live sole beneath. This should be cut off.

Moreover, it sometimes happens that the whole foot becomes hard and rigid, contracting at the heel, losing its elasticity, and its capacity to expand when the foot strikes the ground. In such cases it is sometimes necessary to thin both the wall and the sole, so as to restore the elasticity of the foot; but only an expert should be permitted to administer this kind of treatment; and only an expert would know when it was necessary.

On this very important point, Mr. McLellan says:

The practice of rasping or thinning the wall of the contracted hoof is in many cases a benefit as the hoof thereby regains its proper elasticity and normal size. Then by fitting the growing foot with shoes, increasing in size as the foot increases, very beneficial results are obtained.

The bars of the foot are a continuation of the wall, 
and should be pared if necessary to make them level with the sole. The branches of the sole in the angle between the bars and the wall of the quarters should be kept a little lower than the wall, so as not to be pressed upon by the inner web of the shoe.

As a general rule the frog should not be pared, but any ragged or decayed parts should be cut off; and, moreover, in some cases even the healthy frog should be reduced in size. With some horses the frog is so large and prominent that in its natural state it would come in contact too forcibly with stones and other sharp objects, and perhaps even with the smooth surface of a hard road. The frog sometimes becomes sore, because it plays too large a part in sustaining the weight of the horse. Frog-pressure is beneficial, if not essential; and it is one of the hard problems in shoeing to give the horse enough frog-pressure, and not too much.

A much disputed point is this: Should the heels be "opened out," according to the common practice of farriers? Some authorities say, No. They declare that the cutting of a notch at each side of the frog weakens the bars, and tends to permit the heels to come together, instead of keeping them apart. But I am inclined to think that the usual practice in this respect is right, and that the "opening out of the heels" tends to prevent contraction.

SEATING THE SHOE

Another disputed point is the advisability of trying on the shoe while hot, or "seating it." Some authori- 
ties hold that this should never be done, inasmuch as the burning of the hoof injures its texture. No doubt it does, but the injury is only on the surface of the wall; and, provided that the contact of the hot shoe with the hoof is very slight and very brief, I think that the better fit thus obtained more than compensates for the injury to the wall.

If, however, after the shoe is thus "seated," the foot is pared to make it fit the shoe - instead of altering the shoe to fit the hoof - the foot is bound to be injured.

The very worst practice in shoeing is to nail on an undersized shoe, and then rasp down the hoof to make it fit. This is often done, and it always produces contraction, and, sooner or later, lameness.

The process of correct shoeing is thus described by Mr. A. T. Stark:

The right way to shoe any and every horse is to level and true the hoof with the rasp, finish with the fine side of the rasp - no paring knife or buttress - fit the shoe so that the outside is flush (or a trifle more than flush) with the outside edge of the hoof, nail on the shoe without letting it slip back or out of place, clinch the nails - and that is all; absolutely all.

\section{CONTRACTION}

Bad shoeing and neglect of the foot result in contraction, and what contraction means is thus described by the well-known veterinary surgeon, Dr. A. S. Alexander:

The pain caused by the contracted hoof is intense and never ceasing. Place a cord or rubber band around your finger tip, and instantly there is felt a sensation of fulness, then pain, 


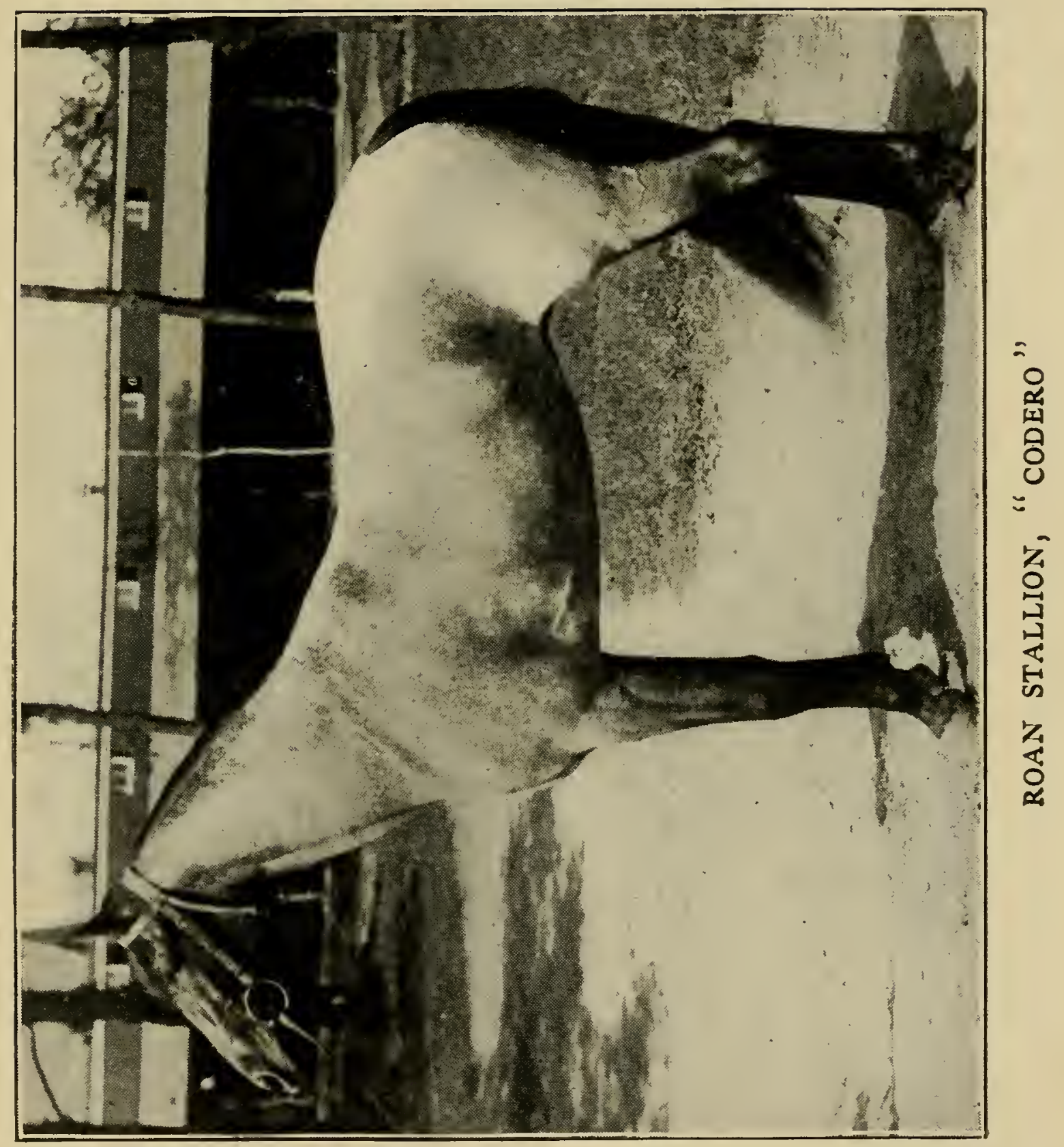



numbness, and throbbing. When the rubber band causes pain, we can remove it instantly. If our shoes pinch, we can kick them off, and sigh with relief as discomfort subsides, and the blood courses back into its usual channels. But alas, poor horse ! If the horny box of his hoof, which corresponds to the leather shoe we wear, contracts and pinches the sensitive parts underneath, he has no relief. His shrunken hoof is a fixture. $\mathrm{He}$ cannot kick it off. He cannot ease the pinching by loosening laces. No; he has to suffer excruciating pain as he works, eats, or lies down on his too often uncomfortable bed, and seeks to rest with his tight boots on!

\section{BAR SHOES}

Bar shoes are often extremely useful for the purpose of protecting a foot which has a strong frog, but is weak at the quarters. In such a case the bar should be so fitted that it will be in contact with the frog, in order to obtain frog-pressure. In other cases the bar is used to protect a weak or diseased frog, and it should then be fitted so as not to touch the frog.

\section{PADS}

The use of rubber and leather pads has already been mentioned. (See page 86.) Generally speaking, no horse should ever be used in the city without a pad, either of rubber or of leather, for the pad not only protects the foot from injury but also serves to hold in place the tar or other material which is needed to keep the foot of the city horse from becoming dry and from contracting. By the way, gas-house tar has sometimes been substituted for the ordinary or North Carolina tar, and has proved injurious to the foot. 
The use of the pad is also a defense against the picking up of nails - an exceedingly common and distressing accident. So many horses are painfully injured and ultimately killed from this cause that, as a matter of economy, it pays to protect the hind feet as well as the fore feet with a leather or rubber pad. A nail may, indeed, penetrate the leather pad, but it will not go into the foot so far as it would without the interposition of the leathern protection; and, moreover, the mere passage of the nail through the leather cannot help but clean it to a certain extent. This cleansing process has a decided value of its own, for blood poisoning is the worst feature of these accidents.

Pads, however, should not be left on very long, for gravel or dirt will gradually work in, and form hard, irregular lumps under the pad, causing pain, and often lameness.

\section{TIPS}

Tips are often useful to prevent or cure contracted heels, and with horses that have good, strong feet, tips for use on country roads are, in many cases, better than shoes for a week or two at any rate. An incipient case of founder ${ }^{1}$ can often be cured by shoeing the horse with tips, for in this way frog-pressure is obtained and the heels are expanded. The tip should be so made that it gradually tapers to nothing, in the likeness of a wedge. This is much the better way. But if the ends are left square and of the same thickness as the front part of the tip, they must be let into the bearing

1 Not, of course, acute founder. 
surfaces of the wall at the bulges so as to be flush with the ground-meeting surface of the heels.

INTERFERING

To be a good horseshoer, a man must have a naturally correct eye, which will enable him to tell whether a foot is absolutely level, and not in the least higher on one side or the other. Most cases of interfering can be cured by a really skilful smith who has an eye and a hand that enable him to give the foot of the horse an absolutely correct bearing. It often happens that a horse that has been shod with an assortment of queershaped shoes to prevent interfering, all of which have failed, can at once be cured of the trouble by a really good mechanic who fits the horse with a shoe that has no obvious peculiarity whatever. Beware of the horseshoer who tries to prevent interfering by using shoes of fantastic shape.

Interfering can often be prevented by making the outside web of the shoe on the offending foot a little heavier or wider than the other side of the shoe.

\section{CAUSES OF BAD SHOEING}

A great deal of bad shoeing, especially in cities, is due to haste and carelessness. The owner of the horse sends the animal to the forge by a boy; and the smith, being in a hurry and perhaps being crowded with work, as always happens when the going is bad, shoes the horse carelessly, and when the horse comes home there is nobody at hand to look at his feet, and consequently, no matter how bad the shoeing may be, nothing will be done about it until the horse goes lame. In some 
shoeing forges it is a deliberate custom to make the shoe too small because in that way a neat looking job can be turned out without much trouble. Every owner of a horse should at least make sure, when the horse returns from the forge, that the shoe is big enough for the foot, especially at the heels; that it supports the wall of the foot at its true outer line-or a little beyond that line, if the foot be contracted. Contracted heels and all the terrible evils that come from them are often caused by bad shoeing, and especially by shoes too small.

But all the foot-ills from which the unfortunate horse suffers cannot be "blamed on" the blacksmith. The owner's neglect to keep the foot soft is responsible for many of them. And so is his neglect to have the horse shod whenever he needs shoeing. Corns especially, result from leaving the shoes on too long.

\section{THE SHOEING OF RACE HORSES}

The shoeing of trotters and pacers so as to balance them properly and to correct faults in gait is a fine art which has been highly developed by ingenious and skilful men. It is beyond the scope of this book. The best work on the subject that I know of is Shoeing and Baiancing the Light Harness Horse, written by James Clark and published by the Horse World of Buffalo. 


\section{CHAPTER XX}

\section{HARNESS}

THE harness of most horses, work-horses especially, 1 is unnecessarily heavy. The harness shown in the illustration (opposite page I I4) weighs only fifty-three pounds, collar and all, and it is big enough for any horse of $\mathrm{r}, 400$ pounds, and yet horses of that weight frequently carry a harness weighing seventy or eighty pounds.

\section{THE BRIDLE}

There is no strain of any account on any part of the bridle, and a small, light bridle is very much more comfortable for the horse, especially in hot weather, than a heavy bridle. The bridle should never exceed two pounds in weight. Bad sores often develop under the crown piece when a heavy bridle is used in hot weather. The place where the crown piece rests is a very tender part of the horse, being unprotected by any bone or muscle, and consequently it is liable to be galled. For this reason, the crown piece of a workhorse's bridle should be soft, flat, and much wider than it is usually made. A throat-latch too tight is a common defect.

\section{BLINDERS}

If any blinder is used, it should be a comparatively small one, flaring outward, so that the horse's eyes will 
not be covered and his forward vision will not be interfered with. A big, heavy, close-fitting blinder, such as is often used, is a most unsightly and really a cruel device, especially uncomfortable to the horse in hot weather. A large blinder like this is often used on carriage horses with the idea that it makes the animal's head look small and therefore gives him a better-bred appearance. There is no cruelty which fashion will not practice if it conduces to the pride or vanity of the owner.

Most horses will act better and feel better without blinders, but some few horses undoubtedly shy more with an open bridle than with blinders, and an open bridle will often make a lazy horse more lazy.

It is a question, too, if a bad, nagging driver will not worry the horse more if the horse has an open bridle. The less a horse sees of that kind of driver, the better.

Shying horses may be divided into two classes, those who are frightened by sounds, and those who are frightened by sights. A horse that is frightened by sounds and not much by sights will always be safer in an open bridle. In fact, many nervous horses wearing blinders will jump and shy at every sound behind them, whereas, if their vision is not obstructed by blinders, they will not be frightened by any sound. On the other hand, some horses that do not care much for sounds but are terrified by things that they see will be safer with blinders than without them; but these cases are infrequent.

A horse that has to do much backing, such as a coal 


\section{HARNESS}

horse, should always wear an open bridle, so that he can see where he puts his hind feet.

Many horses are near-sighted and think that large objects are much nearer to them than they really are. No horse is safe to drive unless he is somewhat accustomed to being driven without blinders, for at any time, by careless harnessing, the blinders may be so arranged as to permit him to see over the top of them, and in that case he is almost sure to be frightened if he has not been accustomed, through wearing an open bridle, to see objects behind him. Many a man has been killed because he happened to use a bridle so ill-fitting or so worn out that the horse could see over the top of his blinders, and not being accustomed to that, was frightened by what he saw behind him. Top wagons are dangerous things in such cases, and even a horse who has been driven in an open bridle, when harnessed to a wagon without a top, may shy and run away when hitched to a top buggy.

There was once a valuable trotting mare that had won many races on the track and had always worn an open bridle. One day her owner, wishing to show her to a customer, put on a new and valuable harness without blinders, hitched her to a Brewster top buggy that was also new, and without any thought of danger drove out of his stable. The mare, seeing the unaccustomed top of the wagon following close upon her, was very much frightened, ran away, smashed the carriage, tore the harness into fragments and caused such injuries to the driver and herself that they were both laid up in their respective hospitals for six months or more. 
A horse with a good head and fine eye always looks better in an open bridle than with blinders; and if he is an intelligent horse is usually safer than if he wore them. Another reason for accustoming every horse to the use of an open bridle, whether you intend to make that use habitual or not, is this - almost any horse that is driven much, especially in the country, is likely at some time or other to rub his bridle off, and in that case, if he is not used to an open bridle, he is almost sure to run away. Colts should be broken both ways, that is, with blinders and with an open bridle.

\section{BITS}

The bit should fit the horse's mouth. If too narrow, it will pinch his cheeks or lips, and if too wide, it will pull through his mouth and hurt the corners. A high authority says:

Do not try to drive a colt with a bit long enough for a grown horse. More horses get bad mouths from bits too long than from any other cause. Half the bits in daily use are from one to five inches too long.

The position of the bit in the horse's mouth should be such that the cheek pieces of the bridle will be taut, but not tight enough to wrinkle the corners of the mouth. The bit should rest about one inch above the bridle tooth in the horse, and in the corresponding place in a mare, that is, about two inches above the corner (incisor) tooth. A bit either too loose or too tight in the mouth is uncomfortable and annoying to the horse.

Some horses go best with a straight bit, but there 
are two objections to the straight bit. In the first place it is of little use in holding a horse if he starts to run or shy, and in the second place it pulls through the mouth, and in the hands of a rough or stupid driver might cause the horse much discomfort. Probably the bit that is best for the average horse is a snaffle bit; that is, a plain bit jointed in the middle. But it should be made larger - not longer - than most bits are made.

If the horse has a tender mouth, he will do best in a leather-covered bit. There are many bits of this kind on the market. Rubber-covered bits are bad because they tend to dry up the saliva in the mouth of the horse, and if the mouth is dry it loses its sensitiveness.

Mr. Stark says:

A horse that is a puller or lugger is made that way usually by a bit that hurts him. The more it hurts him, the harder he pulls. Few horses pull on an easy bit. If you cannot get a big leather bit of your dealer, have your harness-maker cover a common straight bit with several layers of rawhide. The bit when covered should be as large as a small hoe handle.

\section{REINS}

For work-horses it is well to have that end of the rein which fastens to the bit made of chain rather than of leather for, say, two feet from the bit. The reason is that this end of the rein dips into a watering trough when the horse is watered, and the leather may soak up some glander germs or other impurities. It is at least more cleanly to have this part of the rein made of chain. 
A common fault in drivers of work-horses is to have their inside reins too long. This causes the horses' heads to be pulled to one side, which, in turn, is apt to produce a sore shoulder.

Private coachmen often go to the other extreme, and couple their horses' heads so close together that they cannot travel comfortably, are in a continual state of irritation, and are likely to interfere.

Be sure that the hand-pieces of your reins are long enough. Nothing is more dangerous or more likely to make the driver pull unnecessarily on the bit than to have the reins too short for the vehicle.

\section{THE CHECK REIN}

A whole book might easily be written about the use and abuse of check reins. A check rein is always an evil, but sometimes a necessary one. To use a check rein on a mature horse is a confession that he has some defect either of conformation, disposition, or training.

There are several reasons for checking a horse. First, to balance him. Some horses will travel more easily if they are moderately checked with a side check. Without a check such horses are apt either to sprawl, or to lunge forward a little while trotting. The reason probably is that these horses are not well-balanced; that is, their shoulders and forelegs are too heavy for their hind quarters, or vice versa, and perhaps a back too long might produce the same result. Whatever the cause, it is certain that some horses will do better, even on a long journey, if moderately checked, the check being of such a length as to assist the horse in keeping his 
head in the position natural to him. But when you are going up a long hill, do not fail to get out and uncheck him.

Secondly, a check is often an assistance to the driver in preventing a horse from running away or getting out of control. Many a young, spirited horse can safely be driven with a plain, snaffle bit and an overdraw check, or perhaps even a side check, whereas, without a check, he would not be safe to drive, especially when he first comes out of the stable. In some of these cases a curb bit would answer the same purpose, but most good horsemen would prefer to drive a horse with a snaffle bit and a check rein, rather than with a curb bit. The greatest pleasure in driving is the give and take between man and horse. A sympathetic driver, with a light hand, can play upon the bit and the horse will respond to it. It is a kind of silent conversation between horse and man. But this cannot be accomplished with a curb bit.

Thirdly, a check rein may be necessary to prevent a lazy horse or an old one from becoming careless and stumbling. If he actually stumbles, he is indeed worse off with a check rein than without it, for the check rein not only will be of no assistance to him in keeping his feet, but will be a positive disadvantage The only use of a check rein on such horses is to keep them a little more alert and attentive to their business.

Even the overdraw check is not uncomfortable for young, spirited horses who are naturally high-headed, provided that the check is let down when they stand still and that their heads are not kept checked up for 
too long a time; but nothing could be more cruel or irrational than the promiscuous use of the overdraw check. Not one horse in twenty requires an overdraw check, and in nineteen cases out of twenty the overdraw check causes discomfort and even pain.

The overdraw check is especially cruel upon a horse who has any weight to pull, even a moderate weight. The natural position for a horse pulling any weight more than that of a mere sulky is the position in which his neck is somewhat arched, and the overdraw check almost wholly prevents the arching of the neck.

Moreover, a horse cannot look his best, in fact, can hardly be beautiful unless his neck is somewhat arched, and for this reason again the side check is far preferable to the overdraw check. Let any person who loves beauty in horses look first at a carriage or driving horse driven without a check, or with an easy side check, and then go to the race course and see the trotters with their necks stretched out straight and their heads drawn up by overdraw checks. The beauty is almost wholly taken out of them.

The overdraw check may be necessary on most trotters, but there is no question that many and many a trotter would go faster if he were not checked so high. This is a matter of frequent remark among experts in the training business. John Splan, the noted trainer and driver, drove Lady De Jarnette three seconds faster than her record simply by lowering the very high overdraw check which her owner had always supposed it was necessary for her to wear. Lake Queen formerly wore a severe check, and the best she could do 
was a mile in 2.14, and even then she was a roughgaited mare. She was sold, and the next year, in the hands of a new driver and without a check, she became a beautifully gaited mare, and reduced her record to $2.081 / 4$. Some famous trotters have been driven without any check, among them Lou Dillon, the fastest mare of her day, and perhaps, indeed, of any day; Ralph Wilkes, the fastest trotter of the Wilkes family in his day; Alcidalia, and the famous stallions Axtell and Allerton. Willy, whose record is $2.04 \mathrm{~T} / 4$, and who is noted for his good manners and steadiness as well as for his beauty, wears a side check which hangs loose on his neck when he is at speed.

The combination of a severe check rein and a curb bit is something to make any true horseman shudder. It should never be used except perhaps in the case of some vicious or flighty animal, and yet it is in common use with carriage horses of fashionable people, the curb bit and the pulley or bridoon check being the usual combination.

\section{THE COLLAR}

It is hardly necessary to say that the collar should fit perfectly, being just long enough to permit a man's hand to pass between the collar at the bottom and the neck of the horse. If too loose, the collar is almost sure to produce a sore neck or shoulder, and if too tight it will hinder the breathing of the horse and perhaps choke him. It is not very uncommon for horses to drop as if they were shot simply from having too tight a collar. This happens when the horse is making 
some unusual exertion, such, for example, as pulling a load up a steep hill or pulling a sleigh over a piece of bare ground.

For a seasoned draft horse the best kind of collar is a leather one. That is clean and cool, and, properly fitted, will serve better than any other kind. But if the horse is green or fat, and consequently is likely to shrink when put to work, the best collar to use is the Irish collar, so-called. The Irish collar, like the leather collar, is stuffed, but the covering, instead of being leather, is of cloth so that it is easy by making a hole in the cloth to remove the stuffing, or to put in additional stuffing, or to make a little depression at the particular point where a horse has become sore, so that the collar will not bear upon the sore spot.

Collars made of wood were in use many years ago, and, it is said, worked very well if properly fitted. Collars of zinc or other metal can now be obtained, but I have had no experience with them.

Too much care cannot be taken to keep the inside of the collar free from dirt and sweat. If the collar fits well and is kept clean, and the horse's shoulders are sponged off as soon as his work is finished, he will not have a sore shoulder, except perhaps in the case of an animal whose skin is abnormally thin, or whose blood is in bad condition. A careful driver will now and then lift the collar of the work-horse on a hot day, so as to cool his shoulders, and will rub off the sweat and dirt with his hand. The shoulders of a young or green horse can be hardened considerably by washing them with salt and water. 
The sweat pads in common use, especially in the country, are avoided by all good horsemen. They necessarily collect much dirt and sweat, and therefore produce sore shoulders.

\section{HAMES}

The main thing to be said about the hames is that they should always be buckled tight at the top of the collar, for if the hames are wide apart at the top, the collar will have so much play that the horse will get a sore neck. The hames should be made of the lightest possible material so as to reduce the weight of the harness.

\section{SADDLE}

The saddle should be fairly wide, according to the work of the horse and the character of the vehicle, but most work-horse saddles are unnecessarily heavy. Saddle-pads are made too short, and hence many sore backs result. For light driving horses they should be at least sixteen inches long. For work-horses they should range from twenty-one to thirty-six inches. The saddle girth for work-horses is apt to be wrongly shaped. It should be very broad at the bottom to prevent chafing the horse, but it should be very narrow at the top for otherwise, especially if the horse has low withers, the saddle girth may chafe his forelegs.

\section{THE CRUPPER}

The crupper should be large and smooth so as to avoid chafing the horse. On the work-horse a crupper should never be used. 
With roadsters the breeching is often omitted, and in that case the crupper really takes its place. This arrangement is all right for level ground, provided that the crupper is a comfortable one, but in going down hill the horse needs breeching.

\section{BREECHING}

The best form of breeching for a well-made workhorse is the basket or hammock breeching, so-called, which is shown in the illustration facing this page of a horse wearing the model harness. It has a broad strap, almost in the form of a semi-circle, which fits the rump, just above the tail. This does away with the use of the crupper and also does away with the strap that passes over the apex of the rump and is a frequent cause of galls and sores. When holding back with this kind of breeching, the horse sits down in it, so to say, and the strain is well distributed. But this form of breeching should fit the horse perfectly, otherwise it is likely both to gall the horse and to break. It is therefore not suitable when one harness is to be used on two or more different horses, and, moreover, it is not suitable for a thin horse, or a slim-quartered horse. It is indeed almost impossible to make it fit any horse that has not full, well-developed hind quarters.

There is another form of breeching, like the basket breeching, except that the hip strap has free play, running through from side to side, so that it adjusts itself to the movements of the horse. This is a good form of work-horse breeching. For driving horses the ordinary form is the best. 


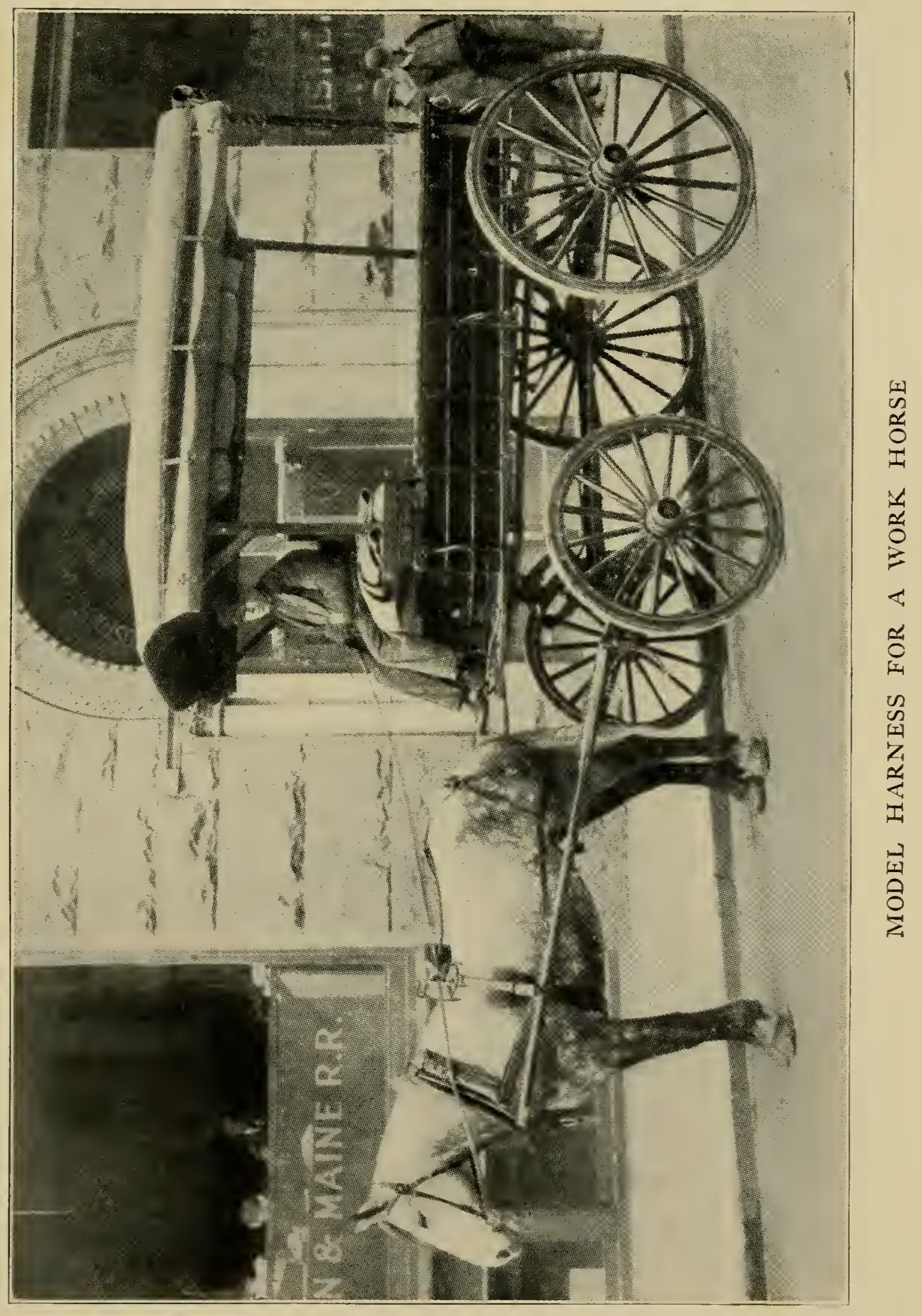



One of the most frequent defects in harnessing, perhaps the most frequent of all, is to put the breeching too low down. This pulls the horse's legs together when he goes down hill or backs, brings a great strain upon him and often causes interfering. The breeching can hardly be too high unless it is so high that it rides up under the horse's tail.

Another frequent defect is to have the hold-back straps so long that the horse holds back his load not from the breeching but from the saddle. This produces a sore back and unnecessarily strains the horse. The whole harness should fit the horse snugly, being neither too tight nor too loose, for this is the only way to avoid chafing. 


\section{CHAPTER XXI}

\section{STABLES}

THE cost of a stable usually has little to do with its 1 comfort or healthfulness. Everyone has seen stables costing many thousands of dollars in which the stalls are too narrow or too short, or slope too much, or the flooring is slippery and dangerous, or some other important defect is apparent. An old, tumble-down, wooden building may be made perfectly comfortable for the horses stabled in it.

Perhaps the most important requisite of a stable is that it should be dry. Dampness is especially bad for horses. A stable constructed against a bank, or partly underground, is almost sure to be damp and unsanitary. Sunlight is essential, and it is the best disinfectant in the world. Sand is the best soil on which to build a stable, gravel comes second, chalk third, and clay last. Every stable that has to be locked up should be provided with slatted doors, so that on summer nights the ordinary doors may be left open.

\section{STABLE FLOORS}

It is a great mistake to have the flooring of the stalls, or even the flooring of the passageway behind the stalls, of any hard, slippery material such as brick, tiles, asphalt, or cement. This makes an extremely uncomfortable floor for the horse to lie upon even though 
well-bedded, for the bedding is likely to slip or be kicked off more or less, and, moreover, there is continual danger of horses slipping upon such a floor. The flooring of the stalls should be of wood. Wood may not be quite so sanitary as the non-porous materials, but its use is perfectly compatible with a clean, wholesome stable. For the passageways, either wood or else asphalt or cement mixed with some substance which will give a rough surface should be used.

\section{CONSTRUCTION OF STALLS}

Stalls should be ten feet long, if possible, though nine feet will do fairly well, and no stall should be less than four feet six inches wide. Any width less than this will not make a comfortable stall even for a small horse. A width of five feet is vastly better, and big horses, say horses weighing over I,400 pounds, should always have stalls at least five feet wide, and six feet would be better. The advantages of a long stall are three: first, it protects a horse from being kicked by his neighbor; secondly, it prevents the horse from getting one foot caught around the partition between the two stalls, a frequent accident; and thirdly, it protects the hind legs of the horse from cold draughts. This last consideration is much more important than is commonly supposed, for a horse coming in with wet fetlocks and legs, especially in winter, is likely to get scratches and mud fever if his legs and heels are exposed to a draught.

Of course, a box stall is the best for every horse, both because he can lie down in it much more comfortably, 
and also because he can walk about in it and thus get what exercise he needs. Moreover, he can amuse himself better in a box stall, having more points of view therefrom. Good dimensions for a box stall are twelve feet by fifteen; ${ }^{1}$ but a box stall only just large enough for the horse to turn around in, say eight feet by eight, is a great deal better than any straight stall. The shape of the box stall is not very important, but, preferably, it should be oblong, as in a stall of that shape the horse is likely to take more exercise if he needs it; he walks to the end of the stall and back, whereas a squareshaped box stall has no end and no beginning.

It is sometimes said that horses do not care to stretch their legs out straight while lying down, and that it is more natural for them to lie "folded up," as horsemen say, that is, with the knees and hocks bent, and their legs under them. Horses in a pasture, it is said, usually lie down in this manner; and that may be true, but if so, it is because during thousands of years their wild ancestors were accustomed to lie "folded up," for in that position they could more easily and quickly spring to their feet in case an enemy approached. But when they have an opportunity, horses in a stable will lie at full length, with every leg stretched out, as can easily be discovered by anybody who will take the pains to investigate the matter. This is a common way for horses to lie in box stalls, and even in straight stalls when they are wide enough.

The slope of the stall from the manger backward

${ }^{1}$ An English authority gives the proper dimensions of a hunter's box as twenty-two feet long and thirteen wide. 
is very important. It should be as slight as possible, not more than one inch in eighty inches. In fact, it is better to have the stall absolutely level, although this may be inconvenient on account of drainage. If a stall slopes too much it is very uncomfortable for the horse, and is apt to result in sprung knees.

The ideal stall has an underflooring of cement or other like material which slopes back from the head of the stall to the gutter behind it, and upon this is laid a removable floor of slatted wood, which is absolutely level.

The upper part of the partitions between stalls should be of network, iron or wooden, so as to permit the free passage of air, only so much of the partition being made solid as is necessary to protect the horse from annoyance by his neighbors when he is eating. This matter is very important for a stall boxed in at the forward end is hot and close in summer. On the other hand, the horse being essentially a nervous, even irritable animal, it is equally important that he should be allowed to eat his meals in peace.

\section{CASTING}

There is a rather common impression that in fairly wide stalls, say, five feet wide, horses are more apt to become cast than in more narrow stalls, but this seems to be a mistake. Some years ago the Boston Work Horse Relief Association made an investigation upon this point, inspecting for the purpose stables containing hundreds of horses, and they found that the wider the stall the less the likelihood of being cast, and that the 
probability of a horse becoming cast increases in proportion to the narrowness of the stall.

Of course, the danger of casting can be avoided by having attached to the top of the headstall a rope or cord so arranged, with a pulley or otherwise, that the horse can get his nose to the floor of the stall but cannot lay his head flat on the floor of the stall, and if he cannot do that he is very unlikely to get cast. Some horses have a habit of becoming cast, and such horses can be protected against casting in this manner. The worst injuries from casting are usually caused by the horse getting his head caught under the hay manger; but in a properly constructed stall this cannot happen, for the manger is continued down to the floor so that there is no vacant space beneath it.

\section{VENTILATION}

Ventilation is, of course, extremely important, and it should be so arranged that draughts will not come directly upon any horse. In cases where this is impossible, the horses that stand in stalls exposed to draughts should be carefully blanketed. In large stables there are always some such stalls, either near a window, or otherwise exposed, and the occupants of these stalls should be protected by light sheets or thick blankets according to the weather.

Ventilation is best procured by a shaft in the center of the ceiling combined with windows placed well above the horses' heads. These windows should open in such a way as to deflect the air entering them from the horses underneath. 
If moisture forms in winter upon the walls or ceiling of a stable, it is sure proof that there is a want of ventilation in it. In such cases you will sometimes find that the tips of the horses' ears are sticky and dirty, this being caused by the ear becoming moist at the tip owing to bad ventilation, and the dandruff and dust forming with the moisture a sticky mixture. I once saw a well-bred, young trotting horse that had been wintered in northern New England, whose ears flopped over a little at the tip, having evidently been frozen, and, no doubt, they became frozen when the horse was taken out to exercise on some particularly cold morning with the tips of his ears in this wet, sticky condition from want of ventilation in his stall.

\section{TEMPERATURE}

Stables should be warm in winter. Fifty-five degrees is about the right temperature. Horses suffer very much from cold, and I believe that a cold stable for a horse doing hard work is worse than a badly ventilated one. Even in warm and crowded stables, horses will do well if well-fed, well-groomed, and well-bedded, although they will be more susceptible to disease than they would be in a properly ventilated stable.

A young horse used to a cold climate, not blanketed, and not groomed enough to take the dandruff and oil from his coat, can stand severe cold in a stable or elsewhere if generously fed; but hard-worked horses that are groomed and blanketed need to be kept in a warm and comfortable place.

Some persons think that if a horse has to stand on 
the street more or less during the day or night, he should not be kept in a warm stable, and should not be blanketed in the stable; but this is a great mistake. Horses do best when kept thoroughly warm in the stable, although they are exposed to great cold outside of it. There is such a thing as storing up heat in an animal's frame, or at least there is such a thing as a slight excess of warmth indoors to make up for a defect in bodily heat outside. The Eskimo and the Russian people live in exceedingly warm houses, and for that reason are better able to withstand the cold outside.

\section{WATERING TROUGHS}

Great care should be taken to keep the watering trough in the stable clean, and in places where the disease of glanders is as prevalent as it is in our eastern cities, the watering trough should be a box containing one or more pails, or receptacles in the shape of pails, so arranged that the water flows in at the bottom of the pail or receptacle, washes over the whole top or rim, and so escapes to the trough or box containing the pails and then out by a waste pipe. In this way each horse practically has a pail to himself, and thus the danger of one horse communicating glanders to another is nearly or quite obviated. The same result could, of course, be obtained, and more certainly, by having a separate, numbered pail for each horse, filling the pail at the trough or faucet and carrying it to the horse; but perhaps this would involve more time and labor than could be afforded in a large stable.

In case infection from glanders is to be feared, the 


\section{STABLES}

only safe way in driving is to avoid all public watering troughs and to carry a pail with you for drawing water.

\section{DISINFECTANTS}

As a disinfecting fluid for stables the United States Department of Agriculture recommends a compound solution of cresol, composed of equal parts of cresol and linseed-oil potash soap; a four per cent solution. A five per cent solution of carbolic acid is a good but rather expensive disinfectant.

For washing mangers, salt and water form a good enough disinfectant for everything except glanders. 


\section{CHAPTER XXII}

\section{STABLEMEN}

F VEN from a mere dollar-and-cents point of view, it is well worth while to employ sober, competent, and good-tempered men in a stable. No man with a loud voice or rough manner is fit to take care of a horse. "An hostler's angry tone," says an old trainer, "will send a quiver of fear down a whole barnful of stalls. I have seen it scores of times."

There are certain men who have an extraordinary power over horses. One such man called "The Whisperer," was famous in Ireland in the last century. Another such was well known around the race tracks in the western states some thirty years ago. This man, like "The Whisperer," was noted for his ability in reforming vicious horses. Neither of them used any medicines, drugs, or paraphernalia of any kind. All that they did was to talk to the horse in a low, insinuating, and monotonous tone, and it was never very long before the most vicious animal would yield to this mesmeric treatment. Sometimes there was a relapse, but a few hours' renewed treatment would restore the patient to quietness and sound temper.

It must be remembered that the horse is at the mercy not only of his driver, but also of the man who takes care of him, when they are not one and the same. All the feed that he receives, all the water that 
he gets in the stable, all the bedding that he has depend upon that one man, and it is very easy for that man to neglect the horse in any one of these respects on any day of the year.

Perhaps the worst enemy of the horse is intoxicating liquor. Drunkenness, or even semi-drunkenness, on the part of drivers and stablemen, is probably responsible for more positive cruelty and for more neglect than any other cause. Be sure that your stableman is sober, industrious, faithful, and fond of animals, for if he has not these qualities he will be worth less than you pay him, no matter how small that sum may be. On the other hand, good wages paid to a good man will bring a better return in dollars and cents, to say nothing of humanity, than any other form of expenditure that can be imagined. It is astonishing how foolishly men, who are shrewd in their business affairs, will sometimes act when it comes to employing a caretaker or a driver for a horse. That sagacious trainer and driver of long experience, John Splan, who has been quoted more. than once in this book, remarks: "I have often known an owner to intrust a horse worth $\$ 10,000$ to a man whom he would not trust with a ten dollar bill."

In a large boarding stable in New York, on every floor, is posted the following notice:

No man shall speak loud to any of the horses or in the stable where they are. Horses of good blood are nervous, and loud, excited talk is felt by every horse who hears it, and keeps them all uneasy. No man shall use profane language in the hearing of the horses. 
This notice is put up by a successful stablekeeper, who is not a particularly humane man, but he knows the nature of a horse and is aware of the bad effect which rough treatment will have upon him. Another practical man, the German Emperor, laid down a rule to precisely the same effect for the treatment of all cavalry and artillery horses in the German army.

A successful dairyman who owns some hundreds of cows says that it pays well to have milk-giving cows groomed every day, "but," he adds, "if the grooming is done by a man who does not like cows, it will do more harm than good." Experienced poultrymen have arrived at the same conclusion in regard to hens, and they all agree that any roughness of treatment will diminish the laying capacity of a hen just as it diminishes the flow of milk in a cow. "Humanity in the poultry yard," is the title of a recent essay in an agriculture magazine, in which the writer says: "Good feed and plenty of water are of little avail when birds are frightened at every approach of the owner."

If these things are true of cows and hens, much more are they true of horses. 


\section{CHAPTER XXIII \\ VACATIONS FOR HORSES}

THERE are thousands of horses hard at work today who have begun to run down hill, and will be worthless or nearly so within a year or two; and yet if these horses could be given a rest and a chance to recuperate they would, in a few months, be worth almost as much as the price originally paid for them. Some of these horses are what is called "grain-burnt." They have had so many years of feeding on hard, dry, stimulating food that their blood and digestive organs are in bad condition. They lose flesh and spirits. Others are simply tired out. Their muscles have been overtaxed, and have lost all elasticity. These horses may be in good flesh, but they are slow and dull. I once saw a horse used by a rural mail carrier that, being naturally a good feeder, and having all the grain that he could eat, was in fine flesh; but he did double the work of an ordinary horse; that is, he traveled twenty-three miles a day for six days in the week, and he was so tired and stiff that to trot was positively painful for him. Now, both of these classes of horses, the grain-burnt and the muscle-tired, if practically sound, can often be restored by a short vacation to a remarkable degree of health and activity.

The following letter to the author from a leading truckman in an eastern city states a case of this kind: 
I write this letter to call your attention to a gray mare, stone blind, which we worked in our business for fourteen years. When she had been worked for about twelve years, she seemed to have a general breakdown, and about that time you and I had a conversation in regard to "reconstructed horses," and you advised me to give this mare three months' lay-off and see what effect it would have. I followed your instructionswe have a large yard - and this mare was turned out every day, and most of the time we hired a boy to take her out and give her some grass. In two months' time she came back perfectly well and seemingly as good as ever. We worked her for about two years from that time, and then we pensioned her and sent her to a farm.

We have done this same thing with three others, and one of these was run down so badly that our veterinary surgeon advised me to have him killed. He declared that one of this horse's lungs was nearly gone, and thought he was not worth one dollar. We had used this horse for about eight years, and concluded that we would try giving him a rest. After three months' rest he was one of the handsomest horses in the city, and he remained so for about two years. This year he died of blackwater on account of being over fat. 


\section{CHAPTER XXIV}

\section{THE DISPOSAL OF OLD HORSES}

THERE is a growing feeling in the community that 1 old or disabled horses should not be sold, but should be killed or otherwise disposed of in a humane manner. To sell a worn-out horse, and thus consign him to a slow and painful death, will be looked upon years hence as an almost incredible cruelty. Only horsemen know how much horses can and do suffer from painful diseases of the feet and legs, from starvation, from cold, from want of grooming and bedding, from whipping and jerking, from the constant state of fear, produced in them by rough and brutal men.

The following is an extract from a circular issued by a western humane society:

It seems almost incredible that after a horse has served his owner for many years he should, in his old age, be sold to the first customer that comes along; and yet that is sometimes done. To sell an old or unfit horse is, in the majority of cases, to consign him to a lingering and painful death.

After long experience, we strongly and respectfully advise you not to give away a horse, except in some unusual case. It is more humane to kill him. Only about one man in a hundred will take good care of a horse for which he has paid nothing. Beware, especially of selling or giving a horse "to go on a farm." Farmers, in general - of course there are many exceptions - feed their horses less grain, and take less care of them, than any other horse-owners in the world. 


\section{CHAPTER XXV}

\section{THE TRANSPORTATION OF HORSES}

I transporting horses by railroad it is important to 1 have plenty of bedding under them, for two reasons: first, to prevent their slipping and falling, especially when the train is making-up, and the "shifter," most vicious of all locomotives, is "kicking" the car about; and, secondly, to act as a cushion. There is much less jar if a good depth of bedding is interposed between the horses and the floor of the car.

It is customary now to ship horses by express rather than by freight, and to use what are called "Palace Horse Cars," instead of stock cars or the ordinary freight car. When the common freight car is used, the horse should be tied at one end, at the rear end in hot weather; and at the forward end in cold weather, to avoid the draught from the partly open door. It makes no difference, I think, whether the horses face forward or backward. Perhaps they are less disturbed by passing trains when they face backward. The practice is to tie them, with ropes coming from each side, so that they stand lengthwise with the car; and when the horse becomes accustomed to the situation, these ropes can be loosened, so as to give him more freedom. Some persons maintain, however, that the horse is more comfortable and keeps his balance better if he stands crosswise of the car. When Alix, then the champion trotter 

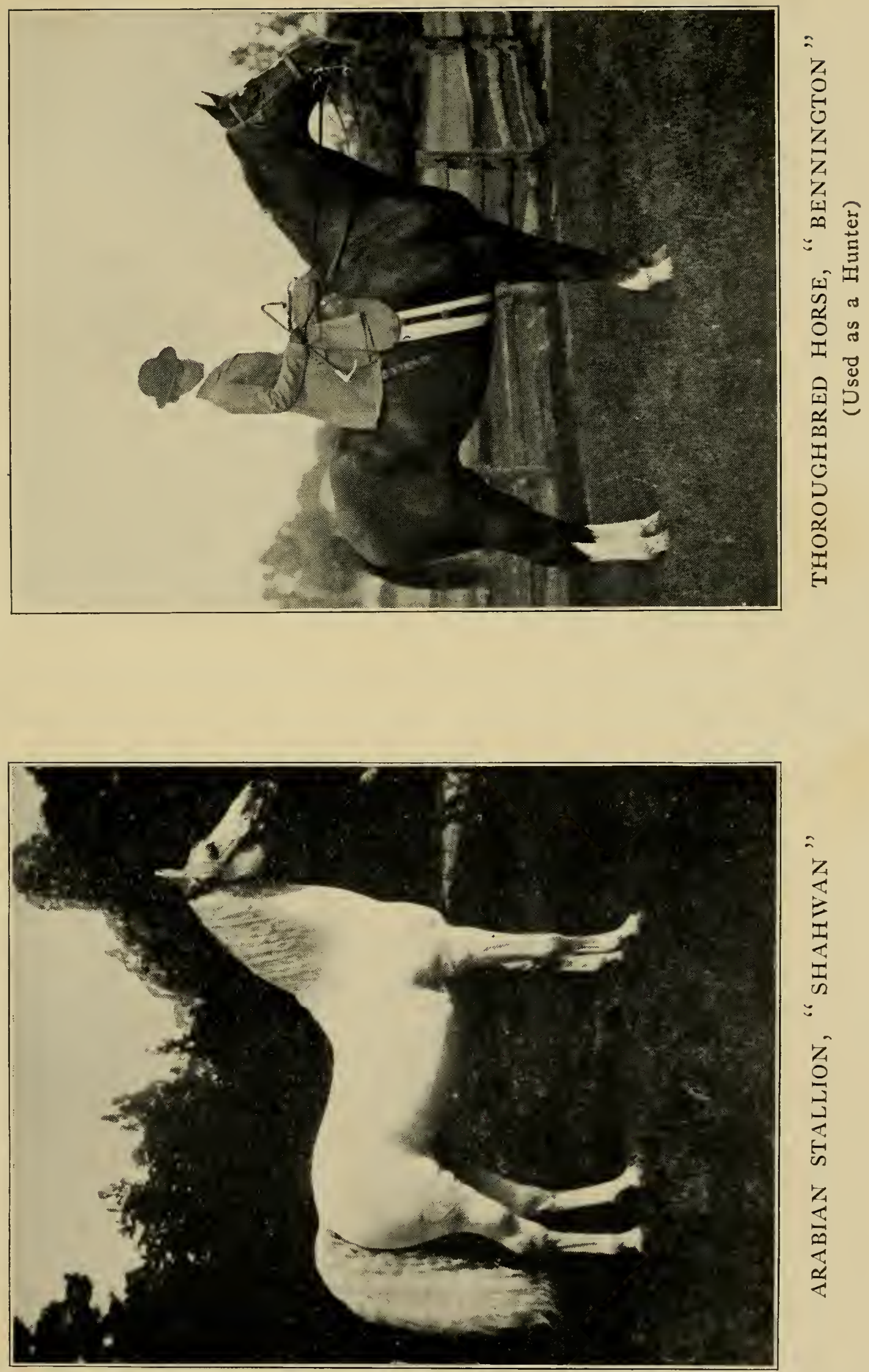

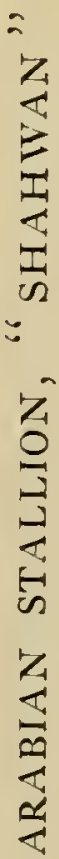





\section{TRANSPORTATION OF HORSES I3I}

of the world, was brought from the West to her eastern home, she made the long journey in an ordinary freight car, and facing the side of the car.

If there are two horses, they will support and comfort each other by standing side by side. There is some danger that a vicious or nervous horse may kick his companion, but if he shows signs of doing so, the other horse can be tied by separate ropes slightly in advance of the dangerous one, and in that position he cannot be kicked.

An attendant should always accompany a horse on the cars, for the horse is more terrified and nervous if left alone. The man, moreover, will be needed to keep the bedding in place, for the horse will paw it backward, especially at first. He will be needed also to regulate the amount of air that comes into the car, and to blanket the horse according to changing circumstances. Horses are usually shipped late in the afternoon. If the weather is hot, the car, baked by the sun, will be uncomfortably warm, and the horse, frightened and nervous at first, will be in a, profuse sweat. The train starts, the sun sets, air blows in, and, as night comes on, the car gets cooler and cooler, and the horse that required no clothing at first, will need one or two thick blankets before morning. When a man accompanies the horse, one door of the car, that on the side where other trains are passed, should be closed and fastened. The other door should be left unfastened, and, by means of a rope or stout cord, the attendant can keep it just so much or so little open as he desires. He should be provided with an overcoat, an old broom 
or shovel, a pail for watering, and a lantern which can be hung from the ceiling of the car. Some men like a hammock to sleep in, but I have always preferred a bunch of hay or straw.

It is best, I think, to feed little or no grain to a horse on the cars so long as he shows any sign of fear or nervousness, but let him have as much hay as he wants. Horses almost invariably shrink while being carred, which shows that the journey takes a good deal out of them. When taken off the cars they always appear to be in high spirits, but this undoubtedly is the result of the nervous stimulation which they have received.

The secret of transporting horses by sea without injury is to feed them very lightly for the first few days-no grain except bran, and not too much hay. If they are fed from the start in the usual manner, seasickness, and in many cases death, will be sure to follow. During the Boer war, when many horses and mules were shipped from this country to South Africa, the losses were sometimes enormous. One vet lost more than half of the horses that he carried on his first trip. In other cases the losses were very small, not more than five or six, and in at least one case a cargo of I,200 mules was transported from New Orleans to South Africa without the loss of a single one. 


\section{CHAPTER XXVI \\ THE ART OF DRIVING}

NO man can be a good driver unless he has the faculty of sympathizing with his horse so as to know just how he feels all the time. He must know when the horse is tired, when he is getting careless, when he is going to shy, when he has it in mind to kick, and so forth. This is the first requisite. The next is a light hand. The pleasure of driving depends on the lively communication, the give and take between man and horse. It is a kind of conversation carried on by means of the reins and bit, and is impossible unless the horse retains the delicate, sensitive mouth which nature gave him. A driver with a heavy hand soon deadens and spoils the mouth of the horse, pulls down his head, and impairs the freedom and elasticity of his carriage. It is because of their light touch that women can often manage with ease a horse that kicks or rears with most men.

The delicacy of the unspoiled mouth of the horse may be seen from this: Let two men be sitting behind a pair of horses, wearing blinders, that are jogging slowly along the road, the reins almost (but not quite) loose on their backs. Suppose that the driver hands the reins to the other man who is equally skilful, and who tries to hold the reins in the same manner. Nevertheless, the horses will detect instantly the change in the 
amount and character of the pressure on the reins, slight though it may be, and will know at once that a new and strange man is driving them, and they will show it by some slight alteration in their pace, and by an inquiring movement of the ears. A boy or girl should be taught to drive, not by holding the reins over some old or underbred horse who has no delicacy of mouth, but by handling a young, spirited, sensitive horse who responds to every touch. "Hold your reins," says a famous horseman, "as if they were made of thread, and would break if you pulled on them." In other words, the effort should be to hold the reins with just that slight amount of pressure which will prevent them from flopping, and will maintain a kind of electric communication between man and horse. Not every man can learn to do this, and I have known professional horse-breakers who could not do it, and whose horses, though otherwise well-trained, always had bad mouths.

But, although the horse should be driven with the lightest possible hand, he should be driven all the time; and this is what he likes. He likes to feel himself under control. The reins should never be really loose, except when the horse is walking. Then, and especially going up hill, let him have his head as he wants it; but keep your eye on him, and be ready to check any departure from a straight line.

A light hand on the reins and a keen eye on the horse's ears - this is the epitome of a good driver. The horse always signals with his ears. If he is about to kick, the ears fly back and the watchful driver, see- 
ing that, gives a sharp word of command - a yell if necessary, and a jerk of the bit, and thus the bad intention is frustrated. When a trotter is on the point of breaking, he gives the same signal. The famous Hiram Woodruff wrote:

Two horses are nearing the wire, the leading one, though tired, might win; but the driver turns his head to look at the ladies in the grandstand, or to see if they are looking at him. At that moment the horse's ears fly back - the driver does not see it, the horse breaks, and the ugly man behind keeps his horse steady and wins by a neck.

The tired horse will let you know that he is tired by flopping his ears a little or turning them slightly backward; and you should take this as a hint to slacken the pace. A good horse always keeps his ears pricked forward when he is in motion, and a roadster was once defined (by myself, I believe) as a horse that one can drive ten miles in an hour or fifty in a day, without taking the prick out of his ears.

You can encourage or rally a tired or faint-hearted horse by moving the bit in his mouth, and this "reefing" as it is called, has been developed into an art by the drivers of trotting horses. So, also, you can keep a stumbling horse on his legs by shifting the bit in his mouth, and touching him lightly with the whip. To punish a horse for stumbling; by jerking the bit or whipping him is cruel and absolutely useless. The only result will be to give him the habit of suddenly starting up after a stumble, and this proclaims to all observers both that the horse is a confirmed stumbler, and that the driver is a bad one. 
A blind horse will quickly learn that a slight lifting of the bit means some obstacle to be stepped over, and that a stronger movement of the bit means a step higher or longer still. I have known an extraordinary sureness of communication to be established in this manner between a blind cab horse and his driver. But with a rough, impatient, or unsympathetic driver, a blind horse is a very unhappy animal.

\section{SHYING}

Shying also can often be prevented by a slight, quickly repeated jerking or rather shifting of the bit, thus diverting the attention of the horse. 'The worst thing that you can do with a shying horse is to whip him. If, indeed, he tries to turn round, you can sometimes prevent this by a cut of the whip, well forward on the side to which he is turning; but as a punishment for shying the whip is worse than useless - it will only give the horse an additional reason for fear the next time that he meets the dreaded object. Sometimes, it is true, by gently tapping a horse with the whip, and at the same time encouraging him with the voice, you can urge him forward. With other horses, however, even this slight use of the whip only adds to their fear and excitement. It is a matter for experiment in each case. Above all things, do not try to force your horse close to the object of his fear, for in that case he will think that you are trying to run him into it. Let him shy, if there is room. Restrain him enough to prevent an accident, but if he wants to go up on the sidewalk, and the way is clear, let him go. When 


\section{THE ART OF DRIVING}

the driver completely ignores the object of dread, the horse, if an intelligent one, will reason that he, too, need have no fear.

Horses are wonderful mind readers. A timid driver makes a timid horse; and it is frequently remarked by dealers in the city, how astonishingly clever horses are in detecting the driver's motive when he turns down one street or up another in order to avoid some particular object, such as a steam roller. It is almost as bad to make the opposite mistake, that of "looking for trouble," and of keeping a green horse going up and down a street in which there are electric cars or other terrible things. This works well sometimes, but more often the horse becomes wrought up, and the association of fear with the object in question is so intensified in his mind that he never fully gets rid of it.

\section{DRIVING DRAFT HORSES}

Most of the foregoing remarks apply to the driving of work-horses as well as roadsters. Left to himself, a draft horse will get into a lazy, haphazard way of traveling, and will usually wander over the road, now on one side, now on the other. The good driver will keep his horse or team in a straight line, and will let them know, but in the most delicate manner, that he is there behind them. Especially in starting a load, should work-horses be well driven. The driver should take a firm hold of the bit, and the horse should be taught to begin slowly, to arch his neck, to keep his legs well under him, and to step on his toes. A loose 
rein means sprawling and slipping, and, in the case of a pair, it usually means also that one horse starts ahead of the other. Horses handled in this way have no confidence in themselves, in each other, or in the driver.

A pair of horses, or a team of three or more, should really make two movements in starting a heavy load. First, at the word of command, or at the tightening of the rein, accordingly as they have been taught, they gather themselves together, arch their necks, tighten their traces, and feel of the load, as it were. Then at the second command or signal, given by voice or rein, they slowly and steadily strain against the collar, and the load moves. Four horses, thus taught, will start a heavy load with so little apparent effort that it seems to follow them of its own accord. It takes long practice and much pains to bring man and horse to this state of efficiency, and driving of this degree should be ranked among the fine arts.

\section{BALKING}

If a horse balks, or refuses to pull, the great thing is patience. If the horse is excited, still more if the driver is excited or angry, let him stop, and wait until both he and the horse are in a quiet frame of mind. A balky horse is sometimes mentally incapable of moving; he is hypnotized, as it were, by himself. Dogs occasionally, and children often, get into the same condition. It is a temporary suspension of will power; and the only thing to do is to divert the attention of the animal, and, failing that, to wait until he has recovered his normal state. Tying a string tight around the 
horse's leg will often serve the purpose - the string to be removed before it becomes painful.

\section{DRIVING ON A JOURNEY}

With these general remarks, let us suppose the driver about to start on a day's work or journey. He will, of course, make sure that he has his blankets with him, and his pail or nose bag, and that his axles are clean and well-oiled, and, if he is not his own groom, he will glance over the harness. Does the bit hang rightly in the horse's mouth? Is the throatlatch too tight? With a check rein the throat-latch is really unnecessary. A check rein is, as a rule, out of place on a work-horse or on an all-day roadster, but some few horses need a check rein to balance and steady them. This is especially the case with horses that are low in front and have straight shoulders. But in such cases, the check rein should be only tight enough to keep the head in the natural position, and it should be unfastened whenever a steep hill is encountered.

Are the reins buckled aright? Of course if one of a pair is more "free" than the other, the driver will shorten the outside rein of that horse, and lengthen the inside rein going from him to the other. Such a pair should wear blinders, and then the driver can quietly "touch up" the lazy horse, without letting the free one see the whip.

The position of the breeching and the length of the hold-back straps should also be regarded; but all these matters are treated above, in the chapter entitled "Harness," and need not be repeated here. 
At last we are off, but slowly. No matter how great the need for haste, the start should be an easy one. A draft horse should be walked for the first half-hour; in fact a draft horse should really never be trotted. The trot jars a heavy horse, and his feet - the weak point in any horse - can hardly stand the pounding of his heavy weight upon pavements or hard roads.

The road horse should be walked for fifty or a hundred yards, and then jogged slowly for three or four miles. Nothing is more sure to exhaust a horse than fast driving for the first few miles. Remember also that the most fatiguing kind of road is a long level stretch. On level ground the pull is incessant, and therefore exhausting. It is on the undulating, up and down, road that fast time can be made with a good horse. On such a road the horse gets his breath and rests his muscles on the down grades. The work is intermittent. For the same reason fire horses can pull a heavy engine easier at a gallop than at a fast trot. for the gallop is a series of pulls, but the trot is a continuous pull.

If the driver has any regard for his horses' feet, he will drive slowly down hill, letting the nags out as they approach the bottom, and, with the momentum thus acquired, galloping up the next hill or part of it. This is the beauty of driving in a hilly country. What sound rings more pleasantly in the ear than the clatter of hoofs and the rattle of boards as you gallop over a little bridge in a hollow! And the horses enjoy that music as much as we do.

A brake, by the way, is absolutely necessary in a hilly 
country, and should be used even on a light carriage. A neatly made brake need not weigh more than twenty or twenty-five pounds, and it will enable you to dispense with breeching - without which the horses will be more cool and comfortable, and will look much better. But avoid the excessive use of the brake, by which you lose the momentum of a slight descent, and take all the liveliness out of your horses.

On a journey, horses should not be driven far without stopping to rest and feed. A halt at every fifteen miles, with a light feed of oats or hay, was the old English rule, and a good one. At these stops the harness should be stripped off.

\section{NOON FEEDING}

The same remark applies to the noon feeding of work-horses. They should be fed in the stable, if possible, and should be relieved of the harness. If it is necessary to feed in the street, loosen the harness, especially the hames, so as to let the shoulders cool, and, in the case of a pair, unhitch the outside traces, so that the horses can shift their position a little. They will rest better that way, and these trifling things make a big difference in the course of a year. Moreover, it is a fact, often spoken of by veterinarians, that spavin, ring-bone, and like forms of lameness are found most often in horses which are kept in harness all day, and stand in harness, perhaps for hours at a stretch.

Staling is another thing to be looked out for, especially in the case of geldings. Some horses will never relieve themselves in this way in harness, and are there- 
fore liable to serious injury. After, say, three hours in harness, they should be taken out and put in some stable for a few minutes. In the country, you can unhitch the horse and lead him into a field. I have often done this. Francis M. Ware, a high authority, declares that suppression of urine is the cause of more illness among city horses than any other one thing; and he advises that drivers should teach their horses to stale in harness at a given signal, by whistling or otherwise, the meaning of which can be learned in the stable. Undoubtedly an intelligent horse could be taught this with a little patience.

Hard-working horses need only a mouthful of hay, besides their grain, at the noon feed, and, if possible, they should rest awhile before feeding. For a horse on a journey, this rest before eating grain is absolutely necessary.

Occasionally the noon feed of a work-horse is interrupted, and he is sent off on some job before he has finished his grain. In such a case it is best not to give him the remainder of his feed later. Oats take about two hours to digest; and if to oats partly digested in the horse's stomach more oats are added, the result is apt to be a serious case of indigestion. "Afternoon colic," as truckmen call it, often arises from this cause.

When the weather is very hot, the noon feed of the work-horse should be half oats and half bran.

\section{WATERING}

The theory that water given to the horse immediately after eating his grain has a tendency to wash the un- 


\section{THE ART OF DRIVING}

digested grain out of the stomach has been partly, perhaps wholly, discredited; but still, if the horse is at all inclined to be "washy," or loose in his bowels, he should not be watered for an hour at least after eating; and in all cases where a horse is to be used right after feeding it is much safer to water him before feeding; and not again until two hours after feeding. A horse should never start on a journey with a full stomach, or anything like it; and for at least an hour before starting he should not be allowed to eat or drink.

On the road the horse should be watered as often as possible. Water in moderate quantities, if not excessively cold, will do no harm, no matter how hot he may be, provided that he is kept going. But if he is about to stand still, or is at the end of his journey, he should receive only a few swallows. A horse in that condition can, however, safely be given a small drink of lukewarm water, and, twenty minutes or so later, another small drink of the same kind, and so on. Horses in general will drink tepid water as readily as if it were cold.

But much the better course is to water the horse, and let him have a good drink when you are, say, not less than two, nor more than four miles from home. This is the custom followed with the stage and post horses in Switzerland, to whom extreme care is given. If your horse is watered at the point just mentioned, the water in his stomach will be well warmed before he arrives, so that there will be no danger of a chill, and, on the other hand, he will not be thirsty when he comes into the stable, which is a great advantage. A thirsty 
horse, especially on a hot day, does not cool off well or quickly.

\section{BRINGING THE HORSE IN COOL}

It is needless to say that a considerate driver will slacken the pace for the last mile or two, so as gradually to cool the horse. This is important, for if the horse comes in with his blood heated, he will sweat in the stable, and it will be a long time before he recovers his normal condition. Moreover, the sudden cessation of hard work suddenly reduces the circulation of the blood in the feet, and that has a bad effect upon the delicate laminae inclosed in the hoof. But the cooling off process must be done with care. It does not mean pulling up when near home, and walking your horse in a cold wind. It means a slow trot, or alternate jogging and walking, or walking simply, according to the weather, and to the condition of the horse - always remembering that it is far worse to bring him in chilled, than to bring him in too warm. If, for any reason, a fast pace must be kept up until the end of the journey, the horse should be unharnessed when he comes to the stable, and walked about for twenty minutes at least, blanketed according to the weather. 


\section{CHAPTER XXVII}

\section{FARM HORSES}

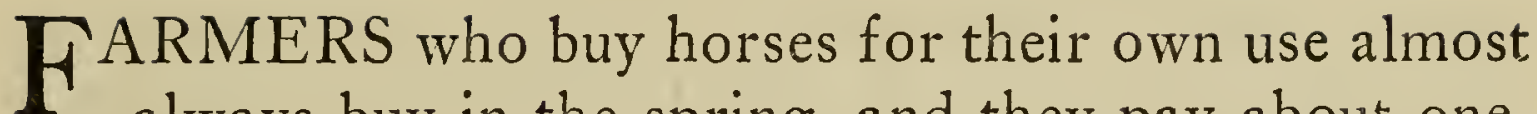
always buy in the spring, and they pay about onefifth more than they would have paid for the same animal in the previous fall $-a$ sum which usually exceeds the cost of wintering him. If the farmer bought in the fall he would have ready for his spring work an acclimated horse, fit for labor, and on terms of friendly intimacy with his owner. Whereas, buying in the spring, he has a fat, soft horse, almost always infected with distemper and often only halfbroken. Many of these green farm horses die of pneumonia, or are ruined by hard work, or by exposure to cold rain before they are conditioned and acclimated.

What has been said in the previous chapters about the care of horses, and also in the chapter on driving, applies, of course, to farm horses; but I cannot help adding a few words here. The work of the farm horse is much more irregular than that of any other horse, and for this reason his shoulders and back should be looked after with special care. Be sure that his collar fits - it is as bad to have it too big as too small. Be sure also that it does not "ride up"; and to prevent this, employ, if necessary, a martingale running from collar to belly girth, or an extra girth running from trace to trace back of the forelegs. In 
plowing or mowing (a mowing machine is particularly hard on a horse's shoulders), lift up the collar now and then to cool the shoulders, wipe off the sweat and dirt, and smooth down the skin. At noon take off the harness and sponge off all the harness marks with clean water; and do the same at night. If the skin is wrinkled, showing that there is inflammation, bathe it with witch-hazel. Examine the shoulders for sore spots, and, if you find any, alter the pressure of the collar so as to avoid them the next day. Some horses have naturally a very tender skin which can be toughened considerably by bathing it three or four times a week with salt and water to which a little vinegar has been added. Salt water - not too salt - is also an excellent antiseptic and healer for cuts and wounds.

It is hard for a tired man to spend any time over his horse at night, but he should remember that the horse is tired also. Give him what he has earned - a good cleaning, far more important at night than in the morning - a good, soft bed to lie on, and all the water he wants after eating his hay. ${ }^{1}$ That man is not to be envied or respected who can go to his own rest without first making comfortable the animal whose labor he exacts, and who is wholly dependent upon his care and mercy.

With these preliminary remarks, let us now take up the pleasant task of buying a pair of farm horses. It is hardly necessary to say that no one kind of horse is suitable for all kinds of farms. On the western prairies, where hills and rocks are unknown,

${ }^{1}$ See page 33. 


\section{FARM HORSES}

a much heavier horse can be used to advantage than on a rough New England farm. Another important consideration is this: are other horses kept for the road, or must the farm horses also be employed to take the family to church or market, and the young people to a dance now and then? In short, the farmer must ask himself, Do I need a farm draft horse, never to be driven faster than a walk, or a lighter, "general purpose" animal? If he decides in favor of the lighter horse, he cannot do better than to select a trottingbred mare or gelding of good bone and substance, weighing, let us say, I, I 50 pounds or more. Such a horse will do all that a $\mathrm{I}, 400$ pound draft horse can do, and much more besides. There are large farms in England where all the work is done by thoroughbred mares, and there are large stock farms in this country where all the work is done by trotters of purest blood. Some persons would go much farther and say that the trotting-bred is the best horse for any kind of farm; and on this point I will cite the interesting experience of Art Hinrichs, a well-known writer on the horse.

My people are of German origin, and when they emigrated to America they brought with them, at considerable expense, German horses. While the fathers lived none of the Hinrichs' farms were worked by anything but Holstein horses, and many a mile of good Illinois and Wisconsin soil was turned over by horses that were as typically German as the men who owned them. However, as the boys came into possession of the various farms of their parents they turned to the Percheron horse for improvement of the tribe imported by their parents. The result was surprisingly beneficial. They were a better class 
of horses and could do the work allotted to them much easier and more cheerfully, and likewise to the growth of various bank accounts.

But later still they traded or sold these horses and replaced them with big, strapping, standard-bred mares, some of them weighing as much as 1,300 pounds, and at this writing a total acreage of 2,700 acres in various farms are worked by standardbred geldings or mares - mostly mares. These wooden-shoe cousins of mine have found that a pair of 15.3 standard-bred geldings, weighing $\mathrm{I}, 200$ pounds each, can do anything that must be done about the farm as easy as a 1,600 -pound pair of "heavies" could do it, and a danged sight quicker. The same argument holds good in their experience with anything in the standard-bred tribe that weighs 1,100 or over and which stands $15.2 \mathrm{I} / 2$ hands or over. They want nothing on their farms but standard-bred workers. Besides, four quarts of oats go farther with the trotting-bred horses than six had served any of their predecessors.

There may be some exaggeration here, and I cannot help thinking that for deep plowing and pulling heavy loads and nothing else, a draft horse would be more efficient than the trotting-bred horse. Sixteen hundred, or possibly seventeen hundred pounds should, however, be the limit. Horses heavier than that are apt to be too slow and clumsy for profitable farm work, and they recover less quickly than the smaller draft horse from disease or injury.

There is one kind of draft horse that has been raised and used almost wholly for farm work, and that is the Suffolk Horse, formerly known as the Suffolk Punch. These horses have been bred for three centuries in the counties of Suffolk and Norfolk on the east coast of 


\section{FARM HORSES}

England, but very few have been exported. They are all of one color, being invariably chestnut, ranging from dark to light. They average about sixteen hands in height, and are not so heavy as the Shires and Clydesdales. They are round-built, stocky, shortlegged horses, with good heads, necks inclined to arch, and strong backs. They have less hair on their legs, and, in general, show more quality than English draft horses of other breeds. They are very good-tempered animals, thrifty and tough. The chief fault found with them is lightness of bone, especially in the forelegs. There are very few Suffolk horses in this country, and those that I have seen - not good specimens perhaps - were inclined to be coarse and phlegmatic. ${ }^{1}$

Setting aside the Suffolk Horse, there can be no question, I think, that the best farm draft horse is the Percheron or grade Percheron. ${ }^{2}$ They are quickermoving and lighter on their feet than any other draft horse, with the possible exception of the Clydesdale, and they are, as a rule, more easily kept than the Clydesdale, sweeter in disposition, and certainly more beautiful.

This last consideration is not to be despised. We hear much of late years about retaining the boys and girls on the farm. The best way to do that is to have every animal on the farm an object of pride and pleasure for the whole family. Let your horses and cattle be beautiful as well as useful, and then the business of farming will be lifted from the muck heap and the ditch into the region of the ideal and eternal.

${ }^{1}$ See page 209. 2 See page 205. 


\section{CHAPTER XXVIII}

\section{SADDLE HORSES}

EVERY young horse should be taught to carry a man on his back, for no one can tell when the necessity for riding him may arise. But not every horse is fit for saddle work. A horse with straight shoulders, and especially with the low withers which usually accompany a straight shoulder cannot, as a rule, carry a man on his back without discomfort and even injury. It will be found that such horses dislike to be ridden, although they may submit to it. Whereas, a horse properly shaped for the saddle almost invariably likes that kind of work after he becomes used to it. It is easier for him to carry a man of moderate weight, say I 60 pounds, than to haul the same man in a vehicle weighing two or three hundred pounds.

But the horse should be ridden at first by a light man or boy, at a slow pace, and for short distances. $\mathrm{He}$ must learn the knack of carrying weight, just as a porter must learn the knack of carrying a heavy trunk on his shoulders. This is especially true of horses not saddle-bred. I have seen big, strong carriage horses almost staggering under the weight of a man when they were first ridden, every leg being moved and every foot put down in an unnatural way. It is, of course, very easy to strain a horse under such circumstances. Perhaps the reason why straight-shouldered, low-withered 
horses dislike to be ridden is that the weight of the rider comes almost immediately above their forelegs and feet, so that they are over-loaded in those parts.

Here is a rule which has few exceptions: The horse that goes down hill easily at a walk or trot has the making of a saddle horse. There is a great difference among horses in this respect as the reader knows. Some horses, not always the small ones either, seem to travel down hill almost as easily as on level ground; whereas others descend a hill in a hesitating, awkward and often in a sidelong manner as if they feared a fall. These horses are not fit for the saddle.

Roughly speaking, the qualifications of a saddle horse are as follows: I, sloping shoulders; 2, fairly high withers; 3 , a springy pastern; 4 , strong but small feet; 5 , a short back; 6 , a head well carried; 7 , a fast walk.

The necessity for a sloping shoulder and good withers has already been stated. But the withers should not be too high. High and prominent withers are very apt to become galled by the saddle, and horses so formed are wholly unsuitable for cavalry purposes.

The springy pastern is essential to the comfort of both horse and rider. A short, straight pastern has the effect of jarring both hoise and man, and the concussion thus caused is bad for the horse, tending especially to injure his fore feet, and to cause unsoundness in the joints of his hind legs, particularly the hock. A pastern too long is bad also, because of the danger of "breaking down." 
A short back is preferable for obvious reasons, but a long back may be a strong one, and this rule as to short backs is subject to many exceptions. A famous English rider to hounds remarked, toward the close of his career, that the best three hunters he had ever owned each had the fault of being over long in the back.

It may be added that a horse with a long back looks much better under a side-saddle than a short-backed one.

A back slightly hollow, rather than a perfectly straight or roach back, is preferable in a saddle horse, for it is associated with an easy gait.

As to action for the saddle, it may be long or short. Some riders prefer one, some the other. But for carrying a heavy man, and for endurance a short-stepping horse is the thing. Whatever the length of the stride, the horse should have sufficient knee action to make him sure-footed. Many low-going, "daisy-cutting" horses have great strength of legs and feet, and very seldom stumble; but, sooner or later, they are pretty sure to trip over some obstacle and bring the rider to the ground.

Hock action adds greatly to the beauty of a saddle horse, and, if not excessive, it makes him easier to ride at the trot; but for endurance the less hock action the better.

No attempt will be made here to instruct the reader in the training of saddle horses. There are many excellent treatises on that subject. A few words, however, about breaking the colt or young horse to ride will be 


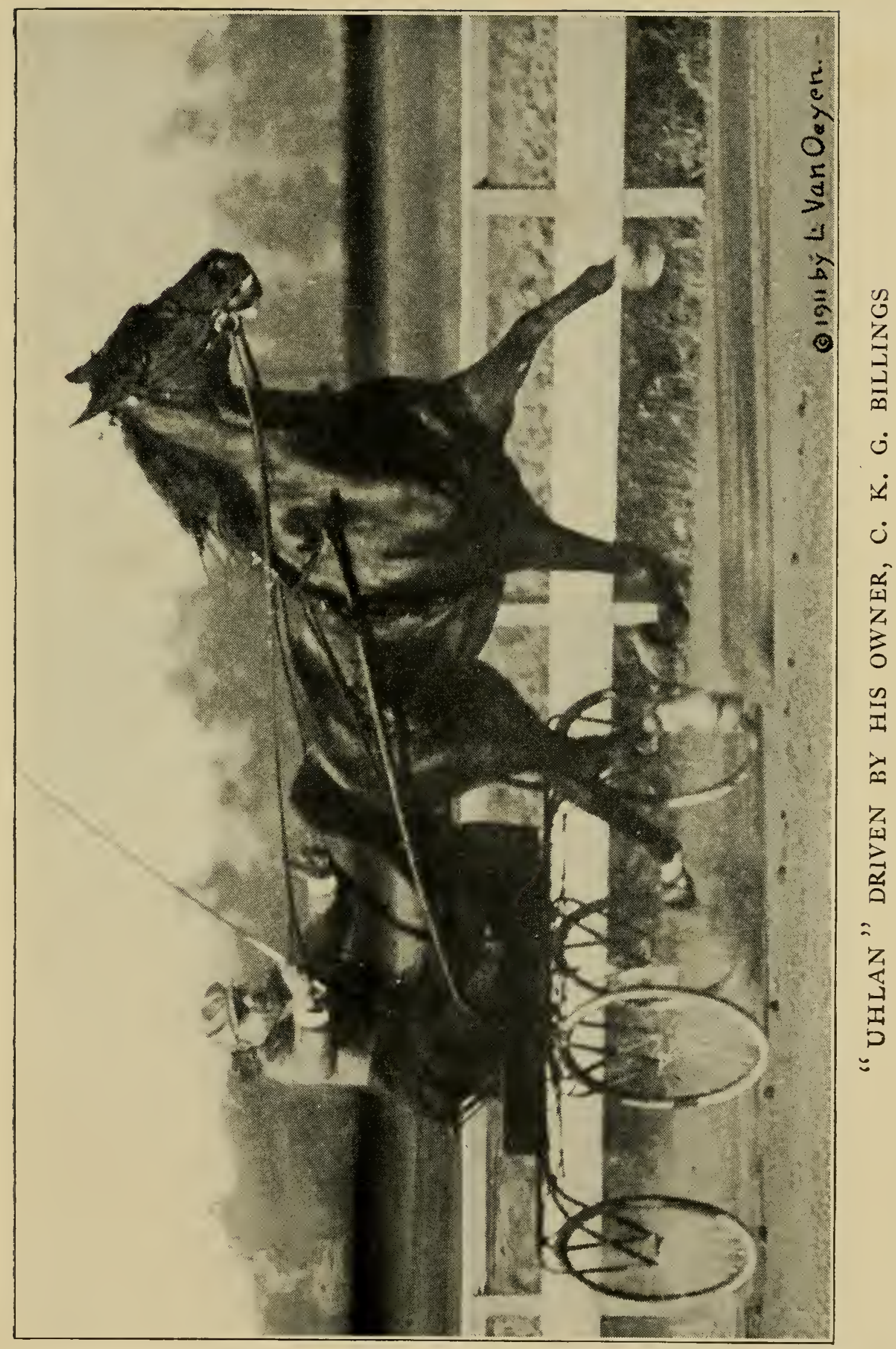



within the scope of this book. Great pains should be taken not to frighten the horse when you first get on his back. The methods of the "broncho-buster" afford an opportunity for the display of courage and skill on the part of the rider, but they do not make good or trustworthy saddle horses. Give the horse his first lesson in a stable, carriage-house (emptied of carriages), or other enclosed place, where he cannot get away, or injure himself. John Porter, the famous English trainer of race horses, whose home is near the downs of Hampshire, always has the yearlings in his charge saddled and ridden for the first time in what is called the Punch-Bowl - a round hollow in the hills the sides of which are so steep that it is easy to prevent a colt from ascending them.

If the horse is a timid, nervous animal, it is not a bad plan to begin in this way: Tie him on each side with a strong headstall and halter ropes as if you were going to clean him. Then, in a slow, quiet way, and after much talking to the horse, accompanied by the feeding of apples or sugar, slip on his back, by means of a box or block placed alongside, or have some one boost you on. The horse may plunge violently for a few minutes, but that will do no harm, and after a lesson or two, he will cease to be afraid, and will not lift a foot during the operation. One advantage of this method is that the horse will probably acquire the habit of standing perfectly still while the rider is getting into the saddle - a great convenience to the latter.

Most American-bred horses are so gentle and intelligent that they are easily broken to ride; but still 
precautions should be taken to avoid any contest or scrimmage, the bad effects of which might be lasting. Therefore, if you do not begin in the manner just described, let some one hold the horse while you get on his back, and if he is in the least a fractious or timid animal, there should be a third man to help you in mounting. No doubt you could jump or scramble on without assistance, but the object is not simply to arrive on the back of the horse, but to get there without alarming or exciting him.

In all cases, it is best, I think, to ride the horse for the first time, or rather to sit on him in the stable, without a saddle; or else to saddle the horse first, and lead him about pulling at the stirrups, etc., before you attempt to mount. The reason is that the saddle may frighten the horse, and you do not want to give him two scares at once. The creaking of the leather of the saddle when the rider takes his seat terrifies some horses, much more than any other part of the performance. Others are frightened or irritated by the tightening of the girths. The Badminton book on riding says :

Many a buck-jumper would never have learned the habit, had he been carefully trained to carry a saddle before he was mounted. . . . . There is nothing more inconvenient than having a horse that is bad to mount, and, as a general rule, the reason is that the animal was not handled with sufficient care and patience in his first lesson.

Do not, by yourself, ride the horse out of the stable or other place in which you have mounted, but let your assistant lead him out, and lead him around, you sitting 
in the saddle and holding the reins, until it is plain that the horse is reconciled to the situation. ${ }^{1}$

Some horses are all right from the start, but others should be led around for several days before they can safely be left to the guidance and control of the rider.

A man can learn to ride, and to ride well, without any instruction; but the self-taught rider may fall into bad habits without knowing it. Much can be learned by observing the position on horseback of a good rider, or even by looking at the picture of one. The Greek riders shown on the frieze of the Parthenon, photographs of which abound, are models in this respectas much so today as they were when the sculptor carved them, some 2,00o years ago. The Greeks had no saddles, and needed a good seat.

To ride properly, a man must sit well down in the saddle, cling with his knees, and abstain absolutely from holding on by the reins. Below the waist his position should be firm and fixed; above the waist his body should be flexible, moving as the horse moves. The toes should be turned almost straight forward, and in that position, if the horse makes any sudden plunge, or other movement, the rider instinctively tightens the grip of his knees, and remains in the saddle, instead of being thrown out of it. A man who rides with his toes turned outward never has a safe seat. It is almost as bad to lean forward over the pommel

1 The writer confesses that, shortly after this paragraph was written, he did exactly what he here advises should not be done, and, in consequence, was thrown from the top of a bank into the bottom of a ditchbut without serious injury. 


\section{THE HORSE}

of the saddle, for if the horse falls the rider is likely to break his neck. Such was the fate of Samuel Wilberforce, Bishop of Oxford, a bold, but bad rider.

Some men sit heavily in the saddle, as inert as a bag of meal; and they make a hard load for the horse to carry. Whereas a rider who sits lightly in the saddle, and moves as if he were a part of the horse himself, is carried with comparative ease. Both for the comfort and for the general appearance of the horse, it is essential that he should be ridden with a light hand. A heavy hand hurts his mouth, spoils the carriage of his head, and interferes with his natural action. Most rearing is caused by heavy hands. Horses seldom rear with women.

The elbows should always be kept in and the hands should be held as low down as possible - nearly or quite touching the pommel of the saddle or the withers of the horse. If the hands are kept down, the bit will remain in its proper place, that is against the back of the mouth; whereas, if the hands are raised, the bit will press against the upper part of the jaw - a position which is uncomfortable, if not actually painful for the horse. One often sees a rider with his hands held high, and the horse with his mouth open, his ears turned backward, his neck stretched upward, and a general expression of misery.

How can a good seat be obtained? By riding bareback, or, perhaps better, by riding at a trot on a smooth saddle, without any stirrups - in each case religiously refraining from holding on by the reins. It is hard work to ride for any distance on a saddle without 
stirrups; but the young man who is ambitious to become a good rider will not mind that.

As to the saddle itself, let it be as simple and light as possible. For ordinary purposes a man should disdain the protection and support of what is known as a Mexican saddle, and should use the plain English saddle, with or without flaps, and with no housing on the stirrups. The stirrup leathers should be so attached that they will pull out of the saddle in case the rider is thrown. An important question is this: Should the ball of the foot only, or the foot itself, as far as the instep, be thrust into the stirrup? The latter method certainly gives you a firmer seat in the saddle, and more control of your horse. Hunting men and jockeys always ride in that way. But for ordinary riding, and especially for riding long distances, the ball of the foot only should rest in the stirrup. That position is less fatiguing than the other because it gives the leg an additional leverage of three or four inches, so that the strain upon the muscles of the calf is very much less. Cavalrymen and herdsmen always adopt this position. But every rider should, of course, be equally at home with both positions of the foot.

Something of the same sort might be said about the difference between rising in the saddle at the trot, technically called "posting," and sitting close to the saddle. Posting is much easier for the man, and far less fatiguing both for him and for the horse; but every rider should be able to sit close, and at a slow trot, say five or six miles an hour, he will look better in that position. Still, even at that rate of speed, the 
horse would prefer to have him "post," and he should do so when any distance is to be covered.

For long distances the walk and the trot are the proper gaits, and the rate, for most horses, should not exceed five or six miles an hour. An occasional canter up a slight hill is allowable because it brings into play different muscles, and is therefore in a way restful to the horse; but the canter is a much more fatiguing gait than the trot, partly because in this gait the horse at times has only one foot on the ground, and still more because at every step he is obliged to lift his own weight, and the weight of the rider, considerably higher than he is obliged to lift them at the trot - in other words, he does so much more work. The pace and the amble are also fatiguing gaits and should be used very little, if at all, on long journeys.

Of course it is a great relief to the horse for the driver to dismount occasionally and walk, especially going up hill, and still more going down hill. In descending a hill, the weight of the rider presses unduly on the fore legs and feet of the horse, and the rider should prevent this as far as possible by leaning backward in the saddle.

The great thing is to ride the horse all the timenot simply to stay on his back, but to ride him, sitting lightly but tensely in the saddle, feeling his mouth gently, sympathizing with him at every step, and indulging him with a walk or a rest, accordingly as you feel that he needs it. To ride carelessly or to loll in the saddle is to fatigue the horse; and to sit sideways, as men sometimes do to rest their tired muscles, is an act 


\section{SADDLE HORSES}

of positive brutality, for it is almost sure to result in a sore back. Nothing could be more unsportsmanlike. In reading of famous running races, especially of those three and four mile races which created so much excitement in former days, one often comes across the statement that such and such a horse was beaten because the rider tired - not the horse but the rider; and a tired or careless rider handicaps a horse on a long journey as much as in a race.

When the saddle horse comes in, pains should be taken to avoid a sore back. The best method is to remove the saddle, and at once wipe off the sweat under saddle and girth with a wet sponge, using cold water. Then rub the back lightly with a towel, so as to dry the hair in part, and after that, put on the horse's blanket. Much rubbing should be avoided, for it tends to make the skin sore; and, moreover, you do not want to leave the back uncovered very long.

If the weather is so warm that the horse does not require a blanket, place on his back, where the saddle comes, a light woolen cloth or a towel fastened loosely with a surcingle, or, if you have nothing else, use the saddle cloth, or the saddle itself.

The object of this whole treatment is, first to remove the salt sweat, secondly to close the pores of the skin, and thirdly to dry the hair. ${ }^{1}$

If the horse has naturally a tender skin, it can be

1 The horses used by the mounted police in Boston are very free from sores, and their treatment is to remove the saddle at once, wipe off the back with a mixture of water, witch-hazel, and salt - and do nothing more. 
toughened somewhat by washing his back with salt and water; but this should be done when the horse is cool. A leather saddle pad, with ventilating holes in it is lighter, more easily cleaned, and more durable than any other saddle pad, and is the best thing of the kind for ordinary use. But for long journeys, something more substantial and softer may be required, either a thick felt pad or a woolen blanket carefully folded. 


\section{CHAPTER XXIX \\ THE CAVALRY HORSE}

THERE is every reason to believe that in the ruture 1 a large force of cavalry will always be maintained by the United States Government, and it is extremely improbable that horses for this purpose will be bred in any number by the Government itself. They must therefore be raised by farmers and other private persons.

What is a cavalry horse? We used to hear of heavy cavalry and light cavalry, the heavy cavalry composed of big men on stout horses and used chiefly for charges against infantry. But the improvements in modern artillery have rendered heavy cavalry. of doubtful value for this purpose; and, it seems likely that in the future light cavalry only will be employed. Even light cavalry, however, is light only by comparison; for the light cavalry horse must carry a trooper weighing, say, one hundred and fifty pounds, and at least ninety or one hundred more in the way of blankets, clothing, arms, ammunition, and so forth. The cavalry horse must not only be able to carry this load for long distances, but he must also be tough enough to stand exposure and hardship, and to subsist upon insufficient food and water. For this purpose, as most authorities agree, there is required a rather short-legged horse standing not over I 5.2, with deep lungs, a short, strong 
back, well ribbed-up, the best of legs and feet, a fairly sloping shoulder, a neck of good length, and a head carried high, and showing intelligence, docility and energy.

The Cossacks, as everybody knows, are famous cavalrymen, and Mr. A. B. Maclay, an authority on this subject, says:

I never saw a Cossack riding what we call a big horse, but plenty of them ride "big little horses." That is to say, sturdy, thick-set horses with great depth of body set upon short legs.

How can such horses be bred? There is much difference of opinion upon this point, even among officers of the United States cavalry. The following breeds or cross-breeds all have their advocates: the thoroughbred, the thoroughbred crossed with other horses, the Arab, the Kentucky saddle-bred horse, the Morgan, the trotter.

The thoroughbred is probably the least adapted of all for cavalry purposes. He is a racing machine, and too thin-skinned, nervous, and irritable to make a good campaigner. On this subject Francis $M$. Ware states his experience as follows:

In keeping riding schools in Boston, Newport, and New York for about twelve years, I tried in vain to make the thoroughbred a useful horse. I used from fifty to seventy horses generally. Riding-school work is not unlike active campaigning. The horses must do all they can do, day in and day out, often thirty and forty miles a day under heavy weights. Not a thoroughbred did I ever find out of hundreds of them that would stand the work for any extended period. They would not endure such work as any ordinary school horse would. 
They did not eat; they shrank to nothing in flesh where other horses kept fat and fresh; they chafed everywhere the saddle or girths touched them; the insects drove them wild; they would not stand crowding in drills without kicking; they were not trustworthy at any time; they stumbled very generally; they went lame frequently and stayed lame persistently; they had no decent fast trot, and usually a lounging walk which patrons did not fancy. In the course of the business I leased many horses to go to camp for a week or so with the militia. Every time I included thoroughbreds in the list they were condemned for making trouble on the picket line and at drill, and they came home with their withers, backs, and elbows sore from the saddles and girths. These are the cold facts. An ounce of experience is worth many a ton of theory.

Mr. Ware cannot be suspected of any prejudice against the thoroughbred, for he prefers him as a saddle horse for his own use.

Gen. John B. Castleman of Kentucky takes the same view of the thoroughbred. He writes:

His breeding and training for generation after generation have fitted him for the running turf and have unfitted him for general use. .... Some cavalry officers without experience in the field, have persuaded themselves that a cavalry horse must be a jumper, and therefore that the thoroughbred is indispensable. The number of horses that make jumpers is in proportion as small as is the number of soldiers that make good officers. To practical cavalrymen it seems useless to injure horses' legs and shoulders by teaching them to jump.

The thoroughbred crossed with other horses sometimes produces a tough, serviceable animal, but in most cases the result is a weedy, leggy horse, with poor bone 
and defective stamina. Here again we may cite the authority of Mr. Ware. Some years ago the New York Jockey Club placed a number of thoroughbred sires at the service of farmers in different parts of the state. Mr. Ware says:

An inspection of the 3,000 or 4,000 animals resulting from this line of breeding will well repay any thoroughbred horse fancier, and especially those who are so actively booming the thoroughbred as a progenitor of cavalry horses. I have seen many of these horses sold around three years old at twenty to fifty dollars.

M. T. Grattan, a well-known breeder and user of horses, himself a veteran of the Civil War, relates his experience with the thoroughbred cross as follows:

Many years ago I bred a lot of tough, hard-bottomed road mares to one of the best thoroughbreds I ever looked at Le Clair by Lightning, a son of Lexington; dam, Eloise by Ebony. My road work in those days before railroads was long and arduous, both in saddle and harness. The half-breds were in no instance equal to their dams under saddle or in harness, or equal to their dams' produce by Black Hawk and other Morgan sires. In only one quality did they excel - they could sprint a half-mile, and some of them a mile.

The Kentucky saddle horse has size, beauty, and sufficient speed, but he is deficient, I think, in the quality most important for a cavalry horse, namely, toughness. He inclines rather to the long than to the shortlegged type, is, it seems to me, a little light through the loins, and in general appearance suggests a horse intended rather for pleasure than for hard campaigning 
on short commons. This remark does not by any means apply to all Kentucky saddle horses, for there are many stoutly bred animals among them, but it does apply, I think, to the majority of them.

The Arab horse has always been used for riding and nothing else. He has very great endurance, intelligence, and docility, can subsist on meagre fare, and is in every respect strong and serviceable. But the poor trotting gait of the Arab must count against him as a cavalry horse. In long or forced marches, an occasional canter is permissible on an up-grade, but the main reliance must be on two gaits only, the walk, and the trot. Now the Arab has never been trained to trot, and is stiff-legged at that gait, with, of course, no speed whatever. The Arab would be extended at seven or eight miles an hour, whereas the trotting-bred horse, being capable of ten or twelve miles an hour, will do eight miles easily.

But, whatever the merits of Arab horses, there are so few of them in this country, and so few obtainable, even in Arabia, that for the present, at least, we must look elsewhere for our supply of cavalry horses.

Much resembling the Arab is the Morgan - and the Morgan horse proved his worth in the Civil War as a cavalry horse. The First Vermont Cavalry, a regiment that was recruited in October, I86I, and served throughout the war, made a remarkable record for efficiency, and all the horses were Morgans bought in the northeastern part of the state, except a few that were procured in New Hampshire on the other side of the Connecticut River. The Newark [New Jersey] 
Advertiser of December I7, I86I, describing the march of this regiment through the city of Newark on its way to Washington, said:

The Green Mountain boys arrived about four o'clock, and marched up Market Street amid the liveliest tokens of enthusiasm. The horses are small; but compact and sinewy, and evidently capable of great endurance. It was the general remark that so splendid a body of animals had never been seen together in this city.

One of the best-known riders in the United States Army is Lieutenant Ralph M. Parker, who for several years was stationed at Norwich University in Vermont - a state institution of semi-milicary character. At this school the students are instructed in riding and in cavalry drill, Morgan horses only being used, and Lieutenant Parker, in a recent number of the American Horse Breeder, thus describes his experience with them:

While, as a rule, for military purposes many of them possess backs a trifle longer than the ideal cavalry back, and the withers are often a trifle low, the other physical qualifications far more than offset these imperfections, which exist in only a portion of the breed. They are low and well-rounded, heavily muscled, but with fairly clean limbs, and generally possess conformation insuring considerable agility, endurance, and forage economy. Their heads are beautiful, ears small and well set on with an air of alertness that is one of the attractions of the Morgan. The forehead, with its pronounced Morgan form, is indicative of a large brain, while the eyes, muzzle, nostril, jaw, and the manner in which the head is usually put on, with a neck of medium length and excellent shape, sloping shoulders, fine 


\section{THE CAVALRY HORSE}

barrel, legs that are well-muscled from the knee and hock upward, with short cannon bones and small, well-proportioned feet under pasterns of proper length, give us little to criticize in the Morgan.

I will in justice, however, mention the points that to me are a little objectionable in the general run of Morgans. Many of them are small under the knee - not short, but what is known as "tied in." Also the pastern is usually too nearly vertical, which might appear to be indicative of an undesirable quality in a mount. Seldom, however, does this produce the effect of a rough gait, as might be expected. The Morgan steps daintily and moves with the grace of a dancer. The Morgan trotting stock has the most beautiful action in the world.

I have seen Morgans perform wonderfully in an endurance test where they were ridden one hundred and fifty-four miles in about thirty-one hours, from which they emerged in excellent condition and took prizes in saddle classes the next afternoon. I have had them compete successfully in jumping contests with thoroughbred mounts of some of the best horsemen in the army. I have used them in cavalry drill, on practice marches, and in every sort of work that cavalry might be called upon to do with its mounts, including cross-country riding, with obstacles difficult for any horse to pass, and always with great satisfaction.

There is in this country only one possible superior to the Morgan horse as a cavalry steed, and that is the trotting-bred horse. The perfect cavalry horse should be, I think, a horse of I,050 pounds; and very few Morgans reach that weight. This matter of weight is very important. Many persons think that a well-bred polo pony would make an ideal cavalry horse; but a 
high-strung pony capable of carrying a heavy man through a half-hour of strenuous play, might not, and probably would not be capable of carrying the same man forty or fifty miles a day.

A trotting-bred horse, with one or more Morgan crosses, will have the desired weight in addition to the good qualities described by Lieutenant Parker. The Morgan cross is prominent in many of our best trotters, so that the material for breeding cavalry horses is ready to hand.

There is one criticism sometimes made both of the Morgan and the trotting-bred as saddle horses. No horse, these critics say, is fit for riding, unless he has the extreme sloping shoulder of the thoroughbred and of the Kentucky saddle horse. This kind of shoulder is absolutely necessary, they declare, because without it, a horse will neither be easy to ride, nor capable of carrying weight. But experience does not seem to bear this out. The Morgan cavalry horse in the Civil War, our cavalry in the recent expedition into Mexico, the mustang and the broncho-- the Arab himself - all these animals are examples of endurance and serviceability, notwithstanding the absence of the extreme sloping shoulder.

Not the slightest attention has been paid by American breeders to raising trotting-bred saddle horsesthey have been regarded as mere chance by-products; and yet the trotting-bred saddle horse has already made a reputation for himself, not only in this country but in England and in Russia.

A charger used in the present war by General Sir 


\section{THE CAVALRY HORSE}

John French who, until a recent date, commanded the British Army, is a stallion of the Baron Wilkes family, presented to him by an American friend. Trottingbred horses by the thousand were exported during the years I9I4, I9I5, I9I6, for the use of the allies, and we shall hear about them later.

The trotting-bred horse has more endurance and a better temper than the thoroughbred, more toughness than the Kentucky saddle horse, more size and more speed than the Arab or the Morgan. 


\section{CHAPTER XXX \\ THE ARABIAN HORSE}

M ORE generous lies have been told about the AraMian horse than about any other animal in the world. The Arabian has so noble a character, so pleasant a disposition, and so much beauty that he has always excited a peculiar admiration and affection. For intelligence, for soundness, and for endurance the Arabian has no superior and perhaps no equal, unless it be the Morgan horse. It is often remarked by men who have had a wide experience with horses, that when any great feat of endurance is performed by a horse, it is apt to be discovered that the animal has a strain of Arab blood pretty close up in his pedigree.

Moreover, the great antiquity which the Arabomaniacs have always asserted for their favorite horse appears to be an historical fact. There is no higher authority on these matters than Prof. H. F. Osborn, and he is convinced that the Arab horse is different anatomically from all other horses, and had a different origin. He says:

We may regard it as settled that the Arabian is a very ancient breed, including characters which were strongly established in a natural state before domestication by man, and which, therefore, are extremely stable in heredity and cross breeding. . . . . This breed has been an uplifting, ennobling quality which has been introduced in the blood of commoner horses for a period dating back from I 600 to 2000 B. C. 
And yet it is doubtful if at this late day any modern breed of horses can be improved by Arab crosses. The thoroughbred horse is founded on the Arabian, so even is the Percheron; and so are the trotting-bred and Morgan horses, the two latter having derived their Arabian blood mainly by way of the thoroughbred. The thoroughbred horse of the eighteenth century was very close to the Arab foundation and resembled the Arabian in size and shape; but the modern thoroughbred is a whole hand, if not more, taller than the Arab, and shows hardly a trace of the Arabian foundation except, perhaps, in the shape of his head and in the fineness of his bone.

The Arabian horse stands from fourteen to fifteen hands high, but is usually much nearer fourteen than fifteen. He is easily recognized by the setting on of his head and neck, and by the roundness of his haunch. The walk of the Arab is very poor, being a careless, stumbling walk much like that of the thoroughbred horse but even worse. His trot is very poor, for he goes in a stiff-legged fashion and is used so little on the trot that he really has no trotting gait at all. He has, of course, a springy canter, but his speed at a run is far less than that of the thoroughbred.

The color of the Arab is usually chestnut, gray, or bay. The Arabs, like most other people, prefer the bay color. Black is rare and considered to be an inferior color. White horses are highly thought of by the Arabs, but seldom occur. Roans, piebalds, duns, and cream-colored horses are never found among purebred Arabs. It is commonly supposed in this country 
that certain spotted horses are of Arabian blood, but no pure Arab was ever of that color.

Some fifteen years ago the writer visited the stud of Mr. Wilfred Blunt in England, who then owned the largest and best collection of Arab horses in that country. It was noticeable that the finest of these Arabs were chestnuts, and Mr. Blunt agreed that this was the case. Fleabitten grays and iron grays are not uncommon in Arabia, and the most beautiful horse that I have ever seen was a gray Arabian. This was Shahwan, a horse foaled in 1887 , imported from Arabia to England by Lady Anne Blunt, and brought to this country in the year I 895 by Mr. J. A. P. Ramsdell of Newburgh on the Hudson. Mr. Ramsdell is well known as a breeder of Arabs and other saddle horses.

For information about Arabian horses, the reader should apply to Mr. Spencer Borden of Fall River, Massachusetts. Mr. Borden has written an interesting book on the subject, and has owned, raised, and ridden many Arabian horses. 


\section{CHAPTER XXXI}

\section{THOROUGHBREDS}

THE word "thoroughbred" means literally pure1 bred, and any pure-bred animal, as distinguished from a mongrel, is a thoroughbred.

But in horse parlance the word has a very restricted meaning. A "thoroughbred" is a running-bred horse whose ancestors on both sides for seven generations are recorded in the English stud-book, or whose ancestors on both sides are recorded in the American stud-book for five generations. A trotting-horse may have a pedigree as long and as good as that of any "thoroughbred," but he is never spoken of as a thoroughbred, except by writers of stories whose heroes always drive "thoroughbreds," if they drive anything at all in the shape of a horse.

There is a marked resemblance between some thoroughbreds and some trotters. The Duke of Magenta, for example, a thoroughbred horse owned by the late W. H. Forbes, might easily have been mistaken for a trotting-bred stallion.

But, as a rule, the thoroughbred can be distinguished at a glance from other horses. The modern thoroughbred is a tall, slim horse, standing from fifteen to sixteen hands, and often even taller. He has a fine, short coat, thin mane, a bony head, good ears, a long and usually straight neck, high withers, small feet, 
straight hind legs, and a slim tail, well set on. The shoulder is usually sloping, but one occasionally sees a thoroughbred with rather straight shoulders, and even the sloping or "pacing" rump, as we call it in this country, is not uncommon. The thoroughbred is usually slow and stiff-legged at the trot, and he has a peculiar long, slouching, shambling walk. In fact he often trips and stumbles while walking or trotting, but he is usually quick enough to recover himself without actually falling.

The thoroughbred is of course founded chiefly on the Arabian horse; and in the eighteenth century he closely resembled the Arabian, being a small, compact animal with more graceful lines and more beauty than he now possesses. By careful breeding, by high feeding, by much severe training and racing, the thoroughbred was gradually transformed, pulled out and straightened out, as it were, until he became a tall, leggy animal of the greyhound type. In the past one hundred years, the average height of the thoroughbred has increased at least four inches - in other words, from a small horse he has become a big horse.

In the eighteenth century and in the early part of the nineteenth, long-distance running races were very common. The match races in this country that created so much excitement in those days - especially the contests between the North and the South, when the gentlemen of New York State matched their money and their horses with the gentlemen from Virginia, Kentucky, and South Carolina - those famous races that still live in turf history, one of which the celebrated Hiram Wood- 


\section{THOROUGHBREDS}

ruff went to see as a small boy, and was soundly whipped for it when he came home, as he relates in his autobiography - these were races of three and four miles, and not only that, but they were run in heats, "the best two in three." Races of this kind, and still more the training that preceded them, developed a very powerful animal of great endurance. Such was the gelding called Wagner that carried the Confederate general, Abe Buford, a man weighing 300 pounds, all through the Civil War.

But in recent years short races have made speed more important than endurance in the thoroughbred, and that horse is, for the most part, different in type from his ancestors of fifty years ago.

The trotter is of course founded largely, one might say mainly, upon the thoroughbred, but the trotter has improved immensely during the past fifty years, not only in speed, but in quality and endurance; and it now seems fair to say that the trotting family is superior to the thoroughbred even in endurance. The long races and severe scoring to which the trotter is subjected have no parallel in the work now required of the runner.

In short, the thoroughbred has ceased to be necessary as a "foundation" horse or as a "cross" except in respect to horses whose business it is to run and jump. As a running race horse he far excels all other breeds in the world; and, more and more, polo ponies and hunters are bred from thoroughbred stock. But for the improvement of harness horses the thoroughbred is no longer necessary or useful. For that purpose the trotting-bred horse has taken his place. 


\section{CHAPTER XXXII \\ THE MORGAN HORSE}

$7 \mathrm{HE}$ Morgan horse is a New England product and 1 might be described without much exaggeration as an Arabian horse adapted to New England life and climate. In October, I 780 , a very beautiful thoroughbred stallion, called True Briton, and afterward Beautiful Bay, was stolen from a King's officer, Colonel James De Lancey, at West Farm on the Bronx River, by some patriot, who mounted the horse, ran him across the bridge, and thence escaped to Connecticut. This horse was the sire of Justin Morgan, founder of the Morgan family. True Briton was a small horse, as all thoroughbreds were at that time, being close to the Arabian stock, and he was described in an advertisement of that date as "very light at the canter and at the trot." This lightness of step is inherent in the Morgans down to the present day.

It is not known certainly what was the dam of Justin Morgan. It has been said that she was by Lindsey's Arabian, a famous horse imported to Connecticut and afterward taken to Virginia. Others have asserted that the dam of Justin Morgan was by Wildair, an imported thoroughbred; others have declared, but without proof, that she was a Canadian horse of Norman stock; and others again contend that she was sired by a Dutch horse. Dutch horses, not unlike the Mor- 
gans in shape and size, but lacking their energy, were often imported to this country at that time and are still to be seen in Holland. However this may be, the son of True Briton proved to be extremely prepotent, and his chief characteristics are reproduced in his descendants today. Even horses with only one sixty-fourth of Morgan blood often show a distinct Morgan type. The founder of the family was foaled in West Springfield, Massachusetts, in or about the year I789. At the age of two he was taken in part payment of a debt by Justin Morgan, a schoolmaster from Vermont, who immediately brought the horse to his home in Randolph in that state. Until the schoolmaster's death in I795, the horse was used by him chiefly as a saddle horse; but after that he passed through many different hands, and led a rather hard life. He died in Chelsea, Vermont, at the age of thirty-two, his death being caused by a kick from another horse; and even at that age he is described as being perfectly sound and smooth. After Mr. Morgan's death he was known at first as the Goss horse, and, later, as The Justin Morgan.

Justin Morgan stood about fourteen hands, and weighed about nine hundred pounds. He was a chunky little horse, with short, clean, flat legs, good but small feet, and round quarters. He had a heavy mane and tail, a short, strong back, a wide, deep chest, a rather long body, sloping shoulders, a rather short neck, well set on, a well-shaped ear, a fine, bony head, carried high, and eyes as intelligent, expressive, and courageous as ever kindled in the head of a horse. D. C. Linsley, in his work on the Morgan horse, 
published in 1857 , and still the main authority on the subject, relates that a lady of St. Johnsbury once told him that, as a girl, she had often ridden Justin Morgan to balls and other entertainments, and that she could never forget "his noble appearance, his high spirit, and perfect docility."

Morgan horses became exceedingly popular in the first half of the nineteenth century and were extensively bred and used not only in New England, but in many parts of the West, and also in Kentucky. They were almost equally good in harness and under saddle, and were extremely courageous, gentle, intelligent, and enduring. They made ideal chargers for dashing militia colonels, and in the Civil War they proved to be more enduring than any other horses used by cavalry on the northern side. The horses used by the First Vermont Cavalry were all Morgans, and they made a remarkable record for efficiency and endurance.

Wonderful stories of Morgan intelligence and courage are still told by the dim light of a lantern in many a country livery stable of northern New England. Not a few of these stories relate to midnight rides in storm and darkness by country doctors; and it was a country doctor who thus described the roadster qualities of the Morgan horse:

The Morgan will trot all day except when ascending a hill. As he approaches it, he will raise his head higher and higher. First, one pointed ear, then the other, will snap backward, then forward, as if he were asking permission to gallop, and then, if the driver does not object, he will lay both ears flat to his 
head, and skim the rise like a bird, always striking into the same tireless trot when he reaches the summit.

Justin Morgan's blood was transmitted mainly by three sons, Sherman, Woodbury, and Bulrush. Sherman was a bright chestnut horse, standing only about I 3.3 and weighing about 925 pounds. Woodbury was a dark chestnut, standing I 4.3 and weighing about I, 000 pounds. Bulrush was a dark bay weighing a little over I,O0o pounds. From Sherman are descended Black Hawk, Ethan Allen, ${ }^{1}$ and Daniel Lambert.

Black Hawk sired Vermont Hero, and Vermont Hero was the father of General Knox, whose family flourished for many years, especially in Maine, and proved to be extremely useful horses.

From Bulrush were descended the Fearnaught and Winthrop Morrill families. These were both highstrung and beautiful strains, and remarkable for their roading qualities; but they are nearly extinct, and the Morgan horses now bred are mainly the descendants of Sherman, and especially of Ethan Allen. Ethan Allen was a beautiful little bay horse, very speedy, a delightful roadster, and attractive in every way. His dam was a gray mare of unknown breeding; but it is

1 The fame of Ethan Allen, the man, was almost eclipsed by that of his namesake, the horse. Not many years ago the late Luke P. Poland of Vermont, entertained at his home in Montpelier a fellow-member of the United States Senate from a southern horse-racing state. The morning after his arrival the southern senator stood aghast before the statue of a man which stands in the centre of Montpelier, and is inscribed with the words: "Ethan Allen." "Good God! Poland," he exclaimed, "I always supposed Ethan Allen was a horse!" 
remarkable how seldom the gray color has occurred in Ethan Allen's descendants.

Perhaps the strain now most prominent, and most likely to be perpetuated, is the Peters branch of the Ethan Allen family, which was established by the late Joseph H. Peters of Bradford, Vermont. Belonging to this branch are the stallions Donald, owned by C. C. Stillman of Cornwall-on-Hudson; Welcome, owned by A. Fullerton Phillips of Windsor, Vermont; Bob B., owned by E. A. Darling of East Burke, Vermont; Ethan Woodbury, owned by F. H. Orcutt of East Burke, and Ajax, owned by Judge Sanders of Cleveland, Ohio.

The widespread popularity of the Morgan family continued until about the year I862. In that year Ethan Allen was defeated by the Hambletonian stallion, George Wilkes, then called Robert Fillingham. This race came at a time when the horse-raising and horse-using public had become infected with the craze for speed, and the result was that the Hambletonian family took the place which up to that time had been held by the Morgan family. Thereafter almost all the horse-raising farmers in New England, as well as in the West, started to breed Hambletonian horses, and the Morgans would have become extinct as a separate family, except for a few staunch friends, Vermont farmers, mainly, who preserved the old strain.

But Morgan blood has entered largely into the American trotter; and the cross between Hambletonian and Morgan has often resulted in animals that combined the best points of both families. Among the famous trotters and pacers that have the Morgan cross 
"close up" are the following: the Wilkes stallions, Baron Wilkes, Wilton, Jay Bird, Red Wilkes, and Gambetta Wilkes; Elyria, the most successful sire among the sons of Mambrino King; Axworthy, founder of a leading family; Dan Patch, 1.56, pacing (with wind shield); Major Delmar, I.593/4 (with wind shield) ; John M., 2.02 $3 / 4$; Tiverton, 2.04 $1 / 2$, and Sweet Marie, 2.043/4.

In the show ring Morgan blood has been even more apparent, and probably it would be no exaggeration to say that most of the trotting-bred horses that have won honors at horse shows were Morgan in part. Flying Cloud (formerly called Carmon), the stallion selected to head the farm established in Colorado by the United States Government for the raising of carriage horses, has two crosses of Black Hawk blood.

Roundness of form and beauty of action - these are the qualities which the Morgan has largely contributed to the trotter. High action was not a characteristic of the original Morgan, nor is it by any means a characteristic of all Morgan horses of today, but it is found in several branches of the Morgan family, and most of all in the Lamberts. Daniel Lambert was a son of Ethan Allen, his dam being Fanny Cook by Abdallah, ${ }^{1}$ the sire of Hambletonian. He was foaled in 1858 , and was a beautiful chestnut, with mane and tail very light in color, and soft in texture. He was a horse of commanding style and magnificent carriage. For many years he was kept in the vicinity of Boston, but late in life he was brought back to Middlebury, Ver-

${ }^{1}$ See page 186. 
mont, where he had been raised. On this occasion the whole town turned out, with a brass band, to welcome him home, and there was a procession through the village streets. "The old horse," relates an eye witness, "kept time to the music, and was the proudest creature that ever walked on earth."

The Lambert horses are very distinctive-highheaded, high-spirited, high-stepping. They are apt to have poor legs, being especially light of bone just below the knee-a defect which they inherit from Fanny Cook; but their speed, carriage, and action more than atone for this defect. "A man can live two or three years in twenty minutes, driving a horse like that!" I once heard a fur-clad New England enthusiast exclaim as, with a jingle of bells and a clattering of hoofs on the floor, his Lambert mare dashed into the stable after an hour or two of impromptu racing on the snowpath. Daniel Lambert is rated as a "Broodmare Sire," and Lambert mares figure prominently in the pedigree of many fast trotters.

Another place where Morgan blood has made a strong impression is among the saddle-bred horses of Kentucky. These horses are noted for their beauty, style, and docility, qualities which, in great measure, they have derived from the Morgan horses that were brought to Kentucky very numerously in the first half of the nineteenth century.

However, notwithstanding the valuable qualities of the Morgan family, the number of pure-bred Morgans was fast diminishing until, in the year I909, the Morgan Horse Club was formed in Vermont. The mem- 


\section{THE MORGAN HORSE}

bers of the club, having abundant means at their command, have procured the best existing individuals of Morgan stock, and have placed the family once more upon a sure foundation.

Mr. Joseph Battell, also, a native and resident of Vermont, who died recently, did a great deal to renew the fame and to perpetuate the blood of the Morgan family. He compiled at his own expense and with great labor, a Morgan Register, and gave to the United States Government a large farm in Middlebury, Vermont, for the raising of Morgan horses. Unfortunately, Mr. Battell's Register is much too inclusive, admitting for registration animals who inherit only a small fraction of Morgan blood. It is expected that the Morgan Horse Club will undertake before long an advanced registration for Morgan horses.

The club has grounds of its own, with a spectators' stand and a circular course, within the limits of the state fair grounds at White River Junction, Vermont, and holds every year, in connection with the state fair, an exhibition of Morgan horses, which is a very picturesque and interesting event. The president of the club is E. A. Darling of East Burke, Vermont; the secretary and treasurer is C. C. Stillman of I 65 Broadway, New York, and the assistant secretary and treasurer, to whom all correspondence should be addressed, is W. S. Blitz, of 35 Nassau Street, New York City. Mr. Blitz keeps at all times a list of persons having Morgan horses for sale, and will answer all inquiries upon the subject of Morgan horses. 


\section{CHAPTER XXXIII}

\section{THE TROTTING-BRED HORSE}

MEN who are familiar with all kinds and breeds 1 of horses now agree, I think, that the American trotting-bred horse is the most useful, all-round horse in the world. He excels not only as a race horse at the trot and pace, but also as a roadster, a saddle horse, a carriage and coach horse, and as a light-weight farm horse. Uhlan, the fastest trotter in the world (his record is 1.58 ), is now used chiefly as a saddle horse, and has carried his owner, a man weighing not less than one hundred and eighty pounds, an eighth of a mile in $13 \frac{1}{2}$ seconds. Uhlan would probably be equally good as a carriage horse or roadster, for he has size, style, endurance, and dacility.

The famous brother and sister, the pacers Hedgewood Boy, 2.0I, and Lady Maud C, 2.001/2, were used for some years as farm horses, and also under saddle, before they acquired fame on the race-course. Numerous trotters and pacers have graduated from milk-wagons, butcher-wagons, and from the ranks of the rural free delivery to the race-track and the sulky. Some years ago a trotting-bred horse called Radowa was sold with a guaranty that he would trot a mile in 2.25 , pace it in 2.20 , and run it in 1.50 .

Certain writers about horses, who are connected with the draft-horse industry, have much to say about 


\section{THE TROTTING-BRED HORSE I 85}

the "little, weedy, undersized trotter." Some trotters are small, and among them may be mentioned Alix, Nancy Hanks, and Lou Dillon, all of whom held the record in their respective days. On the other hand, as samples of large trotters, there might be mentioned among many others, Axford, 2.29 $1 / 4$, weight I,250; a horse with very high action; Willy, 2.04 $1 / 4$, weight I,250, one of the speediest, handsomest, and kindest horses in the world; Invincible, 2.15, weight I,300; Idol Belle, by Red Wilkes, weight $\mathrm{I}, 300$ as a threeyear-old; Brown Braden, 2.13 $1 / 4$, a pacer, weight I,360; Say Tell, by Axtell, weight I,400; Wotan, a Wilkes horse, weight I,400; McKinley, 2.29, weight I,400; King Alar, 2.26, a Clay horse, weight I,450.

To pull a heavy, four-horse coach with a load of seven or eight men, and to do this at a rapid rate, is perhaps the hardest task that a horse can be called upon to perform; and at this game the trotter excels all other horses in the world. This has been proved by the road races held in connection with the New York Horse Show, and also at the London International Horse Show. These races have always been won by trotting-bred horses. Most of these trottingbred coachers stood about sixteen hands high, and many of them had records under 2.30 .

The trotting-bred saddle and coach horses seem all the more remarkable when we remember that they are little more than by-products. They were produced more or less accidentally by breeders and farmers whose real object was speed. By selecting first the proper families among the many families of trotters, 
and secondly, the proper individuals, one could easily produce ideal roadsters, coach horses, light-weight farm horses, and saddle horses.

\section{ORIGIN OF THE TROTTER}

All breeds and families trace back to some great sire who has the capacity, most rare of all capacities, to transmit his own good qualities from generation to generation. ${ }^{1}$ The founder of the American trotting family is Rysdyk's Hambletonian. He was a horse of peculiar breeding, and about half thoroughbred. His sire was Abdallah by Mambrino, a son of Messenger. Messenger, a gray thoroughbred, was foaled at Newmarket in England in I780, and imported to this country in I788. Being a tough, powerful horse, with a natural trotting gait (notwithstanding his breeding), he became the sire of many valuable harness horses, although as a sire of runners he was rather a failure.

Messenger was a horse of great vitality. He had a stormy passage from England, and one who saw him taken off the ship relates that three other horses, his companions on the long voyage -

had become so reduced and weak that they had to be helped and supported down the gang-plank; but when it became Messenger's turn to land, he, with a loud neigh, rushed down, with a negro on each side holding him back, and dashed up the street at a stiff trot, carrying the grooms along in spite of all their efforts to bring him to a standstill.

1 We see the same thing occasionally in the human race, as, for example, in the family founded by John Adams, second President of the United States. 


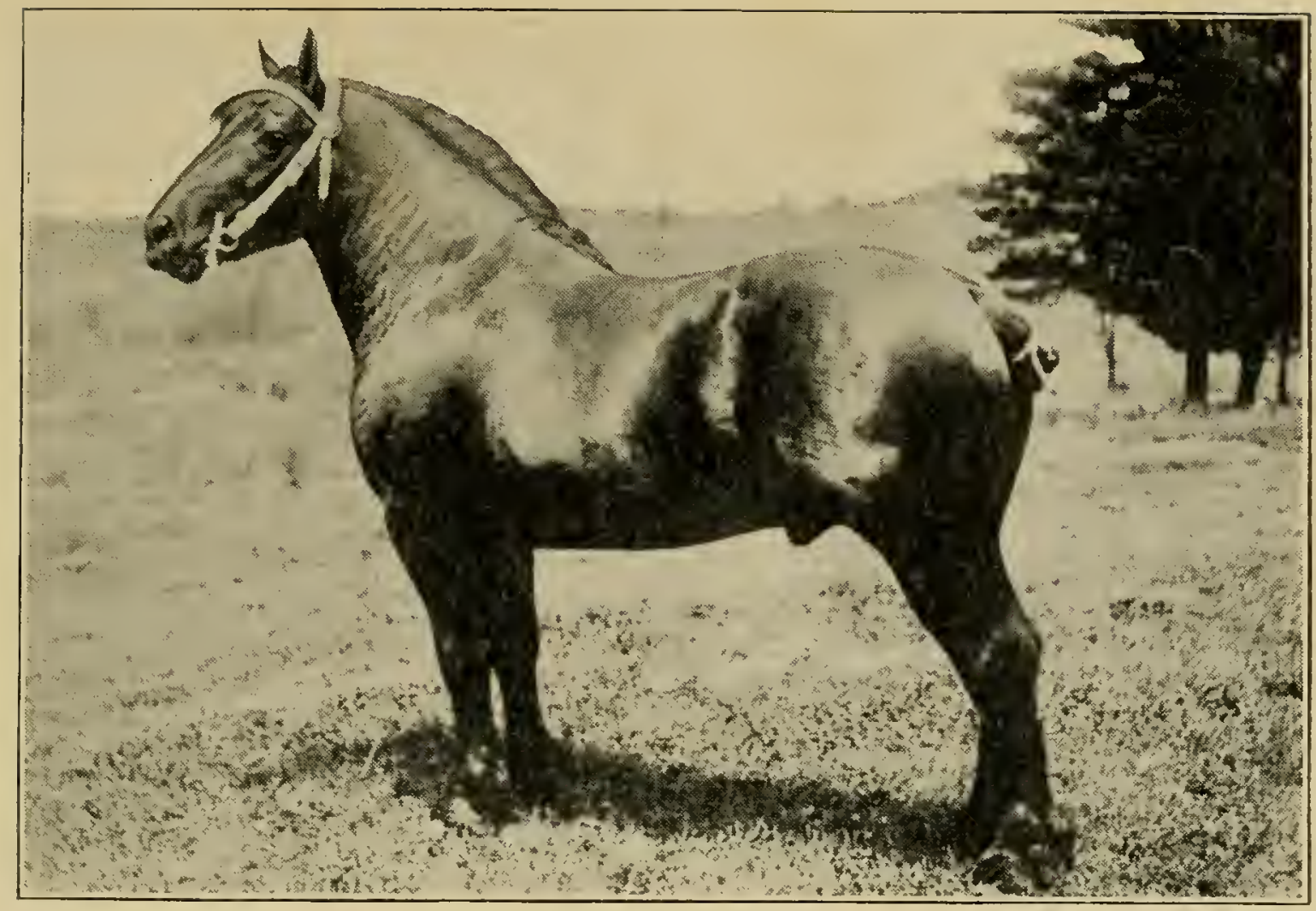

PERCHERON STALLION, "DRAGON"

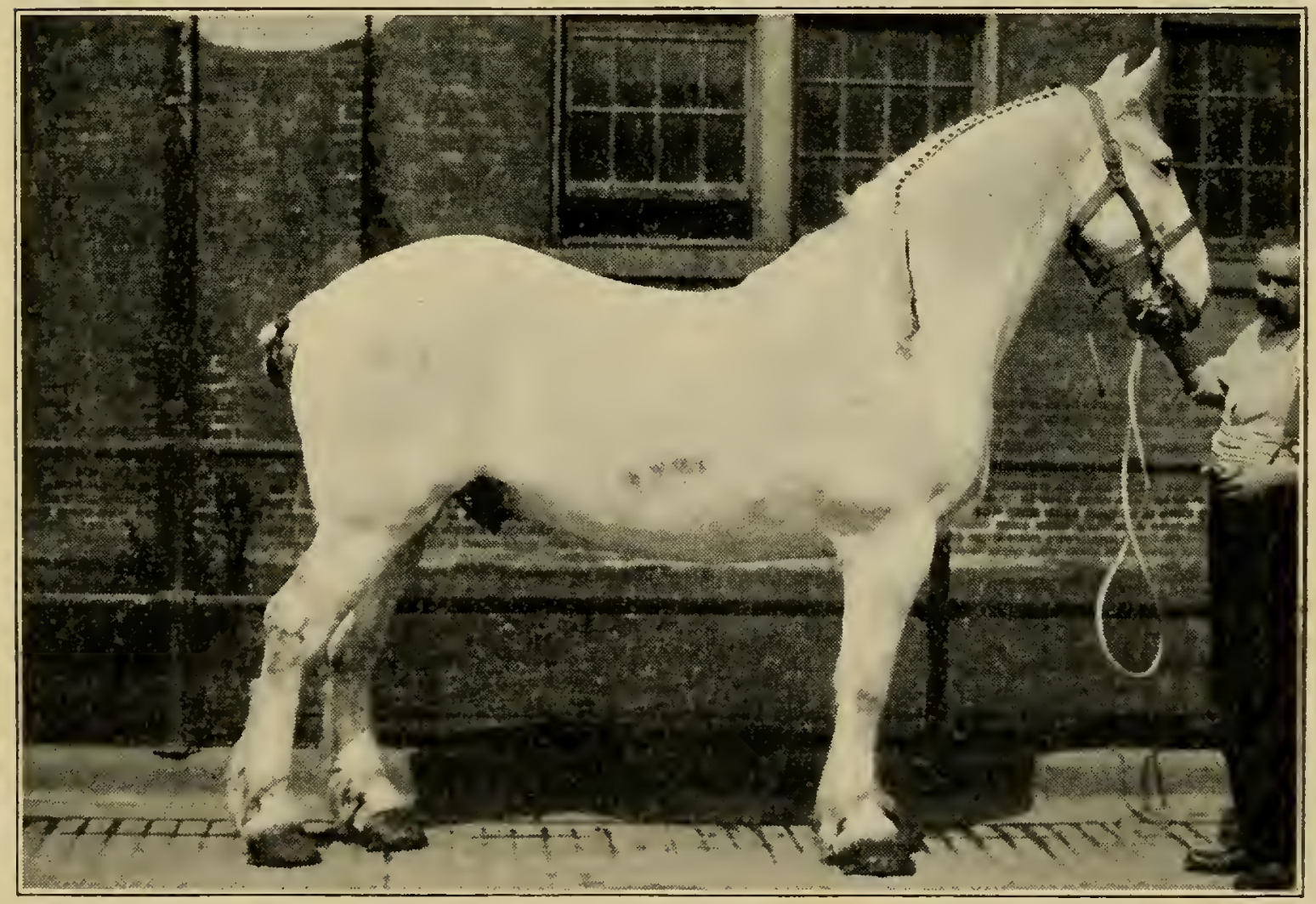

PERCHERON GRADE GELDING

(Sixteen Years Old) 

"When Messenger charged down the gang-plank," Hiram Woodruff declared, "the value of not less than one hundred million dollars struck our soil." 1

The dam of Rysdyk's Hambletonian was a fast road mare, sired by Bellfounder, a Norfolk trotter imported from England in I 822, by James Boott, a rich merchant of Boston. The Norfolk trotters, by the way, were the progenitors of the modern hackney, but possessing much more endurance and vim. They were great roadsters, both under saddle and in harness, and Bellfounder is described as having "a fine slashing gait."

Rysdyk's Hambletonian was a plain horse, but not a coarse one. He was of a rich bay color, with black points, and stood I 5.I at the withers, and I5.3 at the rump. Hamilton Busbey, who knew the horse well, describes him as having "a large, expressive head, with splendid eyes, a rather short neck, massive shoulders and quarters, and legs broad, flat and clean." His tail was well set on, but not well carried. He weighed about I,OOo pounds.

His gait was long and wide, and almost all the early Hambletonian trotters stepped very wide behind, placing the hind feet outside the track of the fore feet. At that time this was considered to be the proper gait for a trotter, but now, for speed, as well as for the show

1 One other imported thoroughbred has played an important part in the development of the trotter, and that is Diomed, a chestnut horse, who, in I780, won the first "Derby." He was brought to this country at the age of twenty-two, and died in 1808 . Comparatively few trotters descend from Diomed, but these few include many of the very best, as, for example, Maud S., Nutwood, Arion, Direct, Nancy Hanks, and Allerton. 
ring, the ideal is the "line trotter," a horse, that is, whose hind feet follow exactly in the track of his fore feet. This involves less waste of muscular effort.

Every horse now prominent in the trotting world traces back to Rysdyk's Hambletonian, and most of them belong to one of three families, and, often, to two or more of these three families.

The branches of the Hambletonian line now most conspicuous. are the Wilkes family, the Electioneer family, the Peter the Great family.

Let us consider briefly these various families.

\section{THE WILKES FAMILY}

George Wilkes, the founder, was a small, brown, well-made horse, with fine action, but having some tendency to pace. His dam was probably, but not certainly, sired by Henry Clay. There was a sulky streak in this horse that crops out occasionally in his descendants, but on the whole the family is a goodtempered family, and a sound one. The leading sons of George Wilkes are about as follows: Alcyone, Alcantara, Baron Wilkes, Onward, Red Wilkes, Gambetta Wilkes, The King, Wilton, Young Jim, Wilkes Boy, Bourbon Wilkes, Favorite Wilkes, Simmons, Patchen Wilkes.

Alcyone, whose dam was Alma Mater by Mambrino Patchen, was a small but very handsome horse of sweet disposition. Unfortunately he died at the age of fourteen. He is represented chiefly by the McKinney family, Zombro being the most distinguished son of McKinney, and San Francisco, a sire rapidly coming 


\section{THE TROTTING-BRED HORSE I 89}

to the front, being a still more distinguished grandson. The McKinneys, as a family, are very fast, of good size and good disposition. Every family has some fault, and that of the McKinneys is a tendency to be coarse.

Alcyone is also the sire of Nelson's Wilkes, a horse now dead, who founded a family in Maine which seems to be taking the place once occupied in that state by General Knox and his descendants, and later by Nelson and his tribe. The Nelson family has failed to "breed on," and will soon be extinct in the male line. The Nelson's Wilkes horses are apt to be small, but that is about all that can be said against them.

Alcantara, a brother of Alcyone, has ceased to be a factor. His only son of importance was the Vermont horse Alcander, who had a Morgan dam. Alcantara was a big, handsome, good-gaited horse, and his great inferiority to Alcyone as a sire is remarkable.

Baron Wilkes. A very fast, high-bred, highspirited family, notable for its colt trotters, whence it is known as the futurity family. The most eminent stallions of this family now are Moko and Mobel, Oakland Baron, The Bondsman, and Margrave. Moko, Mobel, and Margrave are big horses, but as a rule the Baron Wilkes family are small.

Jay Bird. This is another important sub-family, for it includes Ed. Winter, Jay McGregor, and Allerton, who has sired more 2.30 horses than any other stallion. The Jay Birds are commonly large, fast horses with good dispositions. Many of them are roan-Jay Bird having inherited that color from his dam, a Morgan mare. If they have a fault, it is apt to be the 
serious one of bad hocks. Sometimes, also, they lack quality.

William L. is known chiefly as the sire of Axtell, the horse that sold for \$105,000. Axtell is the father of Axworthy, and the Axworthys are now looming up in the very front rank of modern trotting families. They, like the Jay Birds, have the Morgan cross. The Axworthys have all the good equine qualities, except the very important one of good hind legs. In this respect they are in some cases deficient.

The dam of William L. was Lady Bunker by Mambrino Patchen, and she was also the dam of

Guy Wilkes, represented chiefly by Nutwood Wilkès and the McKerron family - a fast, handsome, goodtempered family, long-gaited, and lacking in size and substance.

Onward, cut of Dolly by Mambrino Chief, a big, strong, fast horse, but coarse, and not light in action. This family has produced many fast trotters, but only a few superlatively fast. Among his sons are Rex Americus, Online, and Colonel Cochran.

Red Wilkes, out of Queen Dido by Mambrino Chief, second dam by Red Jacket, and he by Billy Root, a son of Sherman Morgan. Notwithstanding this Morgan cross, the Red Wilkes family lack quality, but they are big, tough, and speedy. Among the Red Wilkes stallions are John R. Gentry, a pacer, Ashland Wilkes, Red Medium, and Alliewood.

Gambetta Wilkes. The dam of Gambetta Wilkes was by the Morgan horse Gill's Vermont, and this is a family of much beauty - its only fault being a tendency 
to pace. Gambetta Wilkes sired many more pacers than trotters. On the other hand, his brother,

The King, sired four times as many trotters as pacers. The King was a strikingly handsome horse.

Wilton, dam by Hambletonian, second dam by Flying Morgan. Wilton, a small brown horse, of great beauty, was blind, but very seldom transmitted this defect. $\mathrm{He}$ is the sire of Moquette, and also of Willy $(2.04 \mathrm{I} / 2)$, one of the most attractive horses ever foaled.

Young Jim, dam by Lear's Sir William. A highbred, handsome horse, the sire of Young Miss, dam of the great Bingen.

Wilkes Boy, dam, Betty Brown, by Mambrino Patchen. This is another horse with much thoroughbred blood, and the Grattan family, noted for their speed, gameness, and substance, are descended from him.

Simmons, Bourbon Wilkes, and his brother, Favorite Wilkes, were all good sires, the first-named especially, but the male line from all of them will soon be extinct.

Patchen Wilkes, dam, Kitty Patchen by Mambrino Patchen, second dam, Betty Brown, also by Mambrino Patchen, is represented chiefly by the pacers, Joe Patchen and Dan Patch, I.56.

\section{THE ELECTIONEER FAMILY}

The chief Electioneer families are those of Bingen, Walnut Hall, Arion, and Chimes. The dam of Bingen was Young Miss by Young Jim, a son of Guy Wilkes, so that in him these two great families are united. The 
sire of Bingen was May King, ${ }^{1}$ by Electioneer, and it is somewhat remarkable that neither May King nor Young Miss ever produced any other foal of the first class. Bingen has one or two brothers, but they have made no reputation. Nevertheless, Bingen is an extremely prepotent horse, and his descendants breed on and on.

Bingen is the sire of Uhlan, the greatest harness horse ever foaled, and among his sons or grandsons are Bingara, Todd, Bertini, Cochato, Aquilin, Admiral Dewey, Border Knight, J. Malcolm Forbes, and the Northern Man.

The sub-family of Bingara is perhaps the most important of the Bingen tribe. Bingara whose dam was by Arion, is an extremely handsome horse as his picture attests, and he transmits beauty, docility, and speed. No family is more uniform in type. Todd died very young, and although his descendants are as remarkable for speed as those of Bingara, perhaps even more so, they are not so similar in type.

As a rule, however, a Bingen horse of whatever sub-family inherits a handsome, brainy head-the Bingen head. Bingen was a round-turned horse of great substance combined with quality, and this unusual combination is found very commonly in his descendants.

The Bingen family are regarded as "natural" trotters. They require comparatively little education

${ }^{1}$ It is worth noting that May Queen, dam of May King, was by Alexander's Norman, out of Jenny, by Crockett's Arabian. Crockett's Arabian was a son of Mokladi, an Arab horse imported by A. Keene Richards. 


\section{THE TROTTING-BRED HORSE I93}

or training, and come to their speed at an early age; and for this reason many of them have been ruined as colts by injudicious trainers who hurried them along too fast. As race horses they are inferior to the family of Peter the Great, presently to be described; but as roadsters and "gentlemen's drivers" they are unsurpassed.

Arion by Electioneer, dam, Manette by Nutwood, held the two-year-old record, and was sold to Mr. J. M. Forbes for \$I25,000. He is a small but handsome bay horse, and he has played an important part in the recent development of the trotter, but mainly as a brood-mare sire. He sired the dam of Bingara, and also the noted brood-mare Fanella. Great nervous energy, but lack of size and substance are characteristics of the Arion family. Among the best sons of Arion are Nico and Lord Roberts.

Walnut Hall, by Conductor, son of Electioneer, dam by Red Wilkes, is the sire of many fast horses, and especially of The Harvester, 2.0I I/2, considered by some authorities the finest trotting stallion ever foaled. The Harvester is still a young horse, but his colts are very promising. His brother, Burning Star, is also a horse of beautiful conformation and good size. Other noted sires of the Electioneer family are: Chimes, Mendocino, Expedition, Advertiser, Sphinx, Egotist, Norval.

THE PETER THE GREAT FAMLY

Peter the Great, a bay horse, standing I 5.3, was sired by Pilot Medium, a gray horse. His dam was 
Santos by Grand Sentinel - he by Sentinel, and Sentinel was a son of Rysdyk's Hambletonian.

The sire of Pilot Medium was Happy Medium (by Rysdyk's Hambletonian), a handsome bay horse, whose dam was the noted, highly-finished trotting mare, Princess - a rival of Flora Temple. It will thus be seen that Peter the Great is an inbred Hambletonian, and yet without a drop of either Wilkes or Electioneer blood. This family should therefore furnish an excellent "outcross" both for the Wilkes and the Electioneer families. As race horses the sons and daughters of Peter the Great are considered to surpass all others, even the Bingens; but they have not, as a rule, the sweet temper or the style and beauty of the Bingara and some other Bingen strains. Their faults are a tendency to be leggy, to have coarse heads, and to be low-headed. Nevertheless there are many handsome, high-headed animals among them, such, for example, as Baron Peter, Peter Pilot, and Azoff.

Peter the Great sired very few colts in the early part of his career, so that Bingen (who is now dead) outstripped him at first, and the grandsons of Peter the Great are not yet so numerous as those of Bingen. However, so far as the matter can now be judged, the family of Peter the Great is not "breeding on" so well as the Bingen family.

\section{MINOR HAMBLETONIAN FAMILIES}

Hambletonian families that have cut a great figure in the past, but are now nearly extinct in the male line, are those of Belmont, Almont, and Major Edsall. 
These were animals of substance and fine conformation, and furnished many handsome carriage horses. Belmont was the sire of Nutwood, and Nutwood's descendants are still prominent in the female line. Major Edsall sired Robert McGregor, and the McGregors were, and are, noted for courage and endurance. Cresceus, the one-time champion trotter, belonged to this family, buk he was a coarse, roughgaited, rather bad-tempered horse, and a failure as a sire.

Dictator, a brother of Dexter, founded a family now represented chiefly by the pacer, Directum I.

Harold, the sire of Maud S., survives in Kremlin, and mares by Kremlin, bred to Bingen, and his sons have produced some notable horses, Bertini especially.

Bellini, by Artillery, is a late-comer, and has sired only a few, but those few include Atlantic Express and King Bertini.

From Strathmore are descended Lou Dillon and Sidney Dillon. This is a small, handsome family, but more productive of pacers than trotters.

\section{SUMMARY OF TROTTING-BRED FAMILIES}

Practically all trotting-bred families trace back to Rysdyk's Hambletonian, and, with two exceptions, they all derive from one or both of the two foremost sons of Rysdyk's Hambletonian, namely, George Wilkes and Electioneer. Of these two branches, that of George Wilkes is, on the whole, the more important. In many cases, notably in the case of Bingen, leading sires combine the blood of both George Wilkes and 


\section{THE HORSE}

Electioneer. The sub-families now most prominent are the following:

Of the Wilkes Strain.-The Axworthy family, represented chiefly by Guy Axworthy, ${ }^{1}$ dam by Guy Wilkes, and by General Watts, dam by Prodigal.

The Mckinney family, represented chiefly by San Francisco, dam by Nutwood Wilkes.

The Baron Wilkes family, represented chiefly by Moko and Mobel.

Other prominent Wilkes sires were: Onward, Red Wilkes, Gambetta Wilkes, Wilton.

Of the Electioneer Strain.-Bingen, represented chiefly by Bingara, dam by Arion, and by J. Malcolm Forbes, dam, Santos by Grand Sentinel (the dam of Peter the Great).

Walnut Hall, represented chiefly by The Harvester, dam by Moko. Walnut Hall is still living.

Arion, still living, represented chiefly by Lord Roberts, dam, Nancy Hanks, by Happy Medium.

Families Not from George Wilkes or Electioneer.-Peter the Great, by Pilot Medium, he by Happy Medium, by Rysdyk's Hambletonian, dam, Santos by Grand Sentinel, by Sentinel, by Rysdyk's Hambletonian; represented chiefly by Peter O'Donna, Captain Aubrey, Peter Wood. Peter the Great is still living.

Bellini, by Artillery, by Rysdyk's Hambletonian, dam by a Clay mare; represented chiefly by Atlantic Express.

1 Since this chapter was written, Lee Axworthy, by Guy Axworthy, dam by Bingen, has reduced the stallion record to $1.581 / 4$. 


\section{CHAPTER XXXIV}

\section{THE KENTUCKY SADDLE HORSE}

THE Kentucky saddle horse is often described as 1 the most beautiful horse in the world. He is an animal of great quality, with a small head, long, slim neck, fine, sloping shoulders, rather long legs, small feet, and quick, lively gait. The origin of the breed is largely thoroughbred, with a considerable mixture of Morgan, trotting horse, and pacing blood. Among the famous saddle stallions that trace in the male line to Justin Morgan are Cabell's Lexington, Coleman's Eureka, Peavine, and Indian Chief.

The Kentucky saddle horse is usually spoken of as the representative American saddle horse; but the name of the Kentucky association is "American Saddle Horse Breeders' Association." It is a national association and was formed in $189 \mathrm{I}$. The list of foundation sires was revised in 1902 and later still was cut down to the single horse that heads it, namely, the thoroughbred, Denmark. The real founder of the now famous Denmark saddle family is, however, not Denmark, but his son, Gaines' Denmark, out of a mare whose breeding has never been established. It is as misleading to make Denmark the foundation sire as it would be to describe Abdallah instead of Rysdyk's Hambletonian as the founder of the trotting family, or True Briton instead of Justin Morgan as the founder 
of the Morgan family. Of the 1,653 horses registered in the first volume of the Saddle Registry as descendants of Denmark, all but six are descendants of Gaines' Denmark.

The Denmark horses are usually dark brown or black, and they combine quality with substance, and a high spirit with docility. The only perfect horse that I ever saw (and he had lost one eye when I first knew him) was a gelding of this strain, the property of Frederick P. Fish of Boston. He stood at least I 6 hands, and yet was almost a pony-built horse, with great depth of lungs and body. He was very handsome, high-headed and high-strung, but extremely intelligent, kind, and docile. He was equally good under saddle and in harness, requiring no check or severe bit, and could trot at least a three-minute gait.

Not all Kentucky saddle horses trace to Denmark, and not all are of the Denmark type. In fact there is a great diversity among them. Many are small and weedy, many are deficient in brains, many are unsound, especially in eyes and hocks. These defects are due largely to inbreeding.

Kentucky saddle horses are usually divided into two classes, according to their training. There is the "walk, trot, and canter horse," and the horse that adds to these gaits the fox-trot or running walk and the amble. These last are known as five-gaited horses. Unless ridden by riders as accomplished as themselves they are apt to mix these gaits, especially as they become older.

In recent years many breeders of Kentucky saddle 


\section{THE KENTUCKY SADDLE HORSE I99}

horses have obtained the desired carriage of the tail by nicking it, that is, by cutting a muscle in the tail, and then bearing up the tail by means of a large crupper so that the tail becomes fixed in that position when the muscle heals. This reprehensible practice substitutes mechanical means for the inward spirit of the horse, and if continued will result in a breed of horses very deficient in natural carriage of the tail.

The secretary of the American Saddle Horse Breeders' Association is R. H. Lillard, Louisville, Kentucky. 


\section{CHAPTER XXXV}

\section{THE HACKNEY}

THE modern hackney is a descendant of the Nor1 folk trotter - a family to which belonged the cob immortalized by George Borrow in Lavengro. The Norfolk trotter was a stout horse, equally good in harness and under saddle, and rich in the blood both of the thoroughbred and the Arab. He was a fast, sure-footed, enduring roadster - such a roadster as was needed in the days when railroads were not, or were only beginning to exist.

But for many years past his descendant, the hackney, has been bred and used mainly as a show horse and he is now so deficient in endurance that he is rejected for army use and even for use as a road-coach horse. Mr. Otho Paget, a leading authority in England on horse matters, says in one of his books: "I have never known a useful horse of hackney blood."

The hackney is a handsome, round-turned, sweettempered animal, with a good deal of knee actionsometimes excessive knee action - but this knee action is usually of the up and down, pounding kind, and not the graceful, round action of the trotting-bred horse.

Some hackneys, however, as, for example, the little stallion Dilham Prime Minister, might be mistaken for trotters, so far as their action is concerned. An English-bred horse, by the way, can almost always be 


\section{THE HACKNEY}

distinguished from an American-bred by the greater width of his back across the loins.

As a show horse the hackney has out-stripped the trotting-bred horse in the smaller classes; that is, in the classes for horses 15.2 and under, but in the classes for horses above that height the trotting-bred horse has proved superior even as a show horse.

The secretary of the American Hackney Horse Society is Gurney C. Gue, who may be addressed in care of the New York Herald. 


\section{CHAPTER XXXVI}

\section{COACH HORSES}

NE hates to think that the coach horse, with his handsome head, his long, graceful "top-line," and proud bearing, resplendent in his harness of polished leather, with gold or silver mounting, and drawing with perfect ease an elegant barouche or victoria one hates to think that this fine animal should disappear from the face of the earth; and perhaps the love of beauty, inherent in the human race, will suffice to preserve him for future ages.

THE CLEVELAND BAYS

The Cleveland bay is a big, upstanding, rangy, goodtempered coach horse that has been bred in England for many years. He was used chiefly as a barouche and landau horse.

There is a Cleveland Bay Society of America, whose secretary is R. P. Stericker, East Orange, New Jersey.

\section{THE FRENCH COACH HORSE}

The French coach horse is a big, strong animal, with a good deal of endurance, due to the fact that he has a large admixture of thoroughbred blood; but the French coachers are usually coarse horses, and are apt to be a little unpleasant in disposition. Not in- 
frequently they make good saddle horses. As a cross for the trotting-bred horse they have not proved successful, and on the whole there seems to be no reason why the French coach horse should be bred in this country in preference to trotting-bred horses. The French coach horse is, it is true, somewhat larger on the average than the trotting-bred horse, but this is his only point of superiority.

The secretary of the French Coach Horse Society of America is Duncan E. Willett, Maple Avenue, Oak Park, Illinois.

\section{THE GERMAN COACH HORSE}

The German coach horse is a good-sized, goodlooking animal, but lacking in endurance and quality. The German horse, in fact, has always been a by-word in England for softness of constitution, although, in order to supply the home demand, many German coach horses were annually imported into England until the outbreak of the present war.

The secretary of the German Coach Horse Breeders' Association is J. Crouch of Lafayette, Indiana. 


\section{CHAPTER XXXVII}

\section{DRAFT HORSES}

$\mathrm{N}$ the first half of the nineteenth century there were I draft horses in Pennsylvania known as Conestoga Horses. The Conestoga Valley, where this equine family originated, was settled mainly by Dutch farmers, and it is highly probable that imported Flemish horses were the foundation of this strain. These Conestoga horses were tall, leggy, long-backed animals, but strong, active, and good-tempered. They were used extensively in Pennsylvania and the adjoining states in hauling canal boats, as well as freight wagons on the highways. Some of the best and lightest of them were much admired as express horses in the city of New York. They have long since passed away, and our present draft horses are all of imported stock. Most of these horses are raised in the West, and the eastern states pay out millions of dollars for them every year. Even the farm horses used in northern New England are mainly from the West. At the present prices draft horses could be raised with profit in Maine, New Hampshire, Vermont, and northern New York. They would not be quite so large as the western-bred horses, but they would have better feet, and more nervous energy.

\section{THE. PERCHERON}

The oldest imported draft family is the Percheron, and it is still the most popular. The Percheron [204] 
originated in France, being founded partly upon the Arab horse, and the breed has been developed mainly in a small district in the northwest of France called Perche. The first notable Percheron stallion brought to this country was Louis Napoleon, imported to Pennsylvania in $185 \mathrm{I}$, and soon afterward taken to Ohio.

Originally the Percheron was a comparatively small horse weighing about I,250 or I,300 pounds, and he was much like a magnified Morgan with short, lively action, an excellent disposition, an arched neck, and a smoothly turned body. Of recent years, by the infusion of Flemish blood, the Percheron horse has become much larger, and the biggest of them now weigh a ton. However, there are many Percherons weighing not over $\mathrm{I}, 400$ pounds, and these smaller horses retain the original characteristics of the breed.

The Percheron is a somewhat smaller horse than the Belgian and Shire, but he is somewhat heavier on the average than the Clydesdale. The Percheron has a smaller and prettier head than any other draft breed, except perhaps the Suffolk Punch, and less hair on his legs. The neck is sometimes a little short, but, as a rule, it is longer than the neck of the Belgian. The neck is well-crested and arched, and in these respects very much superior to the neck of the Clydesdale and Shire, which, though fairly long, is straight. The bone of the Percheron is usually good and probably superior to that of the Shire and Clydesdale, and his action, both at the walk and the trot, has the snap and lightness of a small horse. In fact, the Percheron combines 
weight of body with a light step in greater degree than any other draft horse. This makes him a good heavyweight farm horse. Certainly, also, he has more beauty than any other draft horse, although the Belgian comes near him in this respect. $\mathrm{He}$ is, moreover, easily broken and very docile.

Most Percherons are either gray or black, but there are some bays, browns, chestnuts, and occasionally a roan.

There are a number of other draft breeds in France, differing somewhat from the Percheron, the most important of which are the Boulounais and the Nivernais. These horses are like the Percheron, but a little larger and somewhat coarser.

The secretary of the Percheron Society of America is Wayne Dinsmore, Union Stock Yards, Chicago, Illinois.

\section{THE BELGIAN}

The Belgian draft horse is the only horse bred to any extent in Belgium, and he has been nearly exterminated in that country during the present war. The Belgian is like the Percheron, but even heavier and more stocky, and his neck, though of the same character, is usually somewhat shorter and not so handsome as the neck of the Percheron. The Belgian is the most compact of all the draft breeds, his body being very short, wide and deep. Like the Percheron, his legs are short and free from the long hair of the Clydesdale and Shire. He is not quite so good in action as the Percheron, his neck is apt to be too short and heavy, 


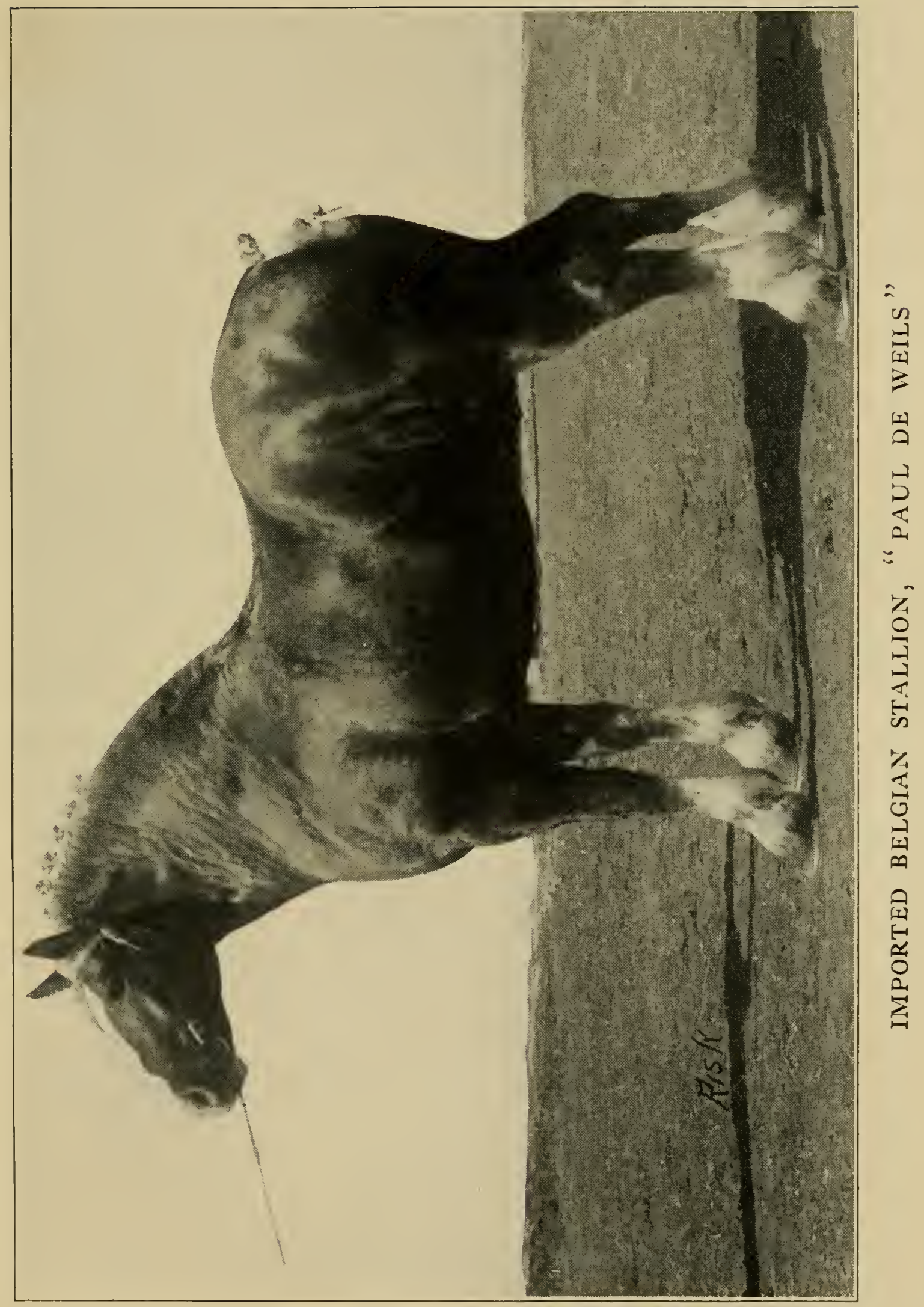



and his croup is often too drooping. Straight pasterns are another rather common defect in the Belgian - as they are indeed in most heavy horses.

The Belgian was not imported to this country until comparatively recent times, in fact, to any extent only during the past ten or fifteen years, but he has already attained a great popularity, and the pure Belgians now in this country will undoubtedly be of much value for breeding purposes.

The color of the Belgian is bay, chestnut, or roan, with an occasional brown, gray, or black.

The secretary of the American Belgian Association is J. J. Conner, Jr., Wabash, Indiana.

\section{THE SHIRE HORSE}

The Shire horse originated in England and is supposed to date back to the war horse of the middle ages. He has been known during the past thousand years or so, first as the War Horse, then as the Great Horse, later as the Old English Black Horse, and finally as the Shire Horse. The Shire is heavier than any other draft horse, except the Belgian, and Shire stallions that weigh 2,000 pounds or over are not at all uncommon. The Shire is also the tallest of the draft breeds, and is less compact than the Belgian or the Percheron. The average height of Shire stallions is probably nearly seventeen hands. The Shire, as a rule, has rather long legs, a rather long straight back, a long straight neck, and a nose inclined to be of the Roman character. $\mathrm{He}$ is a horse of good, heavy bone, but the long hair, or feather, as it is called, on his legs is a great defect 
in a climate like that of the United States. Of all the draft breeds the Shire is the laziest and the slowest walker, and he is not in general quite so sweet-tempered as the Percheron or the Belgian. The color is usually bay or brown with white markings. Blacks, grays, chestnuts, and roans are seen occasionally, but not often.

The secretary of the Shire Horse Association is Charles Burgess, Wenona, Illinois.

\section{THE CLYDESDALE}

The Clydesdale bears the same resemblance to the Shire that the Percheron does to the Belgian. The Clydesdale is not quite so heavy as the Shire, and is much more active. The Clydesdale is, in fact, more active even than the Percheron, and he is apt to be a little hot tempered. He is more rangy, and less wide and compact than any other of the draft breeds, and has, as a rule, more style and knee action and a quicker walk.

He is apt to have a white face, a good deal of white hair on his legs, and a Roman nose; but he shows more quality than the Shire horse, and the hair on his legs is less long and more silky. The Clydesdale has a more sloping shoulder than the Shire horse and a shorter rump. He is a product of Scotland and his early history is obscure, but it is probable that his ancestors were partly of Shire stock and partly of Flemish blood. It is often hard to distinguish a Clydesdale from a Shire.

The secretary of the American Clydesdale Associa- 


\section{DRAFT HORSES}

tion is R. B. Ogilvie, Union Stock Yards, Chicago, Illinois.

\section{THE SUFFOLK HORSE}

The Suffolk horse, formerly known as the Suffolk Punch, boasts a long pedigree, and it is the only breed in the world, so far as I know, which is always of the same color, namely chestnut. The chestnut color ranges from very dark to very light — or, as we should say in this country, from chestnut to sorrel. The English Suffolk Stud Book mentions seven shades of chestnut color, described as the dark, the dull dark, the light mealy, the red, the golden, the lemon, and the bright. It is permissible for the Suffolk horse to have white markings, such as a star in the forehead, or a snip on the nose, and even white ankles may be worn without discredit. As the old name of Suffolk Punch implies, the Suffolk is a round-bodied, stout-built horse on rather short legs. He is well ribbed-up, and his ribs spring out with that arching, barrel-hoop formation which is conspicuous also in the Arab and in the Morgan horse, and which indicates a good constitution. His tail is well set on, and the defect of an extremely sloping rump does not often occur in his breed. The Suffolk has a much finer coat than any other English draft horse, and he is also free from that long hair about the fetlock which is regarded in England as an ornament and in this country as a nuisance.

The Suffolk is apt to be a little short in the neck, and his critics accuse him of being somewhat deficient in bone, especially below the knee. On the other hand, 
the friends of the breed maintain that any seeming deficiency in bone measurement is due to the fact that the bone of the Suffolk is hard and dense like ivory, or like the bone of the thoroughbred, and not of the more porous, spongy texture commonly found in the coarserbred horse. The fixed color of the Suffolk horse, his good quality of bone, and his freedom from long hair on the legs - these characteristics are ascribed to the great antiquity of the breed, and to the fact that it has never been crossed with Flemish horses. The Suffolk Punch originated and has always been bred in the counties of Suffolk and Norfolk on the east coast of England, and has been used mainly as a farm horse. Readers of Sandford and Merton will recall the delight with which Harry's father received the present of a pair of Suffolk Punches for use on his farm.

The original Suffolk was a comparatively small horse, and so late as the year I786 a stallion of this breed was described as "standing I 5.2, of a bright chestnut color, and fit to get good stock for coach or road."

About this time, however, or a little before, more attention began to be paid to breeding, and since the year I 800 the Suffolk has gradually been increased in size and improved in quality. Horses of this strain are neither so tall nor so heavy as the Shires or Clydesdales, but they are quite big enough - and for farm work often too big. The average height is about sixteen hands, and stallions weighing a ton are not very uncommon. Only a few Suffolk horses have been imported to this country, and most American horse- 


\section{DRAFT HORSES}

fanciers, the writer included, have never seen a really good Suffolk horse.

The Hawthorn Farm, in Lake County, Illinois, to which I am indebted for the picture of Ashmoor Romeo, has probably the best collection of Suffolks, and the secretary of the American Suffolk Association is A. Graham Galbraith of De Kalb, Illinois. 



\section{狂art $\widetilde{U} \mathfrak{i n n}$}

\section{DISEASES AND INJURIES}





\section{CHAPTER XXXVIII \\ GENERAL TREATMENT}

IN case of illness, it is an excellent rule to give no 1 medicine whatever unless you absolutely know what is the cause of the trouble. If you have any doubt about that, keep the horse warm and quiet, see that his bowels are open, and leave the rest to nature. If, however, the horse is in pain, the pain should be alleviated in the manner described below.

Above all things, beware of the amateur horsedoctor. Many a good horse has been brought to an untimely end by severe remedies, and especially by drugs of opposite character which never should be given together. One of the finest horses that I ever knew was killed by a large dose of soda, followed, shortly afterward, by a pint of vinegar. The alkali and the acid thus united acted almost like a bomb shell in the stomach of the unfortunate animal.

Hay, bran mashes, and oatmeal gruel are the proper food for sick horses, and the hay should be rather fine hay, with, if possible, a slight mixture of clover. Good nursing, in the case of a sick horse, is more important than good doctoring.

If a horse is kept in the stable by reason of illness or injury or any other cause, look out for his forefeet. They are sure to become dry and hard and to contract unless means are employed to soften them. Many and 
many a horse has gone wrong in his fore feet while he was being cured of some illness or lameness.

There should be a sling in every large stable. Lame horses, afraid to lie down, often suffer excruciatingly from standing on three legs, night and day, perhaps for weeks and even months. Frequently the result is a permanent breaking down of the sound limb which is thus compelled to bear alone the weight normally borne by the two limbs - fore or hind, as the case may be.

A sling is also very useful for relieving horses that from illness or weakness or any other cause are afraid or unable to lie down. Moreover, in every large stable there will be at least one horse that never lies down, and by slinging him up once in a while, so that although his feet rest on the floor the weight of his body is supported by the sling, his fatigue will be relieved, and his usefulness prolonged.

TEMPERATURE, PULSE, RESPIRATION

The normal temperature of a horse is $100^{\circ} \mathrm{F}$.

If his temperature rises to $102^{\circ}$ or over, he should be left in the stable, and fed on hay and bran- no oats or corn. One hundred and four degrees is a dangerous temperature and $107^{\circ}$ usually means death. Every horse-owner should have a self-registering thermometer. By placing this in the rectum, and leaving it there for three minutes, you can tell what is the temperature of the horse, and whether it is safe to use him or not.

The normal pulse of the horse is from thirty-three to forty beats a minute. The pulse can be ascertained by 
pressing the finger at the angle of the lower jaw bone. A horse in normal condition breathes from twelve to fifteen times a minute. The respiration can be gauged by watching the flanks or by pressing the ear to the side.

\section{ADMINISTERING MEDICINE}

If the medicine is given in the form of a ball, as a dose of aloes for instance, the horse's tongue should be grasped by the left hand, and gently pulled out and placed on that part of the right side of the lower jaw which is bare of teeth. With the right hand the ball should then be placed at the root of the tongue; and when that is done the tongue should be released, which will cause the ball to be pushed further back. The mouth should then be closed and kept closed until the ball is swallowed.

Medicine, if not mixed with the grain, is usually given to the horse in liquid form from a bottle which should be of thick glass, like a tonic bottle, or earthenware, to avoid the danger of its breaking. An India rubber bottle is made especially for this purpose.

The head of the horse need not be raised so high as is usually done - if his nose is raised a little above the horizontal line, it will be sufficient. With a quiet horse, a man, standing on a stool or chair, can sometimes raise the horse's head with one hand, and administer the dose with the other, but usually it is necessary to put the halter-rope over a beam, or better yet, to lift the head by a loop placed under the lower jaw, a rope or strap coming from the loop and passing 
over a beam or other projection above the head of the horse. The head should not be held too high, for then the dose may go down the windpipe instead of the throat, and so pass into the lungs, and drown the horse. Many a horse has been killed in that way, and the danger is even greater when an attempt is made to dose the horse through the nostrils.

If the horse should begin to cough while you are dosing him, let down his head at once, for the coughing means that the liquid is going the wrong way - that is, into the windpipe instead of the stomach. Traumatic pneumonia is often caused by careless drenching. 


\section{CHAPTER XXXIX}

\section{CUTS, BRUISEŚ, AND BURNS}

CUTS and wounds should first be washed carefully with warm water and soap, preferably castile soap, and then some antiseptic, such as carbolic acid (one part to forty parts of water), or sulpho-napthol (one teaspoonful of sulpho-napthol in a quart of water), or creolin (one tablespoonful to a pail of water) should be applied. A little salt in water makes a good antiseptic.

The cleansing and disinfecting of the wound, even though the wound be a slight one, should be done thoroughly and as soon as possible, for there is always danger of infection and blood poisoning, especially in the city. After the wound has once been washed and disinfected it should be treated every day, and in severe cases three or four times a day, with alcohol poured into the wound and on the flesh around it. But if there is inflammation or pain, the alcohol treatment should not be used until the inflammation has been reduced. If the painful wound is in the foot or leg the foot or leg affected should be kept for several hours in a soaking tub, with hot water to which sulpho-napthol, sufficient to make the water of the color of skim milk, has been added.

The worst thing possible is to apply a liniment or other stimulating remedy to a wound or cut. That, of course, increases the inflammation. 
The most severe wounds received by horses in the city arise from picking up nails in their feet, and from calking themselves. If such cases are at all serious a "vet" should be called in at once, for there is always danger of blood poisoning. Meantime, the horse should have his foot placed in the soaking tub with hot water and sulpho-napthol, as above described. In severe cases of this kind the injured foot or leg should be kept in the soaking tub for the greater part of the day, and a poultice should be applied at night until the inflammation subsides.

If the nail is picked up on the road, it should be pulled out at once, before the horse is moved a step, and then turpentine or alcohol should be poured into the wound before the horse is walked home.

For healing wounds and cuts the following application is very useful:

Sulphate of copper............. ounces

Sulphate of zinc............... ounces

Sugar of lead................. ounces

Dissolve in 3 quarts of water.

This is also a good remedy for scratches.

Fistulas and poll evil require treatment by a good veterinary surgeon, although I have known them to be cured simply by the continued application of carbolic acid. Severe cases are usually incurable, and the best way for the horse and his owner is to kill the horse.

\section{BURNS}

Burns may be treated with cooking soda, followed by the application of sweet oil; but a better remedy is 
carron oil which is composed of linseed oil and lime water. Care should be taken to protect the horse from a chill, and especially from drafts. A chill causes stagnation of the blood, which is likely to be followed by sloughing of the wounds, or by pneumonia. If the burns are severe, a veterinary surgeon should be called in. When the burns affect more than one-third of the surface of the animal's body, they are almost certain to be fatal. 


\section{CHAPTER XL}

\section{DISEASES OF THE STOMACH AND BOWELS}

THERE is a general opinion that the domestic - animals are "tougher" than the human kind, and have a stronger digestion; but the exact opposite is the case. The horse, especially, has a weak digestion, and the fact that he cannot relieve himself by vomiting makes the presence of undigested matter in his stomach extremely dangerous. No horse could stand for a day the intemperate and irregular feeding in which many men can indulge for months and even years.

\section{COLIC}

The most common and the most fatal trouble of the horse is colic; and, except in chronic cases, it is always the result of some neglect or abuse. No horse should ever have colic.

The most frequent causes are feeding grain when the horse is tired, feeding an unusual amount of grain, watering him when he is heated, allowing him to become chilled, feeding new oats, half-cured hay, new hay, or green corn, and feeding too much grain before he becomes accustomed to it.

There are two kinds of colic, spasmodic and flatulent. Flatulent colic is the more common form, and means simply wind in the stomach, caused by acidity of the stomach. In this form of colic there is 


\section{STOMACH AND BOWEL DISEASES 223}

usually a perceptible distension of the belly. A safe and easy remedy is a dose of common cooking soda, about two tablespoonfuls, with a tablespoonful of ginger, the whole well shaken up in a pint of water. This dose may be repeated, if necessary, in thirty minutes, and again in forty-five minutes. The horse should be quietly walked about, but not forced into a trot.

Colic is apt to be accompanied by violent pain shown especially by the patient's thrashing about, rolling, lying down and getting up, etc. These violent movements are more apt to cause death by rupture than is the disease itself. Therefore, if the first dose above prescribed does not relieve the horse, he should at once be given a hypodermic injection of morphine, amounting to one and one-half grains for a horse of I,O0O or I, IOO pounds, and two grains for a big horse. If a hypodermic syringe is not at hand, the horse may be given, by the mouth, a dose of laudanum and nitre in a pint of water, one ounce of laudanum for a medium-sized horse, an ounce and a half for a big horse, with from one to two ounces of sweet spirits of nitre. The morphine or the laudanum dose, whichever is given, should be repeated in forty-five minutes, if the pain continues, and a third dose may be given, if necessary, about one hour after the second dose. In cases of colic it is often sufficient to relieve the pain, and when that is done, nature will complete the cure.

Spasmodic colic is a spasmodic contraction of the muscular coat of the intestines, and it often develops into inflammation of the bowels. 
The following is a remedy for spasmodic colic:

Chloroform ................ drachms

Tincture of opium............. I ounce

Sulphuric ether $\ldots \ldots \ldots \ldots \ldots \ldots$ I/2 ounce

Linseed oil in sufficient quantity to make the whole mixture equal to a quart. To be given at one dose.

If, in spite of this remedy, the horse still shows signs of pain, he should be given the hypodermic injection of morphine, or the laudanum above prescribed for flatulent colic.

For inflammation of the bowels the following simple remedy may be given:

Common salt..............6 ounces

Warm water................ I pint

Colic may be distinguished from inflammation of the bowels, by the following symptoms:

Colic comes on suddenly; the pulse is not much quickened (unless the attack is long continued); the strength is not much affected; the legs and ears are warm; the pain is intermittent, and the horse, at intervals, seems all right.

Inflammation of the bowels comes on slowly; the legs and ears are cold; the pulse is quick and feeble; the belly is painful to the touch; the pain is constant, and is increased by movement; there is great weakness.

It is often difficult, however, to distinguish colic of one kind from colic of the other kind, or from inflammation of the bowels, and other intestinal diseases. 


\section{STOMACH AND BOWEL DISEASES 225}

Therefore, unless you succeed in relieving the horse immediately, it is best to call in a veterinary surgeon. In these cases delay is apt to be fatal.

\section{SCOURING}

If a horse has any tendency to scour, he should be taught to drink before eating - that is easily done; and he should never be watered until two hours after eating. He should, moreover, be watered as often as possible, so that he will not drink much at any one time; and an hour or so should elapse before he is put to work after eating. Every horse should be worked easily for the first part of his task, and this rule is especially important in the case of a horse with any weakness of the bowels.

Boiled potatoes may be given to prevent scouring, their effect in this respect being exactly opposite to their effect in the raw state. A little starch may be mixed with the grain, say about twice a day, and in severe cases the following remedy may be used:

Reduced iron................. p pound

Powdered gentian ........... $1 / 2$ pound

Nux Vomica............... $1 / 2$ pound

Areca nut ................ $1 / 2$ pound

Bi-carbonate of soda........... $1 / 2$ pound

Add powdered fennel seed, 2 pounds, mix, and give a teaspoonful at each meal for six weeks or so. Then once a day, two or three times a week.

\section{WORMS}

Colts and young horses are apt to have worms, and so are horses in poor condition especially when the poor 
condition is due to want of grain. This is only one example of the general law that when any animal is allowed to get out of condition, it becomes the prey of various hostile creatures that attack it internally or externally.

There are two kinds of worms. There is the large worm, which is long, round, white, and tapering at each end. This worm usually inhabits the stomach and small intestine. If the horse is hidebound, with a staring coat, morbid appetite and distended belly, he probably has worms of this kind.

The other kind is a small, thread-like worm, not much above an inch in length, and it usually inhabits the rectum, not far from the anus. Its presence is often shown by small yellow streaks or patches on the skin directly under the tail. These yellow spots are the eggs of the worm. Worms of this sort cause an itching, and the horse will rub his tail and hind quarters against the stall or any other object which he can reach.

To rid the horse of the larger worms, he should first be given a tonic of some kind, and afterward a dose of physic. The reason for this was humorously explained by an Irish veterinary surgeon of great ability. He. said, "If you want to get a man out of his house, you must first make him good-natured, and then you can coax him out. It is the same with the worm - you must feed him up before you can dislodge him."

The following is a good tonic for this purpose:

Powdered sulphate of iron, one pound; ginger, gentian, nitrate of potash, and bi-carbonate of soda, each one-half pound.

This should be well mixed and a tablespoonful in dry 


\section{STOMACH AND BOWEL DISEASES 227}

bran given three times a day. After one week of this, give the horse a bran mash for a night or two, so as to open his bowels, and then carefully give him one quart of raw linseed oil. The oil should be given on an empty stomach, and the horse should be used very little for the next two days, as the oil will make him feel sick, impair his appetite and weaken him somewhat. After the oil, continue the tonic for ten days more, and at the end of that time, a second dose of oil may be given if the worms still appear to trouble the horse. Sometimes these long worms can be got rid of without physic, by giving the horse a tablespoonful of salt and the same quantity of charcoal mixed with his grain, morning and night, for a day or two - or even longer if he will eat so much salt. This is more likely to be effective if preceded and followed by the tonic above prescribed.

The smaller worms can usually be removed by an injection of salt and water, or by giving an ordinary injection of soap and warm water to clear out the intestines, and then giving immediately afterward another injection of a quart of linseed oil, with which one ounce of turpentine has been mixed. 


\section{CHAPTER XLI}

\section{DISEASES OF THE KIDNEYS AND LIVER}

TROUBLE with the urine seldom occurs; but stable1 men may often be heard to say: "That horse's water is thick and high-colored. He needs a dose of niter;" and forthwith, the horse is dosed. But the color and consistency of the urine vary very much from time to time even in a perfectly healthy horse. In hot weather, the horse gets rid of the water in his system by sweating; and his urine looks comparatively dark and thick. Then comes a cold spell, the horse ceases to sweat, and consequently he stales more frequently, and his urine is very light-colored and watery.

It is a good rule to give no medicine for supposed trouble with the kidneys unless the legs are stocked. If the kidneys need stimulating, and sometimes they do, especially when the horse is changing his coat, give him from one to two ounces of sweet spirits of niter, carefully mixed with his grain, or a tablespoonful of saltpeter. He should not require this more than once or twice a year.

In the case of highly grained horses, like work-horses in the city, it is well to give them once a week in summer a heaping teaspoonful of saltpeter in their mash.

Most geldings in use become "foul," and sometimes are unable to urinate, because the sheath is not 


\section{KIDNEY AND LIVER DISEASES 229}

kept clean. It should be washed with clean, warm water and Castile soap at least once in six months.

\section{AZOTURIA OR BLACKWATER}

This is an acute disease of the kidneys, and it is so named because, when an attack comes on, the urine of the horse is almost black in color, and very thick. The disease is caused by suddenly stopping the work and continuing the grain of highly fed horses. A thin horse is very rarely attacked by it.

When a holiday and a Sunday come together, so that the city draft horse stands in for two days, cases of blackwater always occur. In Chicago, under these circumstances, there were once more than I 50 cases in a single day. But now the nature of the disease is generally known and horse-owners guard against it by reducing the grain of their horses on consecutive days of idleness, and sometimes also by having them led up and down for exercise.

Azoturia very seldom attacks the horse in the stable. It comes on suddenly when he is taken out, and usually after he has gone only a short distance. The horse suffers great pain, sweats profusely, and is very apt to fall to the ground. The only thing to do is to get him into a stable, and send for a veterinary surgeon. If no "vet" is available, the treatment should be as follows: If a sling is at hand, put the horse in it, in order to avoid injury from his throwing himself about. If a sling is not available, put him in a box stall or on the stable floor, with a deep bed of straw under him, and his head padded. Give him a dose of physic, say a 
quart of linseed oil, with one ounce of epsom salts, and also give about two ounces of sweet spirits of nitre Place blankets wrung out in hot water and turpentine over his loins; or else rub white liniment on his loins and hips.

A horse recovering from azoturia is, as a rule, extremely lame in one or both of his hind legs because of atrophy of the muscles of the hip and stifle. However, this lameness is purely mechanical. It causes no pain, and the horse gradually gets over it if he receives regular but gentle exercise - such as to strengthen the muscles and restore them to their normal condition.

\section{THE LIVER}

Diseases of the liver require a good veterinary surgeon both for diagnosis and treatment, but there is a bilious condition into which horses occasionally fall that might be mentioned here.

You have, we will assume, a fat, thrifty young horse doing very little work, who is lively and spirited one day, and very dull and sluggish the next. His coat looks rough, his skin is full of dandruff, and you are disgusted with him. The trouble is probably an inactive liver, and a handful of epsom or glauber salts should be placed in his grain for three or four nights. If this does not bring him round, renew the salts for three or four more nights, or give him a dose of physic. In any case, let him have plenty of bran mashes. 


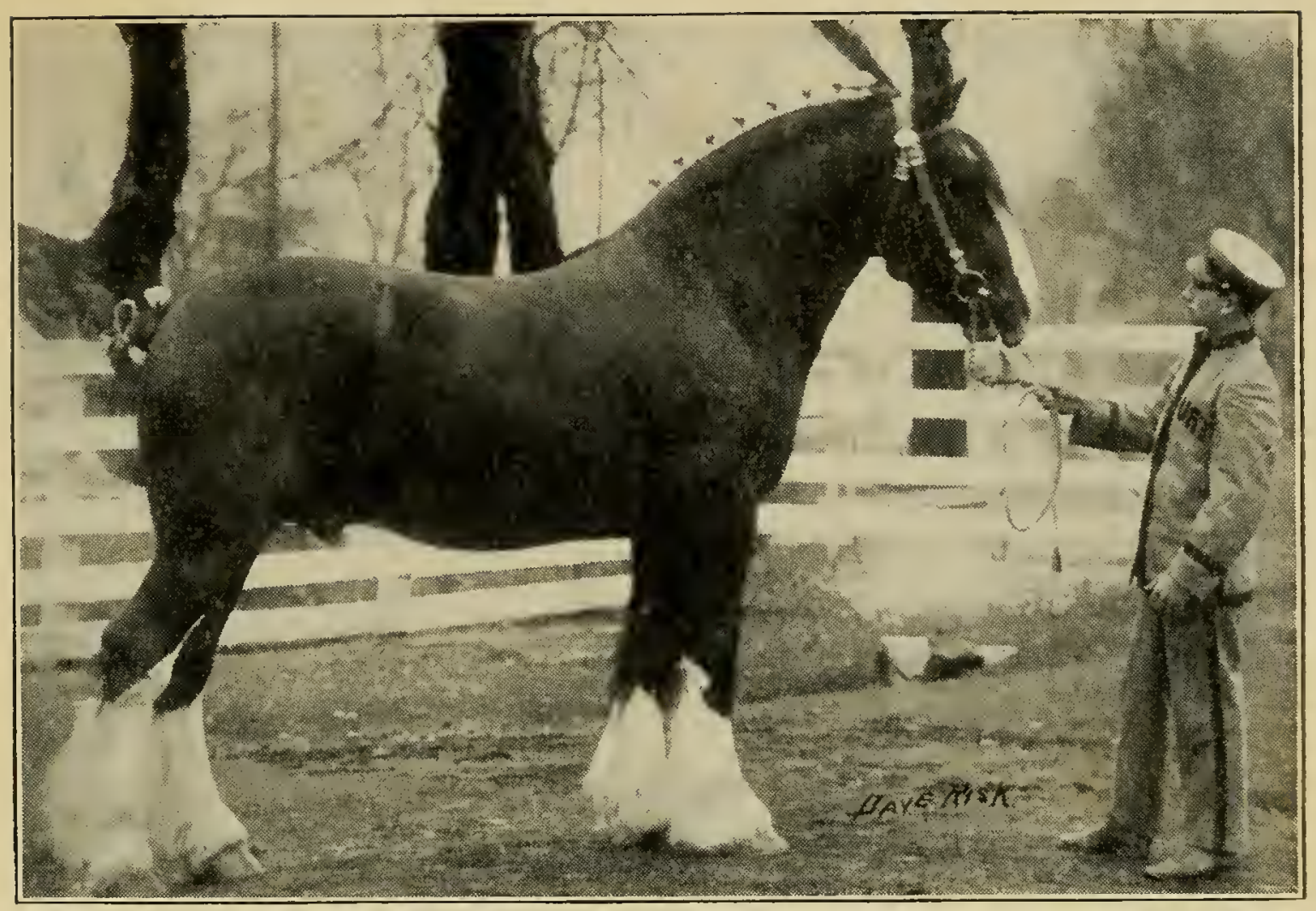

SHIRE STALLION, " ROYAL FRIAR II"

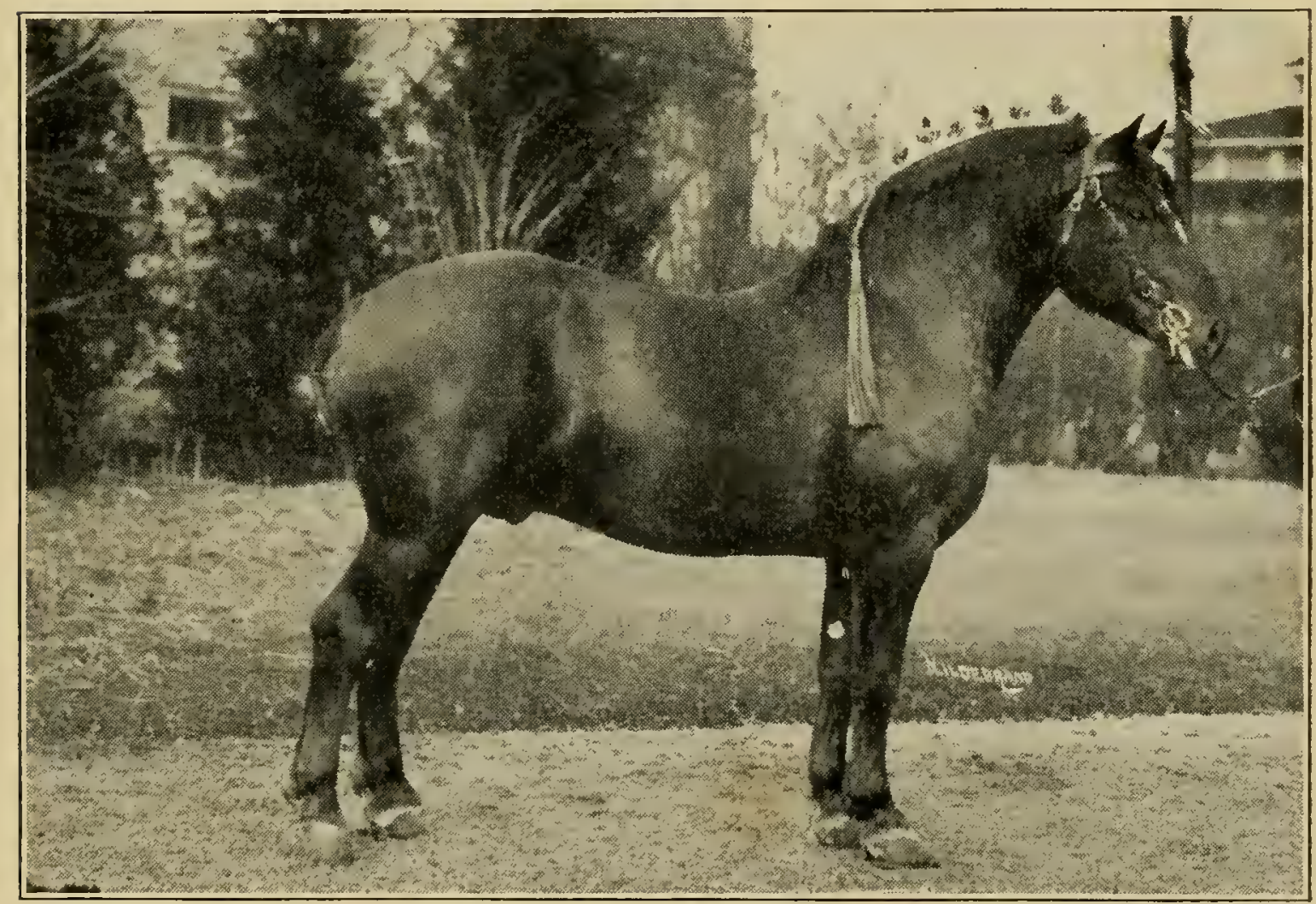

SUFFOLK STALLION, "ASHMOOR ROMEO" 



\section{CHAPTER XLII}

\section{DISEASES OF THE THROAT AND LUNGS}

THE most fatal disease among horses, next to colic, 1 is probably pneumonia; and the lungs and throat are always liable to disease when a change of climate occurs, especially a change from the interior to the seaboard. To prevent any such trouble among new arrivals it is well to give the following:

One-half ounce of quinine and one gill of gin in a pint of water, twice a day for three days. Then drop the quinine for two days, but keep up the gin for ten days; and after the expiration of the two days, renew the quinine for two days more.

A green horse suffers from homesickness as well as distemper, and nursing and petting will do him more good than any medicine. I have seen the whole appearance of such a horse change after a few minutes' handling and coddling by a sympathetic vet or groom.

\section{COUGHS AND COLDS}

For cough, caused by a cold, there is no better remedy than the old-fashioned one of elecampaine. Get the root, and with a knife scrape off about as much as would fill a tablespoon, and give this in the horse's grain two or three times a day. A teaspoonful of chlorate of potash, given in the same way, may perhaps be procured more easily. A horse suffering from a 


\section{THE HORSE}

cough, a cold, or strangles can usually be relieved by steaming his head. Half fill a bucket with hay, pour in boiling water, and hold the bucket under his head. This should be repeated two or three times a day.

\section{SORE THROAT}

For a sore throat such as often occurs in cases of distemper, the best remedy is probably a light blister of mustard applied to the under side of the neck, a short distance below the jaw.

\section{DISTEMPER AND PNEUMONIA}

In a bad case of distemper or influenza, much the better way is to call in a veterinary surgeon, if a good one can be had; and this applies to all serious troubles. And be sure to dio so before the horse becomes so ill that the case is hopeless.

The treatment in distemper is to give the horse fresh air, to keep him warm, quiet, and comfortable, and to coax his appetite with small bran mashes, slightly sweetened or salted. If the lungs are affected, and you will know this by the horse's breathing, antiphlogistine, or a liniment ${ }^{1}$ should be rubbed lightly on the body, back of the forelegs where the lungs are, and aconite may be given to lessen the fever, in doses of thirty drops every four hours. If the horse is weak he should be given some stimulant, such as gin and quinine, half

${ }^{1}$ A standard liniment is as follows: two fluid ounces of alcohol, two fluid ounces of oil of turpentine, one liquid ounce of liquor ammonia Fortier, and water enough to make one pint of liniment. The addition of half an ounce of gum camphor will give the mixture a pleasant odor. 


\section{KIDNEY AND LIVER DISEASES 233}

a pint of gin with a full teaspoonful of quinine, three times a day. The legs should be rubbed night and morning, and should be kept bandaged, but not tightly. This is the treatment for pneumonia.

Founder is apt to follow pneumonia, and therefore in a case of pneumonia the feet should be kept in mind, and should be poulticed if fever appears in them.

\section{HEAVES}

Heaves is a difficulty in breathing accompanied by a hard, dry cough. When a heavey horse breathes there is a double instead of a single motion of his flanks. What interior change has taken place is not certainly known, but it is supposed that the elasticity of the diaphragm is impaired or destroyed. Dusty or smoky hay is the usual cause of heaves, but anything which unduly distends the stomach, so that it presses upon the neighboring organs, may cause heaves. I have known a horse to get heaves by feeding all day upon frostbitten grass. A gross feeder may contract heaves even from the best of hay if he is fed no grain, and is obliged to satisfy his appetite on hay alone. The stomach of a horse is small, and he cannot do well if fed entirely on bulky food. It used to be the custom on New England farms to feed horses almost wholly upon hay, and heaves were then very much more prevalent than now when more grain is fed to horses at work.

The disease is incurable, but may be much alleviated by proper feeding and doctoring. The food should all be moistened, and it should be compact, so as to distend the stomach as little as possible. The hay should be 
sprinkled with water, preferably with lime water. It should be cut fine with a haycutter, if that is practicable, and it should not be more than half the usual quantity. The shortage of hay may be made up by liberal rations of oats and bran mixed with a little water. Linseed meal should also be given occasionally and, if the horse is old or thin, brown sugar, molasses, or molassine.

Horses afflicted with heaves, even though they were formerly most delicate feeders, will always devour their bedding or anything else that is edible. This, of course is the worst thing possible for them, and it should be prevented by bedding the horse with sawdust, shavings, peat-moss, or some other inedible substance. Why these unfortunate animals should have this morbid appetite is not certainly known, but probably it is because they are extremely uncomfortable inside, and they stuff themselves with the hope of obtaining relief, just as human beings sometimes eat when they have a "gnawing" in the stomach caused by indigestion. A horse with heaves always has difficulty in breathing, and is never comfortable. In severe cases this discomfort amounts to distress, and the only humane course is to kill him.

The most useful drug for heaves is probably Fowler's solution of arsenic, the dose being about one teaspoonful, given once a day for a few days, and then both night and morning. This should be given constantly, except that occasionally, say, once a month, the night dose should be omitted for two days, and for one or two days following both the morning and the night dose 


\section{THROAT AND LUNG DISEASES 235}

should be omitted - and after that the arsenic should be resumed in the same manner in which it was left off. Great harm may be done to the health of a horse either by beginning abruptly or by leaving off abruptly a powerful tonic like arsenic.

If a horse is getting too much arsenic he will show it by the very light yellow color of his dung.

\section{BROKEN WIND}

A wind-broken horse is one whose windpipe has become thickened, so that he makes a roaring or whistling sound when pulled or driven hard.

It is usually caused by driving a horse too fast and too far; or by making him pull too heavy a load, especially after eating or drinking. There is no cure for this trouble, but careful feeding will do something to make it less severe. As in the case of a heavey horse, the aim should be to give him food in a form as little bulky as possible - to nourish him without over-distending the stomach. (See the directions given above as to feeding a horse suffering from heaves.) No medicine or drugs of any kind can relieve the brokenwinded horse. Care should of course be taken not to call upon him for any effort when his stomach is full.

Some perfectly sound horses, especially if they are soft and fat, will curve their necks in, when pulling hard on the bit, and so shut off their own wind and make a roaring sound as if they were broken-winded; and it is not always easy to tell in such cases whether there is any real trouble with the air passage or not.

A horse with heaves never breathes naturally even 
when at rest; but a broken-winded horse, except in a very extreme case, breathes like any other horse so long as he is making no effort. It is usually possible to test a horse's wind by having him driven toward you at a rapid trot, and then pulled up suddenly. If, standing close to him, you hear no abnormal sound, it is safe to assume that his wind is untouched. 


\section{CHAPTER XLIII \\ DISEASES OF THE SIIN AND BLOOD}

THE condition of the horse's blood is revealed by his I skin, and the condition of the skin, in turn, is disclosed by the hair. If the horse is out of health, especially if he has worms, his coat will look rough - will "stare," to use the technical expression. Any irritation of the skin will produce the same effect. If the horse is chilled, or if he stands in a burning sun, his hair will point upward.

On the other hand, if the horse is healthy, clean, and comfortable, his hair will lie close to the skin, and will present that beautiful, sleek, and shining appearance which corresponds to the complexion of a human being in exuberant health.

\section{SCRATCHES}

Scratches are usually caused by the heels and pasterns becoming wet, and being allowed to remain wet, so that the parts are chilled. Scratches are especially prevalent when the roads are muddy, as in early spring, and still more when the horse has to travel through slush or melting snow. In perfectly dry weather, even in summer, scratches often follow the clipping of the hair around the pastern. This should never be done, except to shorten the hair when it is excessively long.

The condition of the horse has much to do with this 
disease. A very fat horse, who does not receive sufficient exercise, is subject to scratches, and so is an overworked, run-down horse - in each case the blood being in poor condition.

Trotting horses sometimes have what are called "speed-scratches," due to over-heating of the blood. It is difficult to train some horses without producing this condition. The skin of a high-bred horse is thin, and especially so at the heels on the inside, from the coronet to the pastern joint. Says E. C. Hathaway:

This particular point seems to be the one place where all sorts of dirt and scurf find lodgment, and it further appears to have a secretion of its own, especially when in a fevered condition.

This is the reason why the "swipe" who has charge of a trotter ties towels loosely around the pastern when his charge comes to the stable after a race or a "workout "- to prevent the salt sweat which runs down the leg from touching this particular part.

Mr. Hathaway further says on this subject:

One will find heels with a tendency to crack that are helped by ointments containing grease, vaseline, etc., while others are poisoned by the slightest particle of greasy matter of any kind. . . . The first requisite in both varieties of sore heels is to keep them clean. For this purpose nothing has been found that touches pure castile soap and warm water, not to be applied in the usual perfunctory way by the sponge or by the swipe's hand, but by use of a fairly stiff brush, such as is commonly used at home for washing the hands.

To prevent scratches, put glycerine or vaseline on 
the heels and pasterns before the horse is taken out on wet roads - especially in winter and spring - and when the horse comes in make his legs clean and dry as soon as possible - and especially $d r y$. Never wash them unless you are prepared to rub them dry afterward or to rub them nearly dry (if the hair is long you cannot get them perfectly dry), and then put on a thick bandage or two or three thin bandages on each leg. The purpose of this is of course to keep the legs warm while drying. The bandages should be put on loosely.

To cure scratches, wash the legs with warm water and castile soap when the horse comes in, dry them thoroughly, and then apply the ointment described on page 220 .

Another remedy for scratches - a mild one to be used when the trouble first appears, is this:

Rose water $\ldots \ldots \ldots \ldots \ldots \ldots \ldots \ldots \ldots \ldots$ ounces
Glycerine $\ldots \ldots \ldots \ldots \ldots$ ounces

Sugar of lead, in solution.......... I ounce

It will be noticed that all the remedies for scratches contain lead, and Rising Sun Stove Polish, which contains a good deal of lead, will be found an excellent remedy for scratches if mixed with vinegar.

If the scratches are so bad that matter accumulates, it will be necessary to apply a poultice, and for this purpose you can buy a rubber cylinder or ring which goes on over the hoof and holds the poultice in place. This is an inexpensive contrivance, and saves much trouble.

The poultice should be made of bran, and hot water, 
with a small quantity of sulpho-napthol added to the water. This is the poultice now in universal use by the best veterinary surgeons. They have discarded as being too strong and irritating the other materials, such as linseed meal, formerly used for this purpose.

If the horse that has scratches is over-fat or underexercised, it will be well to give him frequent bran mashes, and also epsom or, perferably, glauber salts, say a handful in his grain at night for three or four days - or longer in an extreme case.

\section{ECZEMA}

A bad state of the blood, especially in horses not receiving sufficient exercise, often shows itself in eczema or skin disease.

In light cases, a tablespoonful of sulphur given for three nights, then omitted for three nights, and given again for three more nights, will usually effect a cure. The spots or blisters on the skin should be treated with a mixture of sulphur and lard, or, in mild cases, with a weak solution of vinegar and water.

Eczema usually attacks horses that are too fat, but sometimes it is caused by thinness of the blood. In the latter case, Fowler's solution of arsenic is a remedy. The dose should be a teaspoonful once a day for a week; then twice a day for a week; then once a day for a week; then stop for a week, and begin again if necessary. (See page 234.)

A blanketed horse that is troubled with eczema should wear a linen blanket next to his coat, to avoid the irritation of a woolen blanket. Eczema is very 
infectious, and one horse will catch it quickly from another if the same harness, brushes, or blankets are used for both. Everything that has touched a horse with eczema should be disinfected by putting it in naphtha, or in a solution of one part of corrosive sublimate to 500 parts of water, or in boiling water.

\section{MANGE}

Mange is caused by an animal - a microscopical insect. Mange is sometimes hard to distinguish from eczema. The itching is usually greater than it is with eczema. Mange, in the most common form, consists of a multitude of little hard pimples, which feel as if small seeds had been sown at the roots of the hair, and had adhered to the skin. There is a little scab on each of these pimples, in which are two or three hairs, and if the scab is removed, a small red spot appears. The itching is intense. In a short time, the hair falls off, the skin becoming dry, wrinkled, and scaly, with raw spots and cracks.

Thorough treatment is necessary in order to destroy the parasite. The skin should first be well washed with soap and warm water, applied with a brush, so as to remove the scales and permit the close application of the dressing. Paraffine oil applied once a day and allowed to dry on the skin is usually effective. Perhaps better is the following mixture:

Oil of $\operatorname{tar} \ldots \ldots \ldots \ldots \ldots 2$ ounces

Kerosene ............. 1/2 ounce

Sulphur .............2 tablespoonsful

Cottonseed oil enough to make the whole I pint. 
Two or three days after the skin has been dressed, the horse should be washed again with soap and warm water. A second application of the dressing may possibly be necessary.

The theory of these mange cures is not only to suffocate and starve the parasites, but, also, to prevent them from moving from one part of the animal's body to another.

Mange, needless to say, is, if possible, more infectious than eczema, and everything that has come in contact with the horse, including the floor and sides of his stall should be disinfected, as above described in the case of eczema, or destroyed. All bedding taken from his stall should be burned.

\section{GLANDERS}

Glanders and farcy were formerly spoken of as two separate diseases, but they are one and the same disease. Farcy is that form or stage of glanders which appears on the surface of the horse in the shape of swellings or tumors, and especially in what are called "farcy buds." These are small, button-like swellings which soon become ulcers. They may appear on any part of the body, but are seen most often on the inside of the hind legs. These "buds" are unmistakable, being unlike any other swelling or tumor. Farcy is really the final stage of glanders, and not, as is sometimes said, the incipient stage.

Glanders in any stage is absolutely incurable, highly contagious, and dangerous to man as well as beast. It is a blood disease, and if any blood or pus from a 


\section{SKIN AND BLOOD DISEASES}

glandered horse gets into the blood of a man, his fate is sealed. More than one man has contracted glanders in his eyes by having an infected horse sneeze in his face.

Besides the "farcy buds," the most certain external indications of glanders are the following:

I. A hard, painless enlargement of the gland between the branches of the lower jaw, the submaxillary gland - the enlargement feeling like a walnut under the skin.

2. A similar enlargement of the lymphatic gland which runs up and down the hind legs.

3. Ulcers or sores of an unhealthy character inside the nose.

4. Swelling of one leg, usually a hind leg.

5. The discharge from one or both nostrils of thick, glutinous matter which adheres around the nostril and gives it a characteristic appearance. This discharged matter is heavy, and will sink in water, but commonly it does not have an offensive odor. A discharge having a bad odor is more likely to be caused by catarrh or by an abscess in the head than by glanders.

But a horse may have glanders, even for a long period, and yet show no external sign of it whatever. A horse in that condition, especially if his lungs are affected by the disease, can transmit the disease to other animals. Such horses are called "spreaders"; and it has often happened that one "spreader" in a large stable has been a source of infection for years, causing the death of many other horses before his own condition was discovered. 
An indication of interior glanders is a sudden falling off in condition. If a horse shrinks up suddenly, without any apparent cause, looking as if he had been deprived of hay or water, glanders may be suspected. This is apt to occur when the horse first contracts glanders. He may fill out again later, but, later still, though possibly months or years later, he will fall away again, and show other external signs of the disease. It seldom, perhaps never, happens that a horse dies of glanders without showing some external symptoms. The disease will appear at the surface when his constitution begins to succumb to it. If a horse with latent glanders contracts any other disease, especially a disease accompanied by fever, the glanders in his system will almost certainly appear in the form of "farcy buds" or otherwise.

It used to be thought that glanders was a spontaneous disease, and that a bad or neglected case of catarrh might develop into glanders. But this is impossible. The disease is a germ disease and can result only from infection of one animal by another.

Great pains should be taken, it need not be said, to disinfect everything that has come in contact with a glandered horse, or upon which he has breathed. Means of doing this are suggested on page $24 \mathrm{I}$. 


\section{CHAPTER XLIV}

\section{DISEASES OF THE LEGS}

THE following suggestions as to the detection and 1 treatment of lameness apply, in the main, to lameness both in the legs and feet. (Diseases of the feet are treated of in the succeeding chapter.)

I. Remember that a lame horse nods on his sound leg. It often happens that the wrong leg is treated for lameness. In testing a horse for lameness, see him backed out of his stall and then moved at a slow trot. Horses quickly warm out of a slight lameness.

2. You can usually find the seat even of obscure lameness provided that you look for it as carefully as if you were trying to discover the error in a column of figures. Begin at the bottom of the foot. Take nothing for granted. Pass no part until you are sure it is sound. Examine every joint, ligament, and muscle until you find the sore place. Handle the horse gently and quietly. Do not be rough with him or frighten him. Do not hurrry.

3. Remember that if a horse is lame from any cause, and whether in the leg or in the foot, the hoof on the lame leg will soon begin to contract and will pinch his foot just as a wooden shoe one size too small would pinch your foot and make you lame if you wore it day and night as the horse does his hoof. Therefore treat the hoof, that is, make it soft and keep it soft, 
and thus prevent fever and contraction, whether the lameness is in the foot or leg. ${ }^{1}$

4. If the horse becomes painfully lame, and you do not know why, put the lame foot and leg into a soaking tub with water as hot as your hand will bear, and keep them there for three or four hours, maintaining the heat of the water. There is nothing like hot water to take out pain and inflammation. This treatment will relieve the suffering from almost every form of lameness, and cannot do any harm. Repeat the process until the horse is relieved.

5. Do not use a lame horse except by advice of a veterinary surgeon.

6. If the horse is lame forward, the chances are that the trouble is in the foot. Tendon lameness is not infrequent, especially among light horses. Shoulder lameness is possible, but extremely rare. If there is lameness in the foot, the muscles of the shoulder will shrink from disuse - because the horse has thrown most of his weight on the sound leg and foot. This is why we hear so much of lameness in the shoulder. In shoulder lameness, the leg is swung outward.

\section{SPAVIN}

Spavin is a disease of the hind legs only. There are two kinds of spavin, bog or blood spavin and bone spavin. Bog spavin is like a windgall. It is a large, soft swelling immediately in front, and to the inside of the point of the hock. It is caused by a sprain of the large

1 Paragraphs 2 and 3 are taken mainly from the valuable booklet issued by The Reducine Company. 
tendon which passes down the leg to be inserted in the pedal bone, the sheath through which it passes at this point being distended by fluid. If it causes lameness, the only possible cure is rest. A bog spavin which causes lameness is usually incurable, and the unfortunate horse is in constant torment from it, whether at work or at rest, and his only release is by death. One often sees in horses suffering from painful bog or bone spavins a peculiar emaciation of the loins which witnesses to the extent of their sufferings.

A bone spavin is a deposit of bone, as the result of inflammation, on the inner and lower part of the hock. Sometimes it "hardens up," as horsemen say, and ceases to trouble the horse; but in other cases the spavin is the cause of continual lameness, and the horse is in perpetual misery. A spavined horse, in order to relieve himself, will throw his weight as much as he can on the sound leg; and this usually produces a spavin in that leg also. The unfortunate horse cannot then relieve himself by going lame, and his situation is most pitiable.

The worst spavins are "diffused" spavins which affect the whole hock. When the spavin occurs on the lower part of the hock the horse can usually be freed from pain and made to travel as if sound by the cutting of a certain tendon.

There are cases also of "occult" or "blind" spavin - the deposit of bone not being visible, although the horse is lame. In these cases the ulceration takes place between the bones of the hock.

If complete rest and time do not cure a case of 
spavin, whether it be bog spavin or bone spavin, there is no cure for it. Blistering and firing are often resorted to, but with little, if any effect.

\section{CURB}

A curb is a strain of the ligament just below the point of the hock. It often causes lameness, but seldom permanent lameness. The treatment should be rubbing with alcohol or Tuttle's Elixir, or with equal parts of iodine, camphor, and glycerine. If a cure is not effected, a mild blister should be applied.

Curbs, like windgalls, are often caused by overworking or over-driving young horses, or horses that are not in condition for hard work. Curbs are apt to come on horses that have crooked or sickle-shaped hocks. A "curby hock" is a hock that, by its shape, shows a tendency to curb.

\section{CAPPED HOCK}

Capped hock is a swelling on the point of the hock caused usually by lying down and getting up in a stall not well-provided with bedding. Sometimes it is caused by kicking in the stall, sometimes by using the horse with traces too short, so that his hocks strike the whiffletree.

The swelling may usually be removed by rubbing it with camphorated oil, or with alcohol in which camphor has been dissolved, or by the application of a liniment, such as Tuttle's Elixir, just strong enough to raise a very slight blister. This last I have found to be an effectual remedy. Massaging alone will often remove the swelling. 
There is another kind of capped hock which consists in a swelling on each side of the point of the hock caused by distension of the sheath of the tendon which passes over that part. This may be due to a sprain, and is usually accompanied by lameness. The treatment should be bathing with hot water, followed by gentle rubbing with alcohol. The horse should be shod with a high-heeled shoe, and should have complete rest until all lameness disappears.

\section{SHOE-BOIL}

A shoe-boil, or capped elbow, is caused by continual irritation from the pressure of the foot or shoe when the horse lies down with the fore leg doubled under him at the knee. Often in such cases you will find in the middle of the foot above the frog, a small, thin very hard projection of horn, between the heels, almost exactly like the blade of a razor. This is easily cut down with a knife, and the shoe-boil disappears. But in other cases the trouble is from the shoe, and in those cases the horse should wear in the stable a leather pad, made for the purpose, which encircles the fetlock of the offending foot, and thus protects the elbow. It is also possible, if the horse is kept in a straight stall, to prevent his doubling up a foreleg in such manner as to produce a shoe-boil by nailing a narrow strip of board across the floor of the stall a few inches back of the place where his forefeet come when he is standing.

Some authorities maintain that shoe-boil is caused simply by pressure on the elbow when the horse gets 
up on his knees; but whatever the cause, the means of prevention are the same.

If the shoe-boil is not large and does not contain matter, it may sometimes be reduced by rubbing it with camphorated oil. If the tumor is hot and painful a poultice should be applied to relieve the horse, and a veterinary surgeon should be called in either to lance it, or to cut it out, as the case may be.

\section{SPRUNG KNEES}

Sprung knces come about in three ways. Some horses, including not a few valuable animals, are foaled and always remain knee-sprung. To this class belonged Robert J., for example, the once famous pacer whose record is $2.0 \mathrm{I} / 4$.

Ordinarily, however, sprung knees are caused either first, by some strain of the tendons or of the kneejoint - it is uncertain which-or, secondly, by defective feet. It is easy to make a young horse, or a horse out of condition, knee-sprung, by working him too hard or too fast, and especially by using him in a vehicle too heavy for him. Light-boned horses are particularly subject to this injury, and I have more than once seen a young, light-boned horse made kneesprung by giving him a few long drives in a vehicle a little too heavy for his weight and strength. Standing in a stall which slopes backward too much will often produce the same result.

In case a horse becomes knee-sprung by overstrain, he should be given light, but regular, work, and his legs should be rubbed two or three times a week with some 


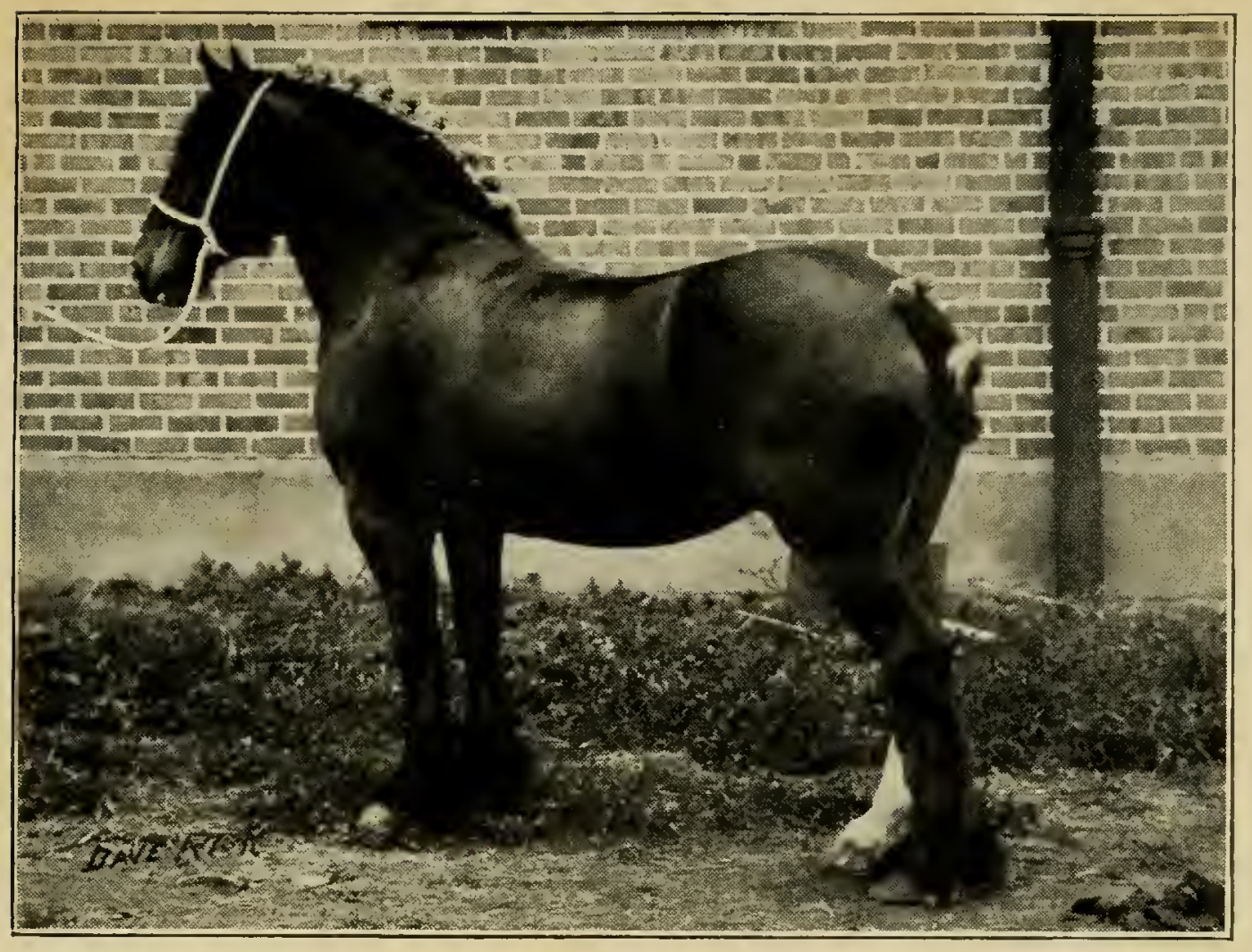

CLYDESDALE MARE, "LIZZIE"

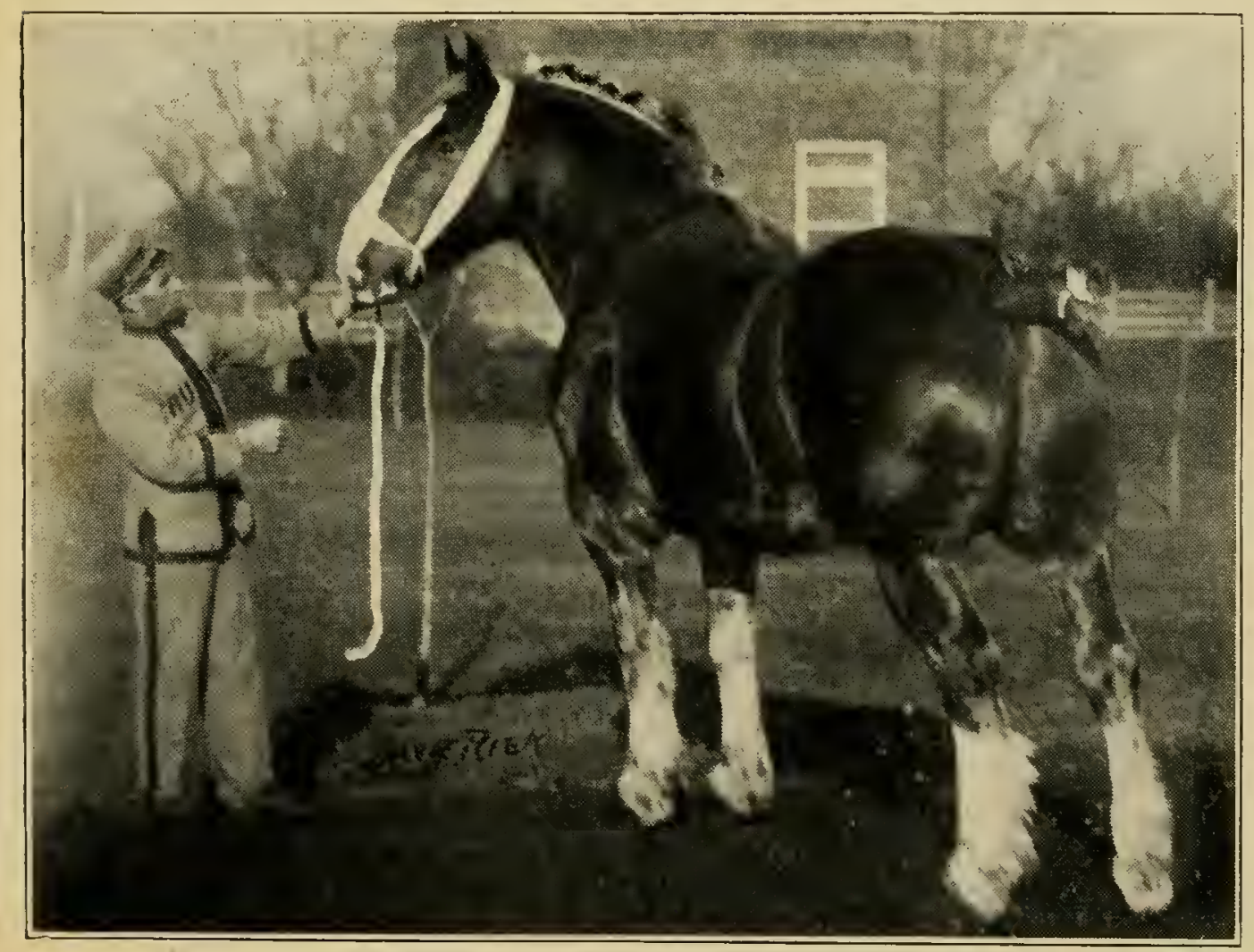

SHIRE GR.ADE GELDING 

mild liniment, which will not blister or burn the skin.

Most important of all, and this applies to all kneesprung horses, they should be fed from the floor, their toes should be kept short, and they should be shod with moderate heel calks, or perhaps better, their shoes should be made thicker at the heels.

A horse may become knee-sprung from defective feet in this way - if his feet are sore, he will stand in an unnatural position in order to take the strain of his weight from the sore part of his feet as much as possible; and the unnatural position of the foot involves, of course an unnatural position of the legs.

Some experts maintain that this defect is always caused by bad feet, and certainly if a horse becomes knee-sprung his feet should be carefully inspected, and looked after. A contracted hoof is especially liable to result in sprung knees.

\section{WINDGALLS}

These are distensions of the sheaths through which the tendons play. The most frequent cause is driving the horse too far or working him too hard when he is "soft" or out of condition. Overloading a horse or driving him too fast in a heavy vehicle are also frequent causes.

Colts and young horses are especially liable to injuries of this kind. Usually windgalls do not cause lameness, but if lameness or fever is present, the treatment should be rubbing with alcohol, then applying bandages soaked in alcohol with a dry bandage outside.

There is no way of removing windgalls except by 
improving the general condition of the horse and attending carefully to his legs and feet. I have known very large, unsightly windgalls to disappear, or nearly so, under such treatment, and that, too, in a horse more than ten years old; but the process required some five years, the improvement being steady but slow.

\section{THOROUGHPIN}

This is a rather large, soft swelling on each side and a little in front of the tendons in that part of the hock known as the "hollows." It looks like, and indeed, is, a kind of windgall and can be pushed through so as to appear on the other side of the leg. It is caused by sprain of the large tendon which passes down the leg to be inserted in the pedal bone, the sheath, through which it passes at this point, being distended by fluid. It does not usually cause lameness; but if lameness does result, the swelling should be rubbed with alcohol. The horse should not be used at all, and should be shod with a high-heeled shoe. If lameness continues, the horse should be blistered and turned out to pasture - or kept in a box stall if the season is unfavorable. 


\section{CHAPTER XLV}

\section{DISEASES OF THE FEET}

THE foot of the horse is a most delicate and com1 plicated contrivance, and every horse-shoer should thoroughly understand its construction. There are two facts about the foot which should especially be borne in mind, first that the main foot-bone is a continuation of the leg bone, so that if the foot is out of shape or balance the leg will be so also; secondly, that the hoof is simply a rigid, horny box enclosing the sensitive parts of the foot, so that $a$ contracted hoof has the same effect as a tight shoe upon the human foot - or rather a worse effect, for the horny box has no elasticity whatever, and, moreover, the unfortunate horse can never remove it.

\section{LAMINITIS OR FOUNDER}

Laminitis, commonly called founder, may be chronic or acute, and acute founder will surely become chronic unless measures are very promptly taken to cure it.

Founder is inflammation of the foot, and chiefly of the small laminae or leaves, five hundred or more in number, which unite the walls of the hoof to the parts within. These laminae surround the front and sides of the pedal bone, the largest being in front, and it is these which are most affected by the inflammation. This is a most painful disease causing the horse intense 
suffering because the diseased laminae are rigidly confined in a horny box, which does not permit any expansion of the inflamed and swollen parts.

It was formerly supposed that founder was a disease of the chest because when the feet are foundered the chest contracts, and has a hollow, instead of a convex appearance; but this is because, in an effort to relieve the forward part of the feet, the horse throws his weight on his heels as much as possible, and toes in, and this position makes him appear hollow-chested, and in time the chest will become deformed.

Chronic founder cannot be cured, and a badly foundered horse should be killed, to put him out of misery. Some relief can be given by keeping his feet soft, as by standing him in moist earth, or by tying wet woolen rags around the coronet every night, and by expanding the heel, through the use of springs or otherwise.

Calks should be avoided as far as possible, and a plain, rolling-motion shoe used; but if calks are necessary to avoid slipping, the four-calk shoe, so called, should be used. In most cases a bar shoe should be employed, with a leather or zinc pad; and the bar should be so fitted as to give frog-pressure, or to avoid frog-pressure, according to the particular condition of the foot in each case.

As stated above, the web of the shoe for a foundered horse should be wide, but concave, and "seated out," so as to protect the sole adjacent to the wall without touching it.

Sometimes a foundered foot has a tendency to 
spread, instead of to contract, and in these cases it is well to hold the foot in place with good, substantial clips on both the inside and outside of the shoe.

A mild blister around the coronet, to stimulate the growth of the hoof, is commonly beneficial.

Acute founder is almost always produced by one of three causes: giving the horse a drink of cold water when he is heated by hard work or a long drive, allowing him to stand unblanketed when heated, or by an over-feed of grain, especially corn. Many and many a fine horse has been ruined by getting loose in the stable, and helping himself to corn or oats carelessly left uncovered. A grain box so constructed that the horse cannot open it should be a fixture in every stable, even the smallest.

Acute founder is shown by pain and tenderness in the feet, which, if examined, will be found abnormally hot, with the artery in the pastern throbbing violently. Usually, only the forefeet are affected, but occasionally all the feet. In a bad case of extreme pain, the nostrils are distended and the horse trembles all over.

Acute founder can usually be cured if taken in hand immediately. A delay, even of two or three hours is dangerous. If possible, remove the shoes, doing it as gently as you can, but if the tools for this purpose are not at hand, do not attempt it until you can procure them. The essential thing is to put the horse at once with his feet in water as hot as your hand can bear it, and to keep him standing in the tub for three or four hours, maintaining the water at the same temperature all the time. If you have no tub-a common washing 
tub will do - you can make a shift with pails, though it may take two men to keep the horse standing in them. The water should come nearly up to his knees. After this soaking the feet should be poulticed with bran and hot water, the poultices changed as they cool, and kept on for several hours. The poultices should then be taken off for a few hours, but renewed, and kept on most of the time for several days.

Internally the horse should be given from ten to twenty drops - according to his size and the degree of fever - of tincture of aconite in a pint of water. This should be given two or three times at intervals of four hours. He might also be given one tablespoonful of saltpeter or two ounces of sweet spirits of nitre. As soon as the patient will take any food he should be given a bran mash, and he should have nothing but hay and bran mashes for several days. Great care should be taken the first time that he is shod, and especially must he be shod so as to protect the wall and sole, and, in most cases, to give frog-pressure. ${ }^{1} \mathrm{He}$ should be worked lightly for some time, and his feet examined every day, and measures taken to cool and soften them in case they become feverish or hard. He should be reshod every four weeks.

\section{NAVICULAR DISEASE}

Navicular disease is often supposed to be founder, and rice versa.

Navicular disease is a decay of the navicular or shuttle bone. This is a small, queerly shaped bone at

${ }^{1}$ See page 95. 
the back of the foot, which acts as a pulley for the tendons; and sometimes the tendons themselves are affected. The navicular bone often becomes honeycombed from decay - and it may be imagined how painful must be that condition. In fact this is one of the most terrible diseases from which the horse suffers, and a horse thus afflicted should either be nerved or killed. The operation of nerving is a difficult one, but after it is performed the horse feels no pain and goes as if sound.

Navicular disease sometimes exists in a very bad form without altering in the least the natural appearance of the foot; but as a rule the feet contract, especially in long-standing cases.

Horses with flat feet are more apt than others to be foundered. Horses that have strong "cup feet" or "mule feet" are more apt to get navicular disease than other horses, because when this kind of foot is shod, it does not get sufficient frog-pressure. Special pains should be taken with such horses to prevent their feet from becoming hard or contracted, and on soft roads they can, for short periods, be used to advantage without shoes or with tips. Calks are more harmful to such feet than to others. I have known a case of chronic founder - not navicular disease - of about six weeks standing, to be cured or almost cured in a horse with cup feet by shoeing him with tips. No doubt, if he had thus been shod when his feet first began to contract, the foundering would have been prevented.

Navicular disease can be distinguished from founder thus : 
A foundered horse steps on his heels; a horse with navicular disease steps on his toes, and the shoes will be worn down accordingly. Founder almost invariably attacks both forefeet equally; but in navicular disease one foot is usually worse than the other, and sometimes only one foot is affected. The affected foot is colder than the other.

A foundered horse goes down hill about as well as up hill; but a horse with navicular disease goes much worse down hill than up. Navicular disease, when it begins, is intermittent. The horse may be lame one day, and not the next; or he may go lame for a part of the distance, and appear to be sound for the rest.

A horse with navicular disease "points" the lame foot when he is standing; that is, he advances it, throwing his weight on the other foot, and if both feet are affected, he will point first one, and then the other. A foundered horse usually stands with both forefeet somewhat advanced. This attitude, indeed, should always raise a suspicion as to the soundness of the horse.

There is no cure for navicular disease, but it can be alleviated somewhat by soaking the foot in cold water, or by tying wet rags of wool around the coronet, and in other like ways.

The shoeing of a horse with navicular disease is very important. The foot should be shod so as to protect the sole and the frog, the navicular bone being immediately underneath the frog. A leather or metal pad is useful for this purpose. Calks should be dispensed with, if possible, but if they are necessary to prevent 
slipping, a "four-calk" shoe should be employed. Toe calks and heel calks should be avoided. If a bar shoe is used, and in most cases it is beneficial, the bar should be of such a character as to protect the frog; that is, it should be wide, and should be fitted so as not to touch the frog at any point. As a rule, the heels of a horse with navicular disease should be lowered. James Clark says, "The foot should be well-poulticed before shoeing, and the coronary band well stimulated with a blister or a penetrating liniment after shoeing that will remove the soreness, and keep the foot in a soft and pliable condition." Springs to expand the heels may also be used, care being taken to keep the feet soft while the springs are in use, as otherwise they would do more harm than good.

\section{THRUSH}

This is a diseased condition of the frog, and is readily detected by a peculiar and offensive smell. It is usually caused by standing in a wet and dirty stall. Stuffing the feet with cow-manure, in order to soften them, has often caused thrush. Sometimes thrush appears from the very opposite cause, that is, from extreme dryness of the frog, produced by want of frog-pressure. Thrush can easily be cured if taken in time, and does not cause lameness unless it is neglected. Yet many horses become lame from thrush because their owners pay no attention to their feet.

An excellent remedy is the application of salt, soaked with kerosene oil. Tow, soaked with tar or carbolic acid, and well pushed into the clefts and crevices is 
another remedy. In an extreme case, poulticing may be necessary.

Blue vitriol will cure the worst case, but its use should be avoided, if possible, because it leaves the foot very hard, and having cured the thrush, you would then have to take measures to cure the hardness.

Thrush neglected often runs into canker, an obstinate disease requiring treatment by a good veterinary surgeon. In the absence of a veterinary surgeon, cleanse the parts thoroughly and throw in calomel.

\section{CORNS}

A corn in the equine foot is not like a corn in the human foot. It is simply a bruise of or injury to the membrane covering the bone of the foot immediately beneath the horny sole. It may occur at any part of the sole, but most often at the inside heel in the angle between the frog and the bar - the sole being thinnest at that point.

A blood-stain in the hoof is not necessarily a cornit may be only a bruise of the sole.

Corns are usually caused by contraction of the hoof, and want of circulation, or by a shoe which pinches the foot because it was too small in the first place, or has been left on too long. ${ }^{1}$

In the case of horses that have corns the shoeing should be such as to get frog-pressure. If a horse has a painful corn, he will, as a rule, "point" the foot when he is standing; and a light tap with a hammer on the wall near the place of the corn will make him

1 See page roz. 
wince with pain. The remedy for a corn is to remove the shoe, pare out the corn - allowing any matter to escape - poultice the foot if there is any inflammation, or, in slight cases, fill the hole caused by the paring with oakum or tow saturated with tar. The horse should be shod in such a manner that no pressure will come on the parts adjacent to the corn; but the shoe should not be replaced until the horse is free from lameness. The lameness produced by a corn is very painful, and a horse subject to corns should be shod often, and his feet should be well-cared for.

\section{QUITTOR}

Quittor is an abscess inside of the hoof, usually situated near the heels, and near the coronet. If left to itself it will in time break out at the coronet, just above the hoof - a most sensitive spot. Quittor is, without doubt, the most painful of all the painful troubles from which the horse suffers. It is like a felon on a man's hand, but worse - for the hand can swell, whereas the equine foot in its horny box cannot swell. A quittor is like a felon on a hand incased in an iron glove. Quittors are caused by bruises, by the prick of a nail, and by neglected corns. Often the trouble is not suspected until, with intense pain to the horse, the pus slowly works its way above the hoof, where it can discharge.

If your horse is lame, and you cannot tell why, do not fail to test him for quittor by gently tapping the bottom and the outside shell of the hoof with a small hammer. A veterinary surgeon should be called to treat a 
quittor, but if no "vet" can be had, take the curved end of a horse-shoer's knife and pare through the sole of the foot at the point where you have detected the quittor. When the place is reached the pus will spurt out to the great relief of the horse. The cavity should be well washed with clean, warm water, and then the horse should be tubbed in a solution of corrosive sublimate - one tablet for every quart of water - the water being deep enough in the tub to cover the pastern.

In case the quittor has been neglected until it breaks open of itself above the hoof, another opening should be made through the sole, and treated as above described. This is necessary because the pus will not fully discharge itself at the coronet. Quittors are, in most cases, incurable.

A quittor used to be called "gravel in the hoof" the theory being that gravel worked up through the sole of the foot and made an outlet for itself above the hoof. This, it is now known, would be impossible, and the real cause of the quittor is always inflammation inside of the hoof.

\section{SIDE-BONES AND RING-BONES}

These troubles are very common, especially with heavy horses, and they are often inherited - or at least the tendency to have them is inherited, and when the horse is used on hard roads, or shod with high calks, the disease develops. Colts whose feet have been neglected, particularly if their toes have been allowed to become too long, often show side-bones or ringbones even before they have been put to work. 
Side-bone is a hardening of the cartilage just above the coronet near the heels. In its natural state this cartilage yields very slightly to the pressure of the hand. When it becomes hard and ossified it is a sidebone.

Ring-bone is more like a spavin, being a deposit of bone, produced by inflammation, on one or both of the pastern bones. It occurs in both fore and hind legs, but more frequently in the hind legs. In one case, that of side-bone, the cartilage turns to bone; in the other case, that of ring-bone, there is a deposit of bone. There may be no enlargement with side-bone, but there must be with ring-bone; and in bad, long-standing cases of both diseases, there is often great enlargement, amounting to a distortion of the foot.

The treatment in both cases is the same: first, the inflammation and fever should be allayed either by soaking in hot water, or by applying swabs or bandages kept wet with cold water; and this may be followed by a blister, and complete rest.

Bar shoes should be used in cases of side-bone or ring-bone, and with ring-bone, a "roller-motion" toe should be employed, and the hoof should be thinned near the coronet.

Nerving is often performed in cases of side-bone and ring-bone. 


\section{CHAPTER XLVI \\ CRIBBING AND WEAVING}

CRIB-BITING or "cribbing" has been observed and discussed for hundreds, if not thousands, of years, but its cause is still in dispute. Some authorities maintain that a horse cribs because his stomach is full of gas, and he tries to get rid of it. Others declare that indigestion is the result, not the cause of cribbing; and this is probably the correct view. A horse cribs because he is idle and restless; he cribs to "pass away the time." He begins by examining all the objects within his reach, licks his manger, takes the halter rope in his teeth, explores the sides of his stall, bites gently at all convenient projections in manger or hay-rack; and from biting to wind-sucking is an easy transition.

Hunger, I am inclined to believe, is a frequent cause of cribbing, although $I$ have never seen this theory advanced. A hungry, idle horse has an uncomfortable feeling in his stomach, nibbles at one object and another, and finally sucks in air for want of anything else to fill the vacuum of which he is painfully conscious. For this reason $I$ think that horses receiving only a small grain ration should be fed with hay three or four times a day - not necessarily a big feed, but enough to prevent them from becoming uncomfortably hungry. This applies especially to the noon feed.

There are other causes of cribbing. For example, a 


\section{CRIBBING AND WEAVING}

thin-skinned horse might contract the habit from being roughly groomed. The process hurts him, and he grips some object with his teeth, and holds his breath. Everyone has seen horses do this when they were irritated or excited; and it is a short step from this habit to cribbing.

The act of cribbing is thus described by the late Captain Hayes:

The exact process is that during a temporary interruption of breathing and visible contraction of the muscles on the anterior margin of the throat, the larynx and base of the tongue are drawn downward, whereupon the upper part of the pharynx becomes filled with air, which, during the then following act of swallowing and return of the larynx and tongue-base to their former positions, partly escapes forward, or the whole may be swallowed, by which one or two champing sounds are produced - peculiar tones like belching.

Perhaps the nearest approach that a human being makes to this habit is the inhaling practiced by some smokers of cigarettes.

Confirmed cribbers have been known to lay hold of their own knees with their teeth as a means of cribbing, and it is said that foals will sometimes use their mother's hocks for this purpose.

Some horses, called "air-snappers," crib without touching any object with their teeth. They stand with the neck arched, and the muzzle approaching the breast; their heads nod a little, they smack their lips, and finally accomplish their object with an upward, jerking motion of the head. "Air-snappers" are worse than ordinary cribbers, and will even leave off 
eating in order to indulge in the habit. It is rather curious that although the "air-snapper" does not touch anything with his teeth or lips, he likes to hold his head over something when he cribs. Thus, if loose in a box stall, he will stand with his head projecting above the lower half of the stall door, when that is practicable, and if he is in a field he will come close to the fence, and put his head over the top rail before he cribs.

It is often asked, will one horse learn cribbing from another? Horses are very imitative, and certainly it is dangerous to have a cribber within the plain view of other horses. The danger would be slight in the case of hard-worked horses, but it would be great in the case of horses that spent many hours in the stable during the daytime. For the same reason, a sound horse should never be driven double with a cribber, for the cribber can easily use the pole or neck-yoke for his purpose, and the other horse would almost certainly imitate him.

Cribbing can usually, or at least often, be cured if taken in hand at once; but the habit is incurable when fully formed. If a horse begins to crib, his surroundings should be changed immediately and his mind diverted. In summer probably the best course is to put him at pasture. If he is kept in a straight stall, change him to a box stall; give him plenty of hay to eat; let him have a companion visible, or at least audible and smellable, in the next stall, and if he continues to crib, let him wear a wire muzzle, except during the hours when he is eating. The wire muzzle is, 
I believe, the best form of treatment even for the confirmed cribber - much better than the tight strap around the throat which always impedes the breathing of the horse, and often causes him to become a "roarer." He need not, except in an extreme case, wear the muzzle while at work, for the amount of cribbing which the horse can do then, if he is used single, as he should be, does no great harm in ordinary cases.

The bad results of cribbing in the form of indigestion are, I believe, exaggerated. Cribbers frequently keep in good condition and live long. A trotting-bred horse with some speed was brought to the city many years ago, and held for sale at $\$ 500$. Unfortunately he became a cribber and was disposed of for \$I 20 to a liveryman who kept him until he died, or was killed, more than twenty years later. He was always the best horse in that stable, and always in good condition.

Sometimes, however, one sees an enlarged abdomen in a cribber, and in such cases a tonic should be given almost continuously. Nux Vomica is good for this purpose, twenty drops in water, once a day, for a horse five years old or over; seventeen drops for a four-yearold; fifteen drops for a three-year-old; ten drops for a two-year-old; six or seven drops for a yearling. The following condition powder may also be recommended for a cribber:

Gentian, well-ground............ I pound

Peruvian bark ............... I pound

Ginger root..............

Dose: a heaping tablespoonful in the grain three times a day. 
Some writers assert that cribbing is hereditary, and also that it is more frequently transmitted by the sire than by the dam. Collin, a French veterinary surgeon, declares that he traced the descendants of a famous Norman stallion and found that forty-five of them were cribbers, and that some of them developed the habit even as foals. Dr. C. A. Matthew, a Pennsylvania "vet," relates the case of a Percheron stallion which in one season, he says, got eighty-two foals, all but four of which were cribbers before they were a year old. The stallion himself was free from this habit or vice, but, upon investigation, Dr. Matthew found that the dam of the stallion was a cribber and had become such at a very early age.

However, we need more evidence on the subject. It is an important subject, for if cribbing is hereditary it cannot be a mere trick or habit, as the best authorities now believe, but must be the result of some diseased or abnormal condition.

\section{WEAVING}

Weaving, like cribbing, is a habit taken up by nervous, restless, and especially by idle horses. The weaver swings his head rapidly from side to side, with the motion of a pendulum, and often he does this with so much energy that he sways on his forefeet. A weaver, like an "air-snapper," prefers to have his head projecting over something, such as the lower half of the door of his box stall, when he weaves. There is no cure for this habit, except to divert the mind of the horse and give him new surroundings, and this treat- 


\section{CRIBBING AND WEAVING}

ment will be effectual only when the horse is a beginner, and not always then. Weavers are usually good, wellbred horses - animals with a superabundance of nervous energy. A lazy, phlegmatic horse is very unlikely to become a weaver.

The fact that cribbers are apt to become weavers also, tends to support the theory that cribbing, like weaving, is a habit, and not a disease or the result of a diseased condition. 



\section{BIBLIOGRAPHY}

THE CARE OF HORSES

Fisher, A. T. Through the Stable and Saddle Room. Bentley, London, I 890.

Timmis, R. S. Miodern Horse Management. Frederick A. Stokes Company, New York, I9I5.

Ware, Francis M. First-hand Bits of Stable Lore. Little, Brown and Company, Boston, I902; Our Noblest Friend the Horse. The Page Company, Boston, I903.

\section{BREEDING AND TRAINING}

Bell, G. A. Breeds of Draft Horses. Farmers' Bulletin No. 6I9, United States Department of Agriculture, I9I2.

Bradiurn, John. Breeding and Developing the Trotter. American Horse Breeder Pub. Co., Boston, I 894.

DAY, W. The Horse: How to Breed and Rear Him. Bentley, London, I88I.

Hayes, M. H. The Points of the Horse. W. Thacker \& Co., London, 1893; Illustrated Horse Breaking. W. Thacker \& Co., 1876.

Stambaugh, V. G. Breaking and Training Colts. Farmers' Bulletin No. 667, United States Department of Agriculture, 1915.

Speed, John G. The Horse in America. Doubleday, Page \& Co., New York, 1915.

\section{VETERINARY WORKS}

Hayes, M. H. Veterinary Notes for Horse Owners. Hurst and Blackett, London, I 906.

Special Report on Diseases of the Horse. United States Bureau of Animal Industry, I903. 


\section{THE ARAB HORSE}

Blunt, Lady Anne. The Bedouin Tribes of the Euphrates. Harper and Brothers, New York, I879; Pilgrimage to Nejd. Murray, London, I88I.

These two books give an interesting and trustworthy account of the Arab horse in his native desert.

Borden, Spencer. The Arab Horse. Doubleday, Page \& Co., New York, I 906.

Davenport, Homer. My Quest of the Arab Horse. William Rickey \& Co., New York, I909.

Tweedie, W. The Arabian Horse. W. Blackwood, Edinburgh, I 894 .

An exhaustive work in two large illustrated volumes.

\section{THE THOROUGHBRED HORSE}

Trevathan, C. E. The American Thoroughbred. The Macmillan Company, New York, 1905.

\section{THE MORGAN HORSE}

Battell, Joseph, and his Executors. The Morgan Horse and Register. 3 vols. American Publishing Company, Middlebury, Vermont.

Dimon, JoHn. American Horses and Horse Breeding. Hartford, Conn., I 895.

Linsley, D. C. Morgan Horses. Published in 1857.

This is the oldest and most important work on the subject. It is out of print, but the Morgan Horse Club has a few copies for sale at five dollars each.

Murray, W. H. H. The Perfect Horse. Boston, i 873.

Parlin, S. W. The American Trotter. The American Horse

Breeder, Boston, I905.

This book contains some valuable chapters about the Morgan horse-especially valuable in respect to pedigrees, as to which there is no better authority in the world than Mr. Parlin. $\mathrm{He}$ was a lieutenant of cavalry and rode a Morgan horse in the Civil War.

Rommel, G. M. The Preservation of Our Native Types of

Horses. Circular No. I37, United States Department of Agriculture, I908; The Regeneration of the Morgan Horse. Circular No. I63, United States Department of Agriculture, I9IO. 


\section{THE TROTTING HORSE}

Bradburn, John. Breeding and Developing the Trotter.

The late Mr. Bradburn was a practical man, and a leading authority on the subject.

Busbey, Hamilton. The Trotting and Pacing Horse in America. The Macmillan Company, New York, I904. Instructive, and agreeably written.

Helm, H. T. American Roadsters and Trotting Horses. Rand, McNally \& Co., Chicago, I878.

A highly original work dealing chiefly with conformation as controlling gait. This book never received the attention which it deserved. The author died some years ago.

Marvin, Charles. Training the Trotting Horse. New

York, I89o.

Mr. Marvin was the trainer at Palo Alto.

Parlin, S. W. The American Trotter. The American Horse Breeder, Boston, 1905.

A most accurate history of the trotter.

Splan, JoHn. Life with the Trotters. Edited by H. T.

White. Chicago, i 889.

A very racy, entertaining, and instructive book.

Woodruff, Hiram. The Trotting Horse of America. Winston, New York, I 868.

This is the classic book on the subject, and perhaps the most readable book ever written on the subject of the horse.

\section{SADDLE HORSES}

Anderson, E. L. On Horseback. New York, 1882. Anderson, E. L., And Collier, P. Riding and Driving. New

York, I905.

BEACH, BELlE. Riding and Driving for Women. New York, I 912.

Bussigny, H. L. DE. Handbook for Horsewomen. New York, I 884.

CARTER, W. H. Horses, Saddles, and Bridles. Ketcheson \& Reeves, Leavenworth, Kansas, 1895.

Dealing especially with cavalry horses.

Dodge, T. A. Patroclus and.Penelope. Boston, 1885.

Melville, Whyte. Riding Recollections. New York, i 899.

Very interesting essays, mainly about riding to hounds in England. 
Plummer and Power. The Army Horse. Washington, D. C., 1903 .

Weir, Robert. Riding and Polo. Longmans \& Co.'s "Badminton Library," London.

A comprehensive English book.

Xenophon. The Art of Horsemanship. Translated by the late Professor M. H. Morgan. Boston, 1893.

A short, most interesting work, with excellent illustrations.

\section{SHOEING}

Clark, James. Shoeing and Balancing the Light Harness Horse. The Horse World Co., Buffalo, 1916.

Roberge, D. The Foot of the Horse. Wm. R. Jenkins Company, New York. 


\section{INDEX}

Abdallah, 18x, 186

Admiral Dewey, 192

Advertiser, 193

Ajax, 180

Alcander, 189

Alcantara, $\mathbf{1 8 8 ,}$ I89

Alcidalia, II I

Alcyone, r88, 189

Alexander, Dr. A. S., 98

Alexander's Norman, 192

Alfalfa, 44

Alix, 185

Allen, H. L., $x_{3}$

Allerton, Iog, III

Alliewood, 190

Alma Mater, 188

Almont, 194

American Belgian Association, 207

American Clydesdale Association, 208

American Hackney Horse Society, 201

American Horse Breeder, The, I 66

American Saddle Horse Breeders' Association, 197, 199

American Suffolk Association, 2 II

Antiseptics, 146, 219

Apples, 44

Aquilin, 192

Arabian Horses, feet of, 30 ; ribs of, 29 ; as cavalry horses, 165

Arion, 4, 191-193, 196

Artillery, r95

Ashland Wilkes, ri

Ashmoor Romeo, 2 II

Atlantic Express, 195

Axford, 185
Axtell, II, I90

Axworthy family, 181, 190, 196

Azoturia, 229, 230

Azoff, 194

Badminton book on riding, 154

Balking, $\mathrm{I}_{3} 8$

Bar shoes, 99, 254, 259

Barley water, 62

Baron Peter, 194

Baron Wilkes, I81, 188, 189

Battell, Joseph, I 83

Beautiful Bay, 176

Beauty in farm horses, 149

Bedding, 48-50; kinds of, 5 I, 52

Belgian draft horses, 206, 207

Bellfounder, 187

Bellini, I95, 196

Belmont, 194,195

Bingara, 192, $193, x 96$

Bertini, 192, 195

Billy Root, 190

Bingen, 191, 192, 195, 196

Bingen family, 192, 194

Bits, ro6, 107

Black Hawk, I 79, I8 I

Blacksmiths, IOI, IO2

Blackwater, 228, 229

Blanketing, 70-75

Blind horses, $135, \times 36$

Blinders, xо3-106

Blitz, W. S., 183

Blunt, Wilfred, $x 72$

Blunt, Lady Anne, 172

Bob B., I80

Bondsman, The, 189

Boott, James, 187

Border Knight, 192

Borden, Spencer, $\mathbf{r}_{72}$ 
Borrow, George, 200

Boston Work-Horse Relief Association, 49, II 9

Bourbon Wilkes, I88, r9I

Bowels, inflammation of, 224; looseness of, 225

Brakes, I4I

Bran, I 5, 39, 4I-43

Bran mash, 42

Breaking or gentling colts, $18-22$

Breeching, II 4, II 5

Breeding, principles of, 3-6

Bridles, IO3

Broken wind, 235

Broodmares, 8-Io; foaling of, 9, ro

Brood-mare sires, 4, 182

Brown Braden, 185

Bruises, 2 I 9

Buford, Abe, 175

Bulrush, r 79

Burgess, Charles, 208

Burning Star, 193

Burns, 220, 221

Busbey, Hamilton, I87

Cabell's Lexington, 197

Calks, 90, 91

Captain Aubrey, 196

Capped hock, 248

Cardigan, Lord, 3 I

Carmon, I8r

Carring of horses, $130-132$

Carrots, 144

Casting, 5O, 56, II 9

Castleman, Gen. John B., I63

Cavalry horses, I6I-169

Check-reins, ro8-i ro

Chimes, I9I, I93

Clark, James, ro2

Cleveland Bays, 202

Clipping, 6o, 78-8I

Clover, 36, 21 5

Clydesdale horses, 208, 209

Coach horses, 202-204

Cochato, 192

Colds, 23 I

Coleman's Eureka, 197

Colic, afternoon, 32; causes of, 34 , 52 ; treatment of, 222-224
Colts, raising, I6-I8; training, 18-22

Collars, III, II2, I45

Colonel Cochran, 190

Conductor, 193

Conformation, 27-29

Conestoga horses, 204

Conner, J. J. Jr., 207

Cooler, 7I, 72

Cooling off, $55,56, \mathrm{I}_{42}$

Corn, 39, 43

Corns, 85, 102, 260

Constipation, 43

Contraction, 85,98

Coughs, $23 \mathrm{I}$

Cresceus, I95

Cribbing, 264-269

Cribs, 35

Crockett's Arabian, 192

Crouch, J., 203

Crupper, I I 4

Cup feet, 257

Curb, 248

Cut feed, 40

Cuts, 2 r 9

Dale, T. F., 40

Dan Patch, I8I, I9I

Daniel Lambert, 4, I79, I8I

Darling, E. A., 180, 183

Denmark, 197

Dexter, I95

Dickerson, John, 88

Dictator, 195

Digestion of horses, 222

Dillon family, 185

Dilham Prime Minister, 200

Diomed, 187

Dinsmore, Wayne, 206

Directum I, 195

Diseases of horses, $215-263$

Disinfectants, I 23

Distemper, 232

Docking, 67-69

Dolly, 190

Donald, 180

Draft horses, 202-2II; driving of, $137,138,140$

Driving, art of, I $33, \mathrm{I} 44$

Duke of Magenta, I73 
Dumb Jockey, I9

Dutch horses, I 76, I 77

Eczema, 240

Ed Winter, 189

Egotist, 193

Electioneer family, I91-193, I95, I96

Elyria, I8I

English horses, 200

Ethan Allen, I79-18 r

Ethan Woodbury, I80

Expedition, 193

Fanella, 193

Fanny Cook, I8I

Farcy, 242-244

Farm horses, I45-I49; treatment of, 52,129

Farriers, ror, 102

Favorite Wilkes, I88, I9I

Fearnaught, 179

Feeding of horses, 32-38

Feeding at noon, I4I

Feet, see Foot

Fish, Fred P., 198

Fistula, 220

Flora Temple, 23, 194

Flying Cloud, I $8 \mathrm{I}$

Flying Morgan, I $9 \mathrm{I}$

Foals, treatment of, II-I4

Forbes, J. M., 193

Forelock, 66

Foot, care of, 49, 85-89; diseases of, $253-263$; of sick horses, 215 ; injuries to, I4O; ointments for, $87-89$; structure of, $29,30,92$

Founder, 95, 253-256

French coach horses, 202, 203

Frog, 96, 97

Frog-pressure, 85, 86, 91, 97, 254, $257,259,260$

Gaits, of saddle horses, $\mathrm{I}_{58} 8$; of cavalry horses, 165

Gaines' Denmark, 197, 198

Galbraith, A. G., 2 II

Gambetta Wilkes, I8x, I88, I90

General Knox, I79

General Watts, I 96
Gentling, 18-22

George Wilkes, 180, I88. See also Wilkes family

German Coach horses, 203

German Emperor, I26

Gill's Vermont, I90

Gin, 42, 23I

Ginger, 42

Glanders, 122, 242-244

Grand Sentinel, I94, 196

Grain, 39

Grain-burnt, 127

Grass, 37,38

Grattan, M. T. I64

Grattan family, r9x

Grooming, 53-55

Grooms, 56, 60, 124-126

Gue, Gurney C., 20I

Guy Axworthy, 190

Guy Wilkes, I90, I9I, 196

Hackneys, 200, 20I

Hames, III

Hambletonian family, I80, 194, 195

Happy Medium, 194, ז96

Harness, IO3-II 5

Harold, I95

Harvester, The, 193, 196

Hats for horses, 6r

Hathaway, E. C., 238

Hawthorn Farm, 2 II

Hay, 35-37

Hay racks, 35

Heaves, 233, 234

Hedgewood Boy, I84

Heels of horse, 96, 97

Henry Clay, 188

Hinrichs, Art, 147

Hoof, See Foot

Hoof ointments, 87-89

Horse, breeding of, 3-6; back of, care of, I59, I60; care of, 3289 ; carring of, r $30-132$; casting of, 50,56 ; color of, 30,31 ; clipping of, $60,78,8 \mathrm{I}$; conformation of, $27-29$; diseases of, 215-263; digestion of, 222; docking of, $67,68,69$; eyes and ears of, 23,25 ; feeding of, 32- 
44; foot of, 29, 30; harness of, IO3-II 5 ; homesick, the, $23 \mathrm{I}$; injuries to, 219-22I; kindness to, value of, r25, 126; nature of, $r$, 124, 133; old horses, disposal of, 129 ; pulse of, 216 ; selection of, 23-3I; shoeing of, 90-102 ; sick horses, 215-218; transportation of, I30-132; teeth of, 82, 83 ; temperature of, 216 ; vacations for, 127 ; watering of, 32$34, \mathrm{I} 42, \mathrm{I} 43$

Horseback riding, I54-I58; see also Saddle horses

Horse hats, 6I

Horse World, The, I4

Horseshoeing, 95-102

Humanity, necessity of, 125, 126

Hot weather treatment, $61-64$

Idol Belle, I 85

Indian Chief, 197

Injuries, treatment of, 215-22I

Interfering, IoI

J. Malcolm Forbes, I92, I 96

Jay Bird family, r8r, r89, r 90

Jay McGregor, 189

Jenny, I 92

Joe Patchen, I9I

John M., I8I

John R. Gentry, I 90

Journeys with horses, I39-I 44

June grass, 37

Justin Morgan, 176, 177, 97

Kentucky saddle horses, 197-I99; as cavalry horses, 164

Kidneys, 228

Kindness, need of, 22, 125, 126, $23 \mathrm{I}$

King Alar, 185

King Bertini, 195

Knee-sprung, 250, 25I

Kremlin, 195

Lady Bunker, 190

Lady de Jarnette, I ro

Lady Maude C., I84

Lake Queen, r ro
Lambert family, 182

Lameness, detection of, 245

Laminitis, $253^{-2} 5^{6}$

Lampas, 84

Lavengro, 200

Leather pads, 86

Lee Axworthy, I 96

Legs, diseases of, 245-252

Lillard, R. H., I 99

Linsley, D. C., I77, I 78

Lindsey's Arabian, I76

Liniment, a standard, 232, footnote

Liquor, horse's worst enemy, 125

Liver, 230

Loin blankets, 78

Lord Roberts, 193, I 96

Lou Dillon, III, I85, 195

Louis Napoleon, 205

Lungs, diseases of, $23 \mathrm{I}$

Maclay, A. B., I62

Major Delmar, I8I

Major Edsall, 194, I95

Mambrino Chief, I90

Mambrino Patchen, 4, I88, I90, I9I

Mane, 65

Manette, I93

Mange, 24I, 242

Mare, see Brood mare

Margrave, 189

Martingale, I45

Maud S., 195

May King, I 92

May Queen, 192

McGregor family, I95

McKerron family, 190

McKinley, I8 5

McKinney family, I88, I89, I96

McLellan, C. A., 94, 96

Medicine, how to give, 217, 218

Mendocino, 193

Messenger, 186, I87

Mobel, ז89, 196

Mokladi, I 92

Moko, I89, I96

Molasses, 46, 47

Molassine, 46

Moquette, I9I 
Morgan blood in Kentucky saddle horses, 182 ; in the trotting-bred horse, I80, I8I

Morgan Horse Club, 182,183

Morgan Horse Register, 183

Morgan, Justin, I76, I77, 197

Morgan horse, I76-183; as a cavalry horse, $165, \mathbf{1} 67, \mathbf{1} 78$; feet of, 30 ; ribs of, 29

Mule feet, 257

Muscle-tired, 127

Nails, picking up, 220

Nancy Hanks, I8 5 , I 96

Navicular disease, 256-259

Nelson, r89

Nelson's Wilkes, 189

Nerving, 247, 257, 263

Nico, 193

Noon feeding, I4 $\mathbf{r}$

Norfolk trotter, 187

Norval, 193

Nutwood, 4, 193, 195

Oakland Baron, 189

Oat crushers, $4 \mathbf{I}$

Oatmeal gruel, 62

Oats, 39, 40, 43; digestion of, $\mathbf{I} 42$

Obrecht, Prof. R. C., 25

Ogilvie, R. B., 209

Old horses, blanketing of, 70; disposal of, 129

Online, 190

Orcutt, F. H., I80

Onward, r88, I90, I96

Overdraw check, I Io

Pads, leather, 99, roo; rubber, 9I, 99; saddle, II3, I60; sweat, II2

Paget, Otho, 200

Parker, Lieut. R. M., I 66

Pasture, 38

Patchen Wilkes, I88, I9I

Peat moss, 5I, 52

Peavine, 197

Percheron horses, 3, I47, I49, 204206

Peter the Great family, I93-196

Peter O'Donna, 196

Peter Wood, 196
Peter Pilot, 194

Peters family (Morgan), I80

Phillips, A. F., I80

Pilot Medium, 193

Pneumonia, 232, 233

Poll evil, 220

Porter, John, I 53

Potatoes, 43, 225

Princess, 194

Prodigal, 196

Pulse, of horse, 216

Quality, 25

Quittor, 261, 262

Queen Dido, I90

Radowa, I8I

Rain-covers, 75, 76

Ralph Wilkes, II I

Ramsdell, J. A. P., I72

Red Jacket, 190

Red Medium, 190

Red Wilkes, I81, 188, 193

Reducine Company, 246

Reins, ro7

Respiration, 2I 7

Rex Americus, 9o

Richards, A. Keene, 192

Riding on horseback, $154^{-1} 58$; see also Saddle horses

Ringbone, 262, 263

Robert Fillingham, r8o

Rubber pads, 86, 91, 99

Rye straw, 52

Rysdyk's Hambletonian, I86, I88, r 9 r, r 94, r96

Saddle horses, 90, II 3, I50-160; gaits of, 198 ; care of, 159,160

Saddle pads, II 3, I60

Saddle Registry, 198

Saddles, I 57

Salt, 45

Salt and charcoal, 227

Salt and water, 123, 146, 219

San Francisco, I88, 196

Sanders, W. B., 180

Santos, 1 94, 196

Say Tell, I 85

Schoenleber, Dr., 32 
Scouring, 225

Scratches, $237-240$

Seiter, Dr. John, 92

Shahwan, I72

Sheath, 228

Sherman, I 79

Shire horses, 207, 208

Shoe-boil, 249

Shoeing, 90-102; of lame horses, see Spavin, Curb, Founder, Navicular disease, etc.

Shoes, seating of, 97 ; web of, 95 ; weight of, 93

Shoulders, care of, 146

Shying, 2 I

Sick horses, 21 5-21 8

Side-bones, 262, 263

Sidney Dillon, 195

Simmons, 199

Slings, $2 \times 6$

Soaking Tub, 87, 219, 220, 246

Sods, 38

Spavin, I, 246-248

Sphinx, 193

Splan, John, 70, IIO, 125

Springs, 259

Sprung knees, 250, 25I

Stablemen, 56, 60, I 24-1 26

Stables, I 16-1 23

Staling, I44

Stallions, choice of, 4,5 ; size of, 6,7 ; treatment of, 7

Stalls, II7-II9

Stillman, C. C., I80, I83

Stark, A. T., 98, 107

Strangles, $23 \mathrm{I}$

Suffolk horses, I48, I49

Suffolk Punch, I49, 209-2II

Sugar, 42, 45-47, 62

Sunstroke, 63

Sweat pads, II 2

Sweet Marie, I8I

Tails, 66-69, 199

Teeth, care of, 82,83

Temperature, of horses, 216 ; of stable, I2I, I 22

The Bondsman, 189

The Harvester, 193, 196

The Justin Morgan, I76, I77, 197
The King, 188, 190, 191

The Northern Man, 192

Thoroughbreds, $173^{-1} 75$; as cavalry horses, I62-1 64

Thoroughpin, 252

Throat, diseases of, 231, 232

Thrush, 259

Tips, 100

Tompkins, Gilbert, 33, 92

Tonics, 226, 240

Tiverton, I 81

Todd, 192

Training of colts, I7-22; of saddle horses, $152-154$

Transportation of horses, I $30-132$

Trotter, see Trotting-bred horse

Trotting-bred horse, $184-196$; as a cavalry horse, 167,168 ; as a farm horse, I47, I48; origin of, I 86 ; shoeing of, 102

True Briton, 176

Uhlan, I92

Urine, 228

Vacations for horses, 127

Vegetables, 43, 44

Ventilation, I2O, I2I

Vermont Hero, I79

Wagner, 175

Walnut Hall, r 91, 193, 96

Ware, F. M., 34, 142,162

Watering of horses, 9, 32-34, 58, $62,142-144,225$

Watering troughs, 122

Weaving, 268, 269

Welcome, r8o

Winthrop Morrill, r79

Wildair, 176

Wilkes Boy, I88, I 90, I9I

Wilkes family, I8I, I88-I9r, I95, I 96

Willett, Duncan E., 203

William L., r 90

Willy, III, I85, I9I

Wilton, I8I, I88, I90, I9I

Windgalls, $25 \mathrm{I}$

Winkers, see Blinders 
Witch-hazel, 146, I 59, footnote Woodbury, 179

Woodruff, Hiram, I35, I74, I87

Worms, 47, 226, 227

Wounds, 2 I 9
Young Jim, I88, 190, 191

Young, John, 22

Young Miss, 19I

Zombro, 188 



